Cochrane Database of Systematic Reviews

\title{
Financial arrangements for health systems in low-income countries: an overview of systematic reviews (Review)
}

Wiysonge CS, Paulsen E, Lewin S, Ciapponi A, Herrera CA, Opiyo N, Pantoja T, Rada G, Oxman AD

Wiysonge CS, Paulsen E, Lewin S, Ciapponi A, Herrera CA, Opiyo N, Pantoja T, Rada G, Oxman AD.

Financial arrangements for health systems in low-income countries: an overview of systematic reviews.

Cochrane Database of Systematic Reviews 2017, Issue 9. Art. No.: CD011084.

DOI: 10.1002/14651858.CD011084.pub2. 
HEADER 1

ABSTRACT

PLAIN LANGUAGE SUMMARY

BACKGROUND

OBJECTIVES

METHODS

RESULTS

Figure 1.

DISCUSSION

AUTHORS' CONCLUSIONS

ACKNOWLEDGEMENTS

REFERENCES

ADDITIONAL TABLES

APPENDICES

CONTRIBUTIONS OF AUTHORS

DECLARATIONS OF INTEREST

SOURCES OF SUPPORT

INDEX TERMS

\section{TABLE OF CONTENTS}

2

4

5

5

7

8

11

13

13

15

20

42

70

70

70

70 
[Overview of Reviews]

\section{Financial arrangements for health systems in low-income countries: an overview of systematic reviews}

Charles S Wiysonge 1,2 , Elizabeth Paulsen ${ }^{3}$, Simon Lewin 3,4 , Agustín Ciapponi ${ }^{5}$, Cristian A Herrera6,7, Newton Opiyo8, Tomas Pantoja 7,9 , Gabriel Rada7,10, Andrew D Oxman 3

${ }^{1}$ Cochrane South Africa, South African Medical Research Council, Cape Town, South Africa. ${ }^{2}$ Centre for Evidence-based Health Care, Faculty of Medicine and Health Sciences, Stellenbosch University, Cape Town, South Africa. ${ }^{3}$ Norwegian Institute of Public Health, Oslo, Norway. ${ }^{4}$ Health Systems Research Unit, South African Medical Research Council, Tygerberg, South Africa. ${ }^{5}$ Argentine Cochrane Centre, Institute for Clinical Effectiveness and Health Policy (IECS-CONICET), Buenos Aires, Argentina. ${ }^{6}$ Department of Public Health, School of Medicine, Pontificia Universidad Católica de Chile, Santiago, Chile. ${ }^{7}$ Evidence Based Health Care Program, Pontificia Universidad Católica de Chile, Santiago, Chile. ${ }^{8}$ Cochrane Editorial Unit, Cochrane, London, UK. ${ }^{9}$ Department of Family Medicine, Faculty of Medicine, Pontificia Universidad Católica de Chile, Santiago, Chile. 10Department of Internal Medicine and Evidence-Based Healthcare Program, Faculty of Medicine, Pontificia Universidad Católica de Chile, Santiago, Chile

Contact address: Charles S Wiysonge, Cochrane South Africa, South African Medical Research Council, Francie van Zijl Drive, Parow Valley, Cape Town, Western Cape, 7505, South Africa.wiysonge@yahoo.com, charles.wiysonge@mrc.ac.za.

Editorial group: Cochrane Effective Practice and Organisation of Care Group.

Publication status and date: New, published in Issue 9, 2017.

Citation: Wiysonge CS, Paulsen E, Lewin S, Ciapponi A, Herrera CA, Opiyo N, Pantoja T, Rada G, Oxman AD. Financial arrangements for health systems in low-income countries: an overview of systematic reviews. Cochrane Database of Systematic Reviews 2017, Issue 9. Art. No.: CD011084. DOI: 10.1002/14651858.CD011084.pub2.

Copyright ( 2017 The Authors. Cochrane Database of Systematic Reviews published by John Wiley \& Sons, Ltd. on behalf of The Cochrane Collaboration. This is an open access article under the terms of the Creative Commons Attribution-Non-Commercial Licence, which permits use, distribution and reproduction in any medium, provided the original work is properly cited and is not used for commercial purposes.

\section{A B S T R A C T}

\section{Background}

One target of the Sustainable Development Goals is to achieve "universal health coverage, including financial risk protection, access to quality essential health-care services and access to safe, effective, quality and affordable essential medicines and vaccines for all". A fundamental concern of governments in striving for this goal is how to finance such a health system. This concern is very relevant for lowincome countries.

\section{Objectives}

To provide an overview of the evidence from up-to-date systematic reviews about the effects of financial arrangements for health systems in low-income countries. Secondary objectives include identifying needs and priorities for future evaluations and systematic reviews on financial arrangements, and informing refinements in the framework for financial arrangements presented in the overview.

\section{Methods}

We searched Health Systems Evidence in November 2010 and PDQ-Evidence up to 17 December 2016 for systematic reviews. We did not apply any date, language, or publication status limitations in the searches. We included well-conducted systematic reviews of studies that assessed the effects of financial arrangements on patient outcomes (health and health behaviours), the quality or utilisation of healthcare services, resource use, healthcare provider outcomes (such as sick leave), or social outcomes (such as poverty, employment, or financial burden of patients, e.g. out-of-pocket payment, catastrophic disease expenditure) and that were published after April 2005. We excluded reviews with limitations important enough to compromise the reliability of the findings. Two overview authors independently screened reviews, extracted data, and assessed the certainty of evidence using GRADE. We prepared SUPPORT Summaries for eligible reviews, 
including key messages, 'Summary of findings' tables (using GRADE to assess the certainty of the evidence), and assessments of the relevance of findings to low-income countries.

\section{Main results}

We identified 7272 reviews and included 15 in this overview, on: collection of funds ( 2 reviews), insurance schemes ( 1 review), purchasing of services ( 1 review), recipient incentives ( 6 reviews), and provider incentives ( 5 reviews). The reviews were published between 2008 and 2015; focused on 13 subcategories; and reported results from 276 studies: 115 (42\%) randomised trials, 11 (4\%) non-randomised trials, $23(8 \%)$ controlled before-after studies, $51(19 \%)$ interrupted time series, $9(3 \%)$ repeated measures, and $67(24 \%)$ other non-randomised studies. Forty-three per cent (119/276) of the studies included in the reviews took place in low- and middle-income countries.

Collection of funds: the effects of changes in user fees on utilisation and equity are uncertain (very low-certainty evidence). It is also uncertain whether aid delivered under the Paris Principles (ownership, alignment, harmonisation, managing for results, and mutual accountability) improves health outcomes compared to aid delivered without conforming to those principles (very low-certainty evidence).

Insurance schemes: community-based health insurance may increase service utilisation (low-certainty evidence), but the effects on health outcomes are uncertain (very low-certainty evidence). It is uncertain whether social health insurance improves utilisation of health services or health outcomes (very low-certainty evidence).

Purchasing of services: it is uncertain whether increasing salaries of public sector healthcare workers improves the quantity or quality of their work (very low-certainty evidence).

Recipient incentives: recipient incentives may improve adherence to long-term treatments (low-certainty evidence), but it is uncertain whether they improve patient outcomes. One-time recipient incentives probably improve patient return for start or continuation of treatment (moderate-certainty evidence) and may improve return for tuberculosis test readings (low-certainty evidence). However, incentives may not improve completion of tuberculosis prophylaxis, and it is uncertain whether they improve completion of treatment for active tuberculosis. Conditional cash transfer programmes probably lead to an increase in service utilisation (moderate-certainty evidence), but their effects on health outcomes are uncertain. Vouchers may improve health service utilisation (low-certainty evidence), but the effects on health outcomes are uncertain (very low-certainty evidence). Introducing a restrictive cap may decrease use of medicines for symptomatic conditions and overall use of medicines, may decrease insurers' expenditures on medicines (low-certainty evidence), and has uncertain effects on emergency department use, hospitalisations, and use of outpatient care (very low-certainty evidence). Reference pricing, maximum pricing, and index pricing for drugs have mixed effects on drug expenditures by patients and insurers as well as the use of brand and generic drugs.

Provider incentives: the effects of provider incentives are uncertain (very low-certainty evidence), including: the effects of provider incentives on the quality of care provided by primary care physicians or outpatient referrals from primary to secondary care, incentives for recruiting and retaining health professionals to serve in remote areas, and the effects of pay-for-performance on provider performance, the utilisation of services, patient outcomes, or resource use in low-income countries.

\section{Authors' conclusions}

Research based on sound systematic review methods has evaluated numerous financial arrangements relevant to low-income countries, targeting different levels of the health systems and assessing diverse outcomes. However, included reviews rarely reported social outcomes, resource use, equity impacts, or undesirable effects. We also identified gaps in primary research because of uncertainty about applicability of the evidence to low-income countries. Financial arrangements for which the effects are uncertain include external funding (aid), caps and co-payments, pay-for-performance, and provider incentives. Further studies evaluating the effects of these arrangements are needed in low-income countries. Systematic reviews should include all outcomes that are relevant to decision-makers and to people affected by changes in financial arrangements.

\section{PLAIN LANGUAGE SUMMARY}

\section{Financial arrangements for health systems in low-income countries}

\section{What is the aim of this overview?}

The aim of this Cochrane Overview is to provide a broad summary of what is known about the effects of financial arrangements for health systems in low-income countries.

This overview is based on 15 systematic reviews. Each of these systematic reviews searched for studies that evaluated different types of financial arrangements within the scope of the review question. The reviews included a total of 276 studies.

This overview is one of a series of four Cochrane Overviews that evaluate different health system arrangements.

\section{Main results}

\section{What are the effects of different ways of collecting funds to pay for health services?}

Financial arrangements for health systems in low-income countries: an overview of systematic reviews (Review) 
Two reviews looked for studies that addressed this question and found the following.

- The effects of changes in user fees on utilisation and equity are uncertain (very low-certainty evidence).

- It is uncertain whether aid delivered under Paris Principles (ownership, alignment, harmonisation, managing for results, and mutual accountability) improves health compared to aid delivered without conforming to those principles (very low-certainty evidence).

\section{What are the effects of different types of insurance schemes?}

One systematic review looked for studies that addressed this question and found the following.

- Community-based health insurance may increase people's use of services (low-certainty evidence), but the effects on people's health are uncertain. It is uncertain whether social health insurance increases people's use of services (very low-certainty evidence).

\section{What are the effects of different ways of paying for health services?}

One systematic review looked for studies that addressed this question and found the following.

- It is uncertain whether increasing salaries of public sector healthcare workers improves the quantity or quality of their work.

\section{What are the effects of different types of financial incentives for recipients of care?}

Six systematic reviews looked for studies that addressed this question and found the following.

- Giving healthcare recipients incentives may improve their adherence to long-term treatments (low-certainty evidence), but it is uncertain whether they improve people's health.

- Giving healthcare recipients one-time incentives probably leads more people to return to start or continue treatment for tuberculosis (moderate-certainty evidence). The certainty of the evidence for other types of recipient incentives for tuberculosis is low or very low.

- Conditional cash transfer programmes (giving money to recipients of care on the condition that they take a specified action to improve their health) probably increase people's use of services (moderate-certainty evidence), but have mixed effect on people's health.

- Vouchers may improve people's use of health services (low-certainty evidence) but have mixed effects on people's health (low-certainty evidence).

- A combination of a ceiling and co-insurance probably slightly decreases the overall use of medicines (moderate-certainty evidence) and may increase health service utilisation (low-certainty evidence). The certainty of the evidence for the effects of other combinations of caps, co-insurance, co-payments, and ceilings is low or very low.

- Limits on how much insurers pay for different groups of drugs (reference pricing, maximum pricing, and index pricing) have mixed effects on drug expenditures by patients and insurers as well as the use of brand and generic drugs.

What are the effects of different types of financial incentives for health workers?

Five systematic reviews looked for studies that addressed this question and found the following.

- We are uncertain whether pay-for-performance improves health worker performance, people's use of services, people's health, or resource use in low-income countries (very low-certainty evidence).

- We are uncertain whether financial incentives for health workers improve the quality of care provided by primary care physicians or outpatient referrals from primary to secondary care (very low-certainty evidence).

- There is no rigorous research evaluating incentives (e.g. bursaries or scholarships linked to future practice location, rural allowances) for recruiting health workers to serve in remote areas. It is uncertain whether giving health workers incentives lead more of them to stay in underserved areas (very low-certainty evidence).

- No studies assessed the effects of financial interventions on the movement of health workers between public and private organisations in low- and middle-income countries.

\section{How up to date is this overview?}

The overview authors searched for systematic reviews published up to 17 December 2016. 


\section{B A C K G R O U N D}

This is one of four overviews of systematic reviews on evidencebased approaches for refining health systems in low-income countries (Ciapponi 2014; Herrera 2014; Pantoja 2014). The purpose is to provide comprehensive outlines of evidence on the effects of health system arrangements, including delivery, financial, and governance arrangements as well as implementation strategies.

The scope of each of the four overviews is summarised below.

1. Financial arrangements comprise variations in how funds are collected, insurance schemes, how services are purchased, and the use of targeted financial incentives or disincentives. This overview discusses financial arrangements.

2. Delivery arrangements include changes in who receives care and when, who provides care, the working conditions of those who provide care, coordination of care amongst different providers, where care is provided, the use of information and communication technology to deliver care, and quality and safety systems (Ciapponi 2014).

3. Governance arrangements include changes in rules or processes that determine authority and accountability for health policies, organisations, commercial products and health professionals, and the involvement of stakeholders in decision making (Herrera 2014).

4. Implementation strategies include interventions designed to bring about changes in healthcare organisations, the behaviour of healthcare professionals, or the use of health services by healthcare recipients (Pantoja 2014).

In 2005 the member states of the World Health Organization (WHO) adopted a resolution encouraging countries to develop health financing systems aimed at providing universal coverage (WHO 2005). Global support for universal health coverage gathered momentum, with the unanimous adoption of a resolution in the United Nations General Assembly that emphasises health as an essential element of international development. The resolution, adopted in 2012, "[c]alls upon Member States to ensure that health financing systems evolve so as to avoid significant direct payments at the point of delivery and include a method for prepayment of financial contributions for health care and services as well as a mechanism to pool risks among the population in order to avoid catastrophic health-care expenditure and impoverishment of individuals as a result of seeking the care needed" (UN 2012). Global support for universal health coverage received further support in 2015 in the Sustainable Development Goals, which include the following target: "achieve universal health coverage, including financial risk protection, access to quality essential healthcare services and access to safe, effective, quality and affordable essential medicines and vaccines for all" (WHO 2015). A fundamental question that governments face in striving for this goal is how to finance such a health system (WHO 2010a).

A good health system should raise adequate funds for health in ways that ensure people can use needed services and are protected from financial hardships associated with having to pay for health services (WHO 2007). Arrangements for financing health systems include three interrelated functions: collection or acquisition of funds, pooling of prepaid funds in ways that allow risks to be shared (i.e. insurance schemes), and allocation of resources (i.e. purchasing or paying for services) (Murray 2000; WHO 2000; Kutzin 2001; WHO 2007; Van Olmen 2010).

Financial arrangements can potentially affect patient outcomes (health and health behaviours), the quality or utilisation of healthcare services, resource use, healthcare provider outcomes (such as sick leave), and social outcomes (such as poverty or employment) (EPOC 2017). Impacts on these outcomes can be intended and desirable or unintended and undesirable. In addition, the effects of financial arrangements on these outcomes can either reduce or increase inequities.

Health systems in low-income countries differ from those in highincome countries in terms of the availability of resources and access to services. Thus, problems related to financial arrangements in low-income countries can be substantially different from those in high-income countries. Our focus in this overview is specifically on financial arrangements in low-income countries. By low-income countries we mean countries that the World Bank classifies as low- or lower-middle-income (World Bank 2016). Because uppermiddle-income countries often have a mixture of health systems with problems similar to both those in low-income countries and high-income countries, our focus is relevant to middle-income countries but excludes consideration of conditions that are not relevant in low-income countries and are relevant in middleincome countries.

\section{Description of the interventions}

We outline our framework for financial arrangements in Table 1 , including five categories of financial arrangements and their definitions. This framework was prepared by modifying the taxonomy for health systems arrangements developed by Lavis and colleagues (Lavis 2015). That framework was developed based on reviewing system-wide frameworks, such as the WHO health system building blocks, and domain specific schemes, such as those related to human resources policy, pharmaceutical policy, and implementation strategies. Although this framework has fewer main categories than the WHO framework, the contents of the building blocks that are not included (human resources, information, and medical products and technologies) are included in the four categories used in the Lavis framework. We found that the Lavis framework was more parsimonious, while at the same time more detailed and comprehensive. We adjusted the framework iteratively to ensure that all of the included reviews were appropriately categorised and that all relevant financial arrangements were included and organised logically. A short description of the categories of financial arrangements follows.

\section{Collection of funds}

Funds can be collected through five basic mechanisms: user fees or out-of-pocket payments, prepaid funding or financing of insurance (voluntary insurance rated by income, voluntary insurance rated by risk, compulsory insurance, general taxes, and earmarked taxes), community loan funds, health savings accounts, and external funding from public or private external sources such as nongovernmental organisations (NGOs) and donor agencies (Murray 2000; Ravishankar 2009). Policymakers have an obligation to decide what combination of these options to use to collect funds, including the extent to which users should pay fees at the point of delivery. 


\section{Insurance schemes}

There are three principal types of prepaid funding or health insurance schemes, in addition to health care that is paid for via general taxation: social health insurance, community-based health insurance, and private for-profit health insurance. Social health insurance schemes are compulsory. Coverage is usually on a national scale but may vary from a specific large group (for example, formal sector employees) to the whole population of a country (Lagarde 2006). Social insurance is usually funded through payroll contributions from employers and or employees, but governments may also contribute (through tax revenue) to cover the poor or unemployed (Carrin 2002; Carrin 2004; Lagarde 2006; Wiysonge 2012). Community-based health insurance schemes, in contrast to social health insurance, are voluntary (Ekman 2004; Lagarde 2006). They are managed and operated by an organisation other than a government or private for-profit company. They can cover all or part of the costs of healthcare services (Adebayo 2015). Private for-profit health insurance works with employer-based or individual purchase of private insurance plans provided by private companies that compete on a market scheme. The degree of regulation of insurance schemes varies from one country to another, and companies cover part or all the costs of healthcare services depending on the characteristics of the purchased plan or package of services and - where permitted according to the person's risk profile (Schieber 2006). In addition to deciding what combination of health insurance schemes to use, policymakers must make decisions about the extent to which there are separate insurance schemes for different population groups and the extent to which there is choice and competition among insurance schemes. They must also make decisions about the governance of health insurance schemes, including regulation of private health insurance and regulations regarding who and what is covered (Drechsler 2005).

\section{Purchasing of services}

Key decisions that policymakers need to make about arrangements for purchasing services are how to fund service organisations (via fee-for-service, capitation, prospective payment, line item budgets, global budgets, case-based reimbursement, or a combination of these) and how to pay healthcare workers (via fee-for-service, capitation, salary, or a combination of these).

\section{Financial incentives for providers of health care}

Policymakers also need to consider a range of targeted financial incentives that are intended to motivate specific behaviours. Incentives targeted at providers include pay-for-performance, budgets that reward providers for savings or penalise them for overspending, and incentives to practice in underserved areas or to select careers where there is a shortage of health professionals.

\section{Financial incentives for recipients of health care}

Incentives for recipients of care include financial incentives for specific types of behaviour (such as preventive behaviours), voucher schemes, and caps or co-payments for drugs or services that are covered by health insurance.

\section{How the intervention might work}

Variations in financial arrangements may influence health and related goals by affecting access to care (e.g. by increasing the availability of resources and services), utilisation of care (e.g. by removing financial disincentives), quality of care (e.g. by paying for performance), equity (e.g. through progressive insurance fees or using tax revenues to pay for services for disadvantaged populations), and efficiency (e.g. by having higher co-payments for services that are less cost-effective, thereby deterring use of less cost-effective services). However, as with any healthcare intervention, financial arrangements can have undesirable effects, and the desirable effects and savings of any option must be weighed against any undesirable effects and costs.

\section{Why it is important to do this overview}

Our aim was to provide a broad overview of evidence from available systematic reviews about the effects of alternative financial arrangements for health systems in low-income countries. Such a broad outline can help policymakers, their support staff, and relevant stakeholders to identify strategies for addressing problems and improving the financing of their health systems. This overview of the findings of systematic reviews also helps to identify needs and priorities for evaluations of alternative financial arrangements, as well as priorities for systematic reviews on the effects of financial arrangements. The overview also helps to refine the framework outlined in Table 1 for considering alternative arrangements for financing health systems.

Changes in health systems are complex and may be difficult to evaluate. The applicability of the findings of evaluations from one setting to another may be uncertain, and synthesising the findings of evaluations may be difficult. However, the alternative to well-designed evaluations is poorly designed evaluations; the alternative to systematic reviews is non-systematic reviews; and the alternative to using the findings of systematic reviews to inform decisions is using non-systematic reviews to inform decisions.

Other types of information, including context-specific information and judgments (such as judgments about the applicability of the findings of systematic reviews in a specific context), are still needed. Nonetheless, this overview can help people making decisions about financial arrangements by summarising the findings of available systematic reviews (including estimates of the effects of changes in financial arrangements and the certainty of those estimates), identifying important uncertainties reported by those systematic reviews, and identifying areas for new or updated systematic reviews. The overview can also help to inform judgments about the relevance of the available evidence in a specific context (Rosenbaum 2011).

\section{O B JECTIVES}

To provide an overview of the evidence from up-to-date systematic reviews about the effects of financial arrangements for health systems in low-income countries. Secondary objectives include identifying needs and priorities for future evaluations and systematic reviews on financial arrangements, and informing refinements in the framework for financial arrangements presented in the overview (Table 1).

\section{METHODS}

We used the methods described below in all four overviews of health system arrangements and implementation strategies in lowincome countries (Ciapponi 2014; Herrera 2014; Pantoja 2014). 


\section{Criteria for considering reviews for inclusion}

We included systematic reviews that:

1. had a Methods section with explicit selection criteria;

2. assessed the effects of financial arrangements (as defined in Background);

3. reported at least one of the following types of outcomes: patient outcomes (health and health behaviours), the quality or utilisation of healthcare services, resource use, healthcare provider outcomes (such as sick leave), or social outcomes (such as poverty, employment, or financial burden of patients, e.g. out-of-pocket payment, catastrophic disease expenditure);

4. were relevant to low-income countries as classified by the World Bank (World Bank 2016);

5. were published after April 2005.

Judging relevance to low-income countries is sometimes difficult, and we are aware that evidence from high-income countries is not directly generalisable to low-income countries. We based our judgments on an assessment of the likelihood that the financial arrangements considered in a review address a problem that is important in low-income countries, would be feasible, and would be of interest to decision-makers in low-income countries, regardless of where the included studies took place. So, for example, we excluded arrangements requiring technology that is not widely available in low-income countries. At least two of the overview authors made judgments about the relevance to lowincome countries and discussed with the other authors whenever there was uncertainty. We excluded reviews that only included studies from a single high-income country due to concerns about the wider applicability of the findings of such reviews. However, we included reviews with studies from high-income countries only if the interventions were relevant for low-income countries.

We excluded reviews published before April 2005 as these were highly unlikely to be up-to-date. We also excluded reviews with methodological limitations important enough to compromise the reliability of the findings (Appendix 1 ).

\section{Search methods for identification of reviews}

We searched Health Systems Evidence in November 2010 using the following filters.

1. Health system topics = financial arrangements.

2. Type of synthesis = systematic review or Cochrane Review.

3. Type of question = effectiveness.

4. Publication date range $=2000$ to 2010 .

We conducted subsequent searches using PDQ ('pretty darn quick')-Evidence, which was launched in 2012. We searched PDQ up to 17 December 2016, using the filter 'Systematic reviews' with no other restrictions. We updated that search, excluding records that were entered into PDQ-Evidence prior to the date of the last search.

PDQ-Evidence is a database of evidence for decisions about health systems, which is derived from the Epistemonikos database of systematic reviews (Rada 2013). It includes systematic reviews, overviews of reviews (including evidence-based policy briefs) and studies included in systematic reviews. The following databases are included in Epistemonikos and PDQ-Evidence searches, with no language or publication status restrictions.
1. Cochrane Database of Systematic Reviews (CDSR).

2. Database of Abstracts of Reviews of Effectiveness (DARE).

3. Health Technology Assessment Database.

4. PubMed.

5. Embase.

6. CINAHL.

7. LILACS.

8. PsycINFO.

9. Evidence for Policy and Practice Information and Co-ordinating Centre (EPPI-Centre) Evidence Library.

10.3ie Systematic Reviews and Policy Briefs.

11. World Health Organization (WHO) Database.

12.Campbell Library.

13.Supporting the Use of Research Evidence (SURE) Guides for Preparing and Using Evidence-Based Policy Briefs.

14.European Observatory on Health Systems and Policies.

15.UK Department for International Development (DFID).

16. National Institute for Health and Care Excellence (NICE) public health guidelines and systematic reviews.

17. Guide to Community Preventive Services.

18. Canadian Agency for Drugs and Technologies in Health (CADTH) Rx for Change.

19. McMaster Plus KT+.

20.McMaster Health Forum Evidence Briefs.

We describe the detailed search strategies for PubMed, Embase, LILACS, CINAHL, and PsycINFO in Appendix 1 . We screened all records in the other databases. PDQ staff and volunteers update these searches weekly for PubMed and monthly for the other databases, screening records continually and adding new reviews to the database daily.

In addition, we screened all of the Cochrane Effective Practice and Organisation of Care (EPOC) Group systematic reviews in Archie (i.e. Cochrane's central server for managing documents) and the reference lists of relevant policy briefs and overviews of reviews.

\section{Data collection and analysis}

\section{Selection of reviews}

Two of the overview authors ( $\mathrm{CW}$ and $\mathrm{CH}$ ) independently screened the titles and abstracts found in PDQ-Evidence to identify reviews that appeared to meet the inclusion criteria. Two other authors ( $A O$ and $\mathrm{SL}$ ) screened all of the titles and abstracts that could not be confidently included or excluded after the first screening to identify any additional eligible reviews. One of the overview authors screened the reference lists.

One of the overview authors applied the selection criteria to the full text of potentially eligible reviews and assessed the reliability of reviews that met all of the other selection criteria (Appendix 2). Two other authors ( $\mathrm{AO}$ or $\mathrm{SL}$ ) independently checked these judgments.

\section{Data extraction and management}

We summarised each included review using the approach developed by the SUPPORT Collaboration (Rosenbaum 2011). We used standardised forms to extract data on the background of the review (interventions, participants, settings and outcomes); key findings; and considerations of applicability, equity, economic

Financial arrangements for health systems in low-income countries: an overview of systematic reviews (Review) 
considerations, and monitoring and evaluation. We assessed the certainty of the evidence for the main comparisons using the GRADE approach (Guyatt 2008; Schünemann 2011a; Schünemann 2011b; EPOC 2016).

Each completed SUPPORT Summary underwent peer review and was published on an open access website, where there are details about how the summaries were prepared, including how we assessed the applicability of the findings, impacts on equity, economic considerations, and the need for monitoring and evaluation. The rationale for the criteria that we used for these assessments is described in the SUPPORT Tools for evidence-informed health policymaking (Fretheim 2009; Lavis 2009; Oxman 2009a; Oxman 2009b). As noted there, "a local applicability assessment must be done by individuals with a very good understanding of on-the-ground realities and constraints, health system arrangements, and the baseline conditions in the specific setting" (Lavis 2009). In this overview we have made broad assessments of the applicability of findings from studies in high-income countries to low-income countries using the criteria described in the SUPPORT Summaries database with input from people with relevant experience and expertise in low-income countries.

\section{Assessment of methodological quality of included reviews}

We assessed the reliability of systematic reviews that met our inclusion criteria using criteria developed by the SUPPORT and SURE collaborations (Appendix 2). Based on these criteria, we categorised each review as having:

1. only minor limitations;

2. limitations that are important enough that it would be worthwhile to search for another systematic review and to interpret the results of this review cautiously, if no better review is available; and

3. limitations that are important enough to compromise the reliability of the findings and prompt the exclusion of the review.

\section{Data synthesis}

We describe the methods used to prepare a SUPPORT Summary of each review in detail on the SUPPORT Summaries website. Briefly, for each included systematic review we prepared a table summarising what the review authors searched for and what they found, we prepared 'Summary of findings' tables for each main comparison, and we assessed the relevance of the findings for lowincome countries. The SUPPORT Summaries include key messages, important background information, a summary of the findings of the review, and structured assessments of the relevance of the review for low-income countries. We subjected the SUPPORT Summaries to review by the lead author of each review, at least one content area expert, people with practical experience in lowincome settings, and a Cochrane EPOC Group editor (AO or SL). The authors of the SUPPORT Summaries responded to each comment and made appropriate revisions, and the summaries underwent copy-editing. The editor determined whether the overview authors had adequately addressed comments and the summary was ready for publication on the SUPPORT Summary website.

We organised the review using a modification of the taxonomy that Health Systems Evidence uses for health systems arrangements (Lavis 2015). We adjusted this framework iteratively to ensure that we appropriately categorised all of the included reviews and included and logically organised all relevant health system financial arrangements. We prepared a table listing the included reviews as well as the types of financial arrangements for which we were not able to identify a reliable, up-to-date review (Table 2). We also prepared a table of excluded reviews (Table 3), describing reviews that addressed a question for which another (more up-todate or reliable) review was included, reviews that were published before April 2005 (for which a previous SUPPORT Summary was available), reviews with results that we considered nontransferable to low-income countries, and reviews with limitations that were important enough to compromise the reliability of the findings.

We described the characteristics of the included reviews in a table that included the date of the last search, any important limitations, and what the review authors searched for and what they found (Appendix 3). We summarised our detailed assessments of the reliability of the included reviews in a separate table (Table 4) showing whether individual reviews met each criterion in Appendix 2.

Our structured synthesis of the findings of our overview was based on two tables. We summarised the main findings of each review in a table that included the key messages from each SUPPORT Summary (Table 5). In a second table (Table 6), we reported the direction of the results and the certainty of the evidence for each of the following types of outcomes: health and other patient outcomes; access, coverage or utilisation; quality of care; resource use; social outcomes; impacts on equity; healthcare provider outcomes; adverse effects (not captured by undesirable effects on any of the preceding types of outcomes); and any other important outcomes (that did not fit into any of the preceding types of outcomes) (EPOC 2016). The direction of results were categorised as: a desirable effect, little or no effect, an uncertain effect (very low-certainty evidence), no included studies, an undesirable effect, not reported (i.e. not specified as a type of outcome that was considered by the review authors), or not relevant (i.e. no plausible mechanism by which the type of health system arrangement could affect the type of outcomes).

We took into account all other relevant considerations besides the findings of the included reviews when drawing conclusions about implications for practice (EPOC 2016). Our conclusions about implications for systematic reviews were based on types of financial arrangements for which we were unable to find a reliable up-to-date review along with limitations identified in the included reviews. These limitations include considerations related to the applicability of the findings and likely impacts on equity. Our conclusions about implications for future evaluations were based on the findings of the included reviews (EPOC 2016).

\section{RE S U L T S}

We identified 7272 systematic reviews for eligibility across all four overviews. Following the screening of titles and abstracts, we excluded 6958 reviews as clearly irrelevant for this overview (Figure 1 ). We assessed the full texts of 60 reviews for eligibility and found 15 of them to meet the inclusion criteria for this overview (Table 2). We list excluded reviews of financial arrangements in Table 3. We excluded 13 reviews because of important methodological limitations (Ekman 2004; Ensor 2004; Buchmueller 2005; Attree 2006; De Janvry 2006; Siddiqi 2007; Patouillard 2007; Lagarde 
2008; Bhutta 2009; Lee 2009; Bellows 2011; Faden 2011; Meyer 2011), 6 for being out-of-date (Giuffrida 1997; Giuffrida 1999; Bock 2001; Gosden 2001; Forbes 2002; Kane 2004), 25 because a more relevant review was available (WHO 1996; Chaix-Couturier 2000; Giuffrida 2000; Gosden 2000; WHO 2003; Borghi 2006; Doran 2006; Eichler 2006; Handa 2006; Lagarde 2006; Petersen 2006;
Rosenthal 2006; Bosch-Capblanch 2007; Lagarde 2007; Gemmill 2008; Mannion 2008; Oxman 2008; Sutherland 2008; Barnighausen 2009; Fournier 2009; Lawn 2009; Van Herck 2010; WHO 2010b; Petry 2012; Yoong 2012), and 1 because it was not transferable to lowincome countries (Lucas 2008). Appendix 4 lists the reviews still awaiting classification.

\section{Figure 1. Flow diagram}

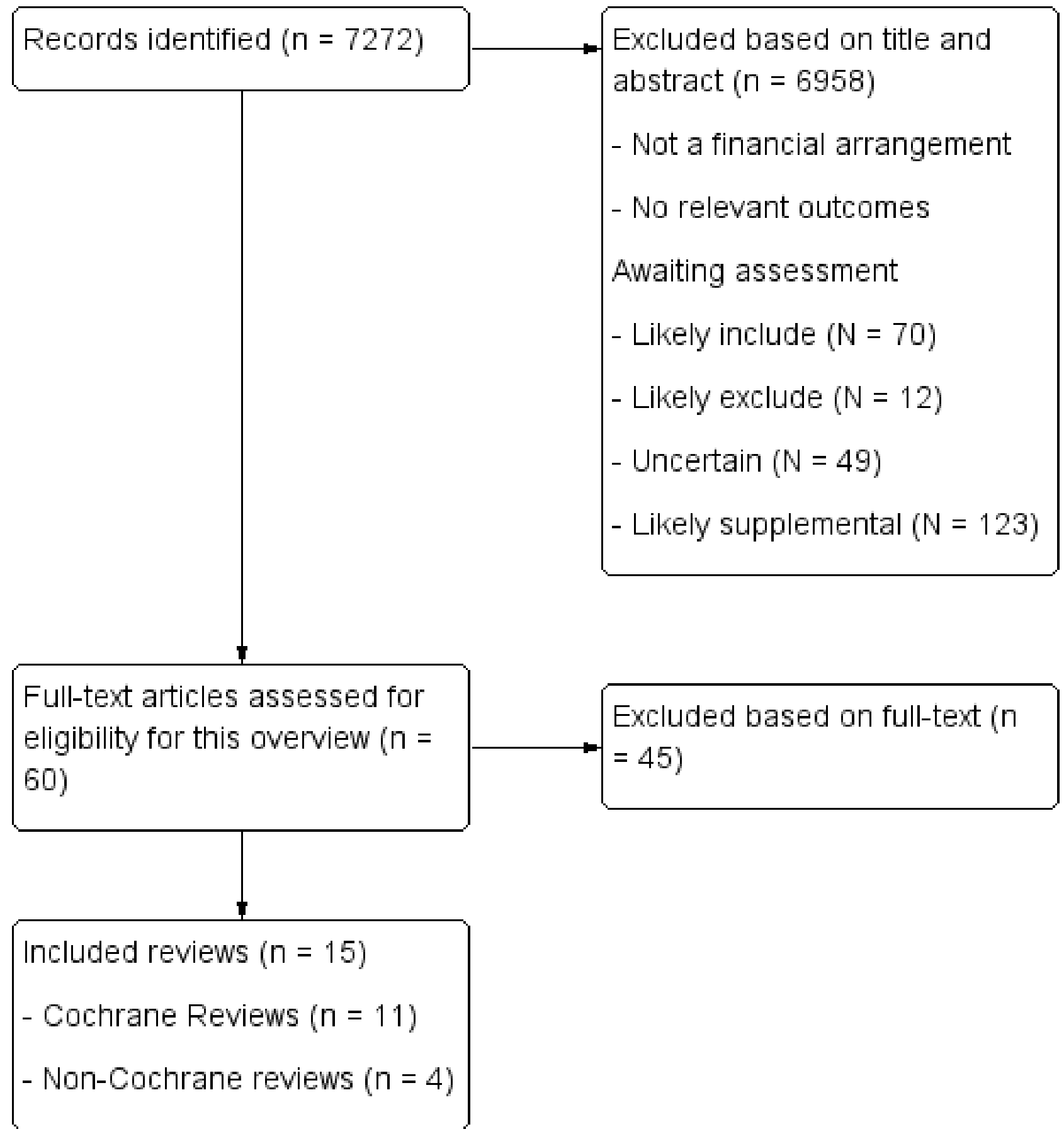

\section{Description of included reviews}

The 15 included systematic reviews were published between 2008 and 2015 (Table 2). Of these, 11 were Cochrane Reviews (Akbari
2008; Haynes 2008; Lagarde 2009; Lagarde 2011; Scott 2011; Witter 2012; Acosta 2014; Rutebemberwa 2014; Grobler 2015; Luiza 2015; Lutge 2015). The dates of the most recent search reported in the included reviews ranged from February 2007 in Haynes 2008 
to June 2015 in Lutge 2015. The number of primary studies on financial arrangements in each included review ranged from zero in Rutebemberwa 2014 to 78 in Haynes 2008.

Four reviews had no included studies from a low- or middle-income country (Scott 2011; Acosta 2014; Grobler 2015; Luiza 2015), while six reviews included only studies conducted in low- and middleincome countries (Lagarde 2009; Carr 2011; Hayman 2011; Lagarde 2011; Acharya 2012; Witter 2012). Four reviews included studies from a mix of low-, middle- and high-income countries (Akbari 2008; Haynes 2008; Brody 2013; Lutge 2015) .One review did not have any included studies (Rutebemberwa 2014).

The reviews reported results on financial arrangements from 276 studies with the following designs.

- $115(42 \%)$ randomised trials.

- $11(4 \%)$ non-randomised trials.

- $23(8 \%)$ controlled before-after studies.

- $51(19 \%)$ interrupted time series studies.

- $9(3 \%)$ repeated measures studies.

- $67(24 \%)$ other non-randomised studies (including cohort and case-control studies).

Overall, 119 (43\%) of the studies in the 15 included reviews were conducted in low- and middle-income countries, $67(24 \%)$ in the USA, 25 (9\%) in Canada, and 55 (20\%) in Western Europe. The other 10 studies (4\%) were conducted in Australia (8 studies), the United Arab Emirates (1), and Taiwan (1).

Study settings varied and included primary care; family, workplace and community settings; and outpatient and inpatient settings in hospitals and non-primary care health centres. The studies included in the reviews involved various health workers, including physicians, nurses, and pharmacists. Recipients of care participating in studies included in the reviews included children and adults. Outcomes examined by the reviews included healthcare provider performance, patient outcomes, access to care, coverage, utilisation of healthcare services, equity, and adverse effects.

We grouped the financial arrangements addressed in the reviews into five categories.

- Collection of funds: two reviews (Hayman 2011; Lagarde 2011).

- Insurance schemes: one review (Acharya 2012).

- Purchasing of services: one review (Carr 2011).

- Incentives for providers of care: five reviews (Akbari 2008; Scott 2011; Witter 2012; Rutebemberwa 2014; Grobler 2015).

- Incentives for recipients of health care: six reviews (Haynes 2008; Lagarde 2009; Lutge 2015; Brody 2013; Luiza 2015; Acosta 2014).

\section{Methodological quality of included reviews}

We describe the methodological quality (reliability) of the included reviews in Table 4. We judged the 15 reviews to have only minor limitations.

\section{Effect of interventions}

We summarise the key messages from the included reviews in Table 5. Table 6 summarises the key findings of the different financial interventions considered by each of the included reviews and the certainty of this evidence by outcome. Table 7 provides a summary of the main findings, organised into the following categories.

- Interventions found to have desirable effects on at least one outcome with moderate- or high-certainty evidence and no moderate- or high-certainty evidence of undesirable effects.

- Interventions found to have moderate or high certainty evidence of at least one outcome with an undesirable effect and no moderate or high certainty evidence of desirable effects.

- Interventions for which the certainty of the evidence was low or very low (or no studies were found) for all outcomes examined.

\section{Collection of funds}

We included one review of the effects of user fees, Lagarde 2011, and one of the effects of external funding (aid), Hayman 2011. We found no relevant systematic reviews for financing of insurance, community loan funds, or health saving accounts.

Lagarde and Palmer conducted a review of the impact of user fees on access to health services in low- and middle-income countries (Lagarde 2011). The authors included 17 studies from 17 countries. The type of health services and the level and nature of payments varied. While some of the studies assessed the effects of large-scale national reforms, other studies looked at small-scale pilot projects. All of the evidence was of very low certainty, so it is uncertain whether changes in user fees impact utilisation or equity.

Hayman and colleagues compared the effects of aid delivered under the Paris Principles (Paris Declaration 2005) versus aid delivered outside this framework, on Millennium Development Goal 5 (maternal health) outcomes (Hayman 2011). The principles of the Paris Declaration on Aid Effectiveness include ownership (i.e. recipient countries set their own development strategies); alignment (i.e. donor countries and organisations bring their support in line with strategies set by recipient countries and use local systems to deliver that support); harmonisation (i.e. donors coordinate their actions, simplify procedures and share information to avoid duplication); management for results (i.e. recipient countries and donors focus on producing and measuring results); and mutual accountability (i.e. donors and recipient countries are accountable for development results). The authors included 10 studies for aid delivered under the Paris Principles and 20 studies for aid in general. The review shows that it is uncertain whether aid delivered under the Paris Principles improves maternal and reproductive health outcomes compared to aid delivered without conforming to those principles (Hayman 2011).

\section{Insurance schemes}

We included one review that assessed the effects of both community-based health insurance and social health insurance in low- and middle-income countries (Acharya 2012). We did not find any eligible reviews of the effects of private health insurance. Acharya 2012 included 24 studies conducted in subSaharan Africa, Latin America, Southeast Asia, and Eastern Europe. The studies found that community-based health insurance may increase utilisation of health services, but it is uncertain if it improves health outcomes or changes out-of-pocket expenditure among those insured in low-income countries (Acharya 2012). It is uncertain if social health insurance improves utilisation of health services and health outcomes, leads to changes in out-of-pocket

Financial arrangements for health systems in low-income countries: an overview of systematic reviews (Review) 
expenditures, or improves equity among those insured in lowincome countries (very low-certainty evidence).

\section{Purchasing of services}

We included one systematic review of the effects of payment methods for primary-care physicians (Carr 2011). We did not find any eligible reviews on payment methods for specialist physicians, non-physician healthcare workers, or health service organisations. Carr 2011 assessed the impact of increasing salaries on performance of public sector employees in the health, education and judicial sectors in low- and middle-income countries. The authors found only one eligible study, conducted in Brazil, that provided very low-certainty evidence of the effects of increasing teachers' wages on students' grades in public schools (Carr 2011). It is uncertain whether increasing the salaries of health professionals or other professionals in the public sector improves either the quantity or quality of their work.

\section{Financial incentives for recipients of care}

We included two reviews on financial incentives for recipients of care (Haynes 2008; Lutge 2015), plus one review each for conditional cash transfers (Lagarde 2009), voucher schemes (Brody 2013), caps and co-payments for drugs (Luiza 2015), and reference pricing for drugs (Acosta 2014). We did not find any eligible reviews on non-conditional financial benefits for recipients of care.

Haynes and colleagues assessed interventions for enhancing medication adherence (Haynes 2008). The authors included 78 trials evaluating 93 diverse interventions, including rewards. The review shows that it is uncertain whether interventions to increase adherence to short-term treatments improve adherence or patient outcomes. Interventions to increase adherence to long-term treatments may improve adherence, but it is uncertain whether they improve patient outcomes.

Lutge and colleagues assessed the effects of financial incentives in the management of tuberculosis (Lutge 2015). They included 12 randomised trials: 10 conducted in the USA and 1 each in South Africa and Timor-Leste. This review shows that one-time incentives probably improve patient return for start or continuation of treatment and may improve return for tuberculin skin test reading compared to routine care. However, incentives may not improve completion of tuberculosis prophylaxis, and it is uncertain whether they improve completion of treatment for active tuberculosis. Immediate incentives may not improve adherence to anti-tuberculosis treatment compared to deferred incentives, and cash incentives may slightly improve patient return for tuberculin skin test reading and completion of tuberculosis prophylaxis compared to non-cash incentives. Higher cash incentives may slightly improve patient return for tuberculin skin test reading compared to lower cash incentives. In addition, incentives may improve adherence to anti-tuberculosis prophylaxis compared to other interventions. Finally, incentives may slightly improve return to clinic for completion of treatment and prophylaxis for latent tuberculosis compared to other interventions (Lutge 2015).

Lagarde and colleagues assessed the effects of conditional cash transfers on health outcomes and use of health services in low- and middle-income countries (Lagarde 2009). The authors included six studies conducted among disadvantaged households in low-income areas of five countries in Latin America and one in sub-Saharan Africa. The review shows that conditional cash transfer programmes probably lead to an increase in the use of healthcare services. The effects were uncertain for immunisation coverage (increased vaccination rates in children for measles and tuberculosis but only in specific groups or temporarily, and without change in one study) and for health outcomes (mixed effects on anaemia and positive effects on mothers' reports of children's health outcomes - a $22 \%$ to $25 \%$ decrease in the probability of children aged under three years being reported ill in the past months).

Brody and colleagues assessed the effects of voucher schemes on health service utilisation and health outcomes (Brody 2013). The review included 24 studies conducted in Southeast Asia and sub-Saharan Africa. Vouchers may improve the utilisation of reproductive health services, the targeting specific populations, and the quality of health goods or services, and they may reduce the costs of health services (low-certainty evidence). The effects of voucher systems on health outcomes are uncertain (very lowcertainty of the evidence).

One included review that assessed the effects of cap and co-payments on rational drug use included 32 studies (Luiza 2015). It found studies of cap policies (5 studies); cap with co-insurance and a ceiling policy ( 6 studies); cap with fixed co-payment policies ( 2 studies); fixed co-payments policies ( 6 studies); tier co-payment with fixed co-payment policies (2 studies); fixed co-payment with ceiling policies (10 studies); and coinsurance with ceiling policies (10 studies). None of the included studies took place in a low-income country or reported health outcomes. Introducing a restrictive cap may decrease use of medicines for symptomatic conditions and overall use of medicines; may decrease insurers' expenditures on medicines; and has uncertain effects on emergency department use, hospitalisations, and use of outpatient care. Introducing a combination of cap, coinsurance and a ceiling may increase the overall use of medicines, may increase the use of medicines for symptomatic and asymptomatic conditions, and may decrease both patients' and insurer expenditures. Introducing a combination of cap and fixed co-payment has uncertain effects on the overall use of medicines and on the insurer's expenditures and may increase the use of medicines for symptomatic conditions. Introducing fixed co-payment has uncertain effects on the overall use of medicines, may decrease the use of medicines for symptomatic and asymptomatic conditions, and may decrease insurers' expenditures on medicines. Introducing a fixed and tier copayment has uncertain effects on these outcomes. Introducing a combination of ceiling and fixed co-payment may slightly decrease the overall use of medicines; has uncertain effects on insurer expenditures on medicines; and may lead to little or no difference in emergency department, hospitalisation, and outpatient care. In addition, introducing a combination of ceiling and coinsurance probably decreases the overall use of medicines slightly and may decrease the use of medicines only for symptomatic conditions, may slightly decrease the short-term insurer expenditure on medicines, and may increase healthcare utilisation (Luiza 2015).

Acosta and colleagues assessed the effects of reference pricing and other pricing and purchasing policies for drugs (Acosta 2014). Reference pricing is a system in which a benchmark or reference price is established within a country as the maximum level of reimbursement for a group of drugs. Maximum pricing is a fixed, maximum price that a drug can have within a 
health system. Index pricing is a maximum refundable price to pharmacies for drugs within an index group of therapeutically interchangeable drugs. The 18 included studies took place in high-income countries. Reference pricing may reduce insurers' cumulative drug expenditures by shifting drug use from costshare drugs (more expensive drugs in the same group as the reference drugs, for which patients have to pay the difference between the reference price and the price of the drug purchased) to reference drugs. It may decrease the insurer's drug expenditures, may increase the use of reference drugs, and may reduce the use of cost share drugs. Index pricing may increase the use of the generic drugs and reduce the use of brand drugs, may slightly reduce the price of generic drugs, and may have little or no effect on the price of brand drugs. It is uncertain whether maximum pricing affects drug expenditures (Acosta 2014). The effects of reference pricing, index pricing and maximum pricing on healthcare utilisation or health outcomes is uncertain (very low-certainty evidence).

\section{Financial incentives for providers of care}

We included three reviews of the effects of pay-for-performance (Akbari 2008; Scott 2011; Witter 2012), plus one review of the effects of incentives to practice in underserved areas (Grobler 2015).

Witter and colleagues assessed the effects of pay-for-performance schemes on the provision of health care and health outcomes in low- and middle-income countries (Witter 2012). It is uncertain whether pay-for-performance improves provider performance, the utilisation of services, patient outcomes, or resource use in low-income countries. Unintended effects of pay-for-performance schemes might include adverse selection (e.g. exclusion of highrisk individuals from care), over-reporting, and distortion (i.e. ignoring important tasks that are not rewarded with incentives).

Scott and colleagues examined the effect of changes in the method and level of payment on the quality of care provided by primary care physicians (Scott 2011). The review included seven studies conducted in the USA and Western Europe. The review found that the effects of financial incentives to improve the quality of health care provided by primary care physicians is uncertain.

Akbari and colleagues assessed the effects of interventions to improve outpatient referrals from primary care to secondary care (Akbari 2008). The authors included four studies of financial interventions conducted in high-income countries. The effects of financial interventions on referral rates are uncertain.

Grobler and colleagues assessed the effects of incentives to practice in underserved areas (Grobler 2015). They included one interrupted time series study from Taiwan of the effects of national health insurance on the equality of distribution of healthcare professionals. It is uncertain whether the introduction of a mandatory national health insurance scheme improves the geographic distribution of physicians, doctors of Chinese medicine, and dentists (very low-certainty evidence). Another review found no studies of the effects of financial interventions on movement of health workers between public and private organisations in lowand middle-income countries (Rutebemberwa 2014).

\section{DISCUSSION}

\section{Summary of main results}

Our framework for financial arrangements for health systems consists of five categories and 22 subcategories. Fifteen reviews (which focused on 13 of the subcategories in our framework) published between 2008 and 2015 met our inclusion criteria. Eleven of the 15 reviews were Cochrane Reviews. Forty-three per cent of the studies included in the reviews took place in low- and middleincome countries. The main findings of this overview for the five categories of financial arrangements are as follows.

- Collecting funds: there is uncertainty whether introducing or increasing user fees affects service utilisation. The effect of removing or reducing user fees is also uncertain (very lowcertainty evidence).

- Insurance schemes: there is low-certainty evidence that community-based health insurance may increase utilisation of health services, but it is uncertain if social health insurance improves utilisation. The effects of community-based health insurance and social health insurance on health outcomes are uncertain (very low-certainty evidence).

- Purchasing of services: there is uncertainty whether salary increases would be effective for attracting and retaining staff (very low-certainty evidence).

- Incentives for recipients of care: one-time incentives probably improve patient return for start or continuation of TB treatment, and conditional cash transfer programmes probably lead to an increase in service utilisation (moderate-certainty evidence). Incentives may improve adherence to long-term treatments and return for tuberculosis (TB) test reading; vouchers may improve health service utilisation; and introducing a restrictive cap may decrease use of medicines for symptomatic conditions, overall use of medicines, and insurers' expenditures on medicines (lowcertainty evidence). Other effects of recipient incentives are uncertain.

- Incentives for providers of care: the effects of provider incentives are uncertain (very low-certainty evidence), including the effects of: provider incentives on the quality of care provided by primary-care physicians or outpatient referrals from primary to secondary care; incentives for recruiting and retaining health professionals to serve in remote areas; and pay-for-performance for provider performance, utilisation of services, patient outcomes, and resource use in low-income countries.

\section{Overall completeness and applicability of evidence}

The subcategories for which we did not find an eligible systematic review were financing of insurance and health savings accounts (collection of funds), private health insurance (insurance schemes), funding of health service organisations and payment methods for specialist physicians and non-physician health workers (purchasing of services), non-conditional financial benefits (targeted financial incentives for recipients of care), and budgets and incentives for career choices (targeted financial incentives for providers of care). Subcategories for which there are uncertain effects include external funding (collection of funds), caps and co-payments for drugs and health services (recipient incentives), and pay-for-performance and incentives to practice in underserved areas (provider incentives). 
Few reviews reported equity impacts or economic impacts.

Four reviews had no included studies from low- and middle-income countries (Scott 2011; Acosta 2014; Grobler 2015; Luiza 2015), and most $(57 \%)$ of the studies in the 15 included reviews were conducted in high-income countries. The latter often have very different on-the-ground realities and health system arrangements compared to low-income countries. It was challenging to draw firm conclusions regarding the applicability of the findings from these reviews to low-income countries. These differences are particularly important in relation to interventions that require substantial resources for their design and implementation or that may require advanced technology or specialised skills for their delivery. The applicability of findings for complex interventions that may require substantial changes to the organisation of care is also uncertain.

Six reviews included only studies conducted in low- and middleincome countries, focusing on: user fees (Lagarde 2011), external funding (Hayman 2011), social health insurance and communitybased health insurance (Acharya 2012), payment methods for primary care physicians (Carr 2011), pay-for-performance (Witter 2012), and conditional cash transfers (Lagarde 2009). It is uncertain whether these interventions will yield similar effects if implemented in other low-income country settings. However, the uncertainty about the transferability of findings from one low-income setting to another is generally less than it is for the transferability of findings from high-income settings to low-income settings.

\section{Certainty of the evidence}

The included reviews were generally well-conducted, with only minor limitations (Table 4). Most of the evidence is of low or very low certainty (Table 6), with only three interventions having moderate-certainty evidence: conditional cash transfers and onetime only incentives for TB prophylaxis (Lagarde 2009 and Lutge 2015 , respectively) for desirable effects and a combination of a ceiling and fixed co-payments for drugs (Luiza 2015) for undesirable effects.

\section{Potential biases in the overview process}

Although the searches used for PDQ-Evidence are relatively comprehensive, it is possible that we failed to identify some relevant reviews. We also excluded reviews that were published before April 2005. It is possible that some of those reviews provide information that is still useful and that might supplement information provided by the included reviews. However, although our cut-off was arbitrary, it is unlikely that we excluded a substantial amount of useful information. Seven included reviews were published more than five years ago (Akbari 2008; Haynes 2008; Lagarde 2009; Carr 2011; Hayman 2011; Lagarde 2011; Scott 2011), and it is possible that more recent research has been published since then that might change their conclusions. None of these considerations would likely bias the results of this overview, but they might limit its comprehensiveness.

Classification of the interventions in the included reviews was sometimes uncertain and required judgment, for example, for a review of strategies for expanding health insurance coverage in vulnerable populations (Jia 2014), which the implementation strategies overview finally included (Pantoja 2014). This was also the case for a review of the effects of rapid response systems on clinical outcomes (Ranji 2007), which the delivery overview considered for inclusion (Ciapponi 2014). Although these judgments and differences in approaches to characterising health system interventions are unlikely to have introduced bias into this overview, they might result in some confusion, since there is no universally agreed upon classification system for financial arrangements. Moreover, any system for categorising health system interventions is to some extent arbitrary. For example, payment methods (fee-for-service versus capitation versus salary versus mixed methods of paying health workers) entail financial incentives and could be considered financial incentives targeted at providers of care. On the other hand, pay-for-performance could be considered a payment method. We elected to classify payment methods, which are typically targeted at broad behaviours, such as increasing the overall delivery of services, rather than specific behaviours. We categorised pay-for-performance as financial incentives targeted at providers of care, since by definition it is targeted at specific measurable actions (delivering specific services) or achieving specific predetermined performance targets. This categorisation and some others are consistent with what some review authors have done (e.g. Witter 2012), but they are inconsistent with what other review authors have done (e.g. Jia 2015).

Judgments about the relevance of some interventions to lowincome countries (applicability, equity, economic considerations, and monitoring and evaluation) were sometimes difficult to make. While these judgments might have been biased, it seems unlikely. All of these judgments were made by at least two overview authors on the basis of the relevant SUPPORT Summaries, which are peer reviewed by the contact author of the summarised review, content experts, and individuals from low- and middle-income countries. Our decision to focus on relevance to low-income countries, as classified by the World Bank, was somewhat arbitrary, as are the cut-offs used by the World Bank. However, it is unlikely to have impacted on the selection of reviews for inclusion or our interpretation of the relevance of the findings.

Our general approach towards including reviews of studies from high-income countries was inclusive rather than exclusive to enable readers to assess for themselves the relevance of the findings of those reviews. Similarly, our approach has been to assume that findings are applicable to low-income countries unless there are specified important differences between the settings where the studies were done and settings in low-income countries, or if identified factors that would likely modify the effects of the interventions in low-income countries.

\section{Agreements and disagreements with other studies or reviews}

We identified three related overviews published in the last 10 years (Althabe 2008; Lewin 2008; Bambra 2014). These overviews addressed a range of financial and other health system arrangements in diverse settings and populations. As with our overview, most of the studies included were from high-income countries, and they rarely reported data on patient outcomes, equity, costs, and cost-effectiveness.

Althabe and colleagues conducted an overview of systematic reviews of strategies for improving the quality of maternal and child health in low- and middle-income countries (Althabe 2008). Of 23 reviews included in this overview, only two included financial arrangements (Wensing 1998; Town 2005). One of the reviews, 
which included three observational studies, found that provider incentives were partly effective in improving professional practice. In the other review, which included randomised controlled trials, only one out of six studies reported that provider incentives improved professional practice. Heath outcome data were not reported. The authors conclude that the "use of financial interventions has not been well studied; financial incentives and disincentives may be difficult to use effectively and efficiently, although their impact on practice needs to be considered" (Althabe 2008). Their findings are consistent with ours.

Lewin and colleagues summarised the evidence from systematic reviews on the effects of governance measures, financial and delivery arrangements, and implementation strategies that have the potential to improve the delivery of cost-effective interventions in primary health care in low- and middle-income countries (Lewin 2008). Six reviews included in that overview addressed financial arrangements (Lagarde 2006; Petersen 2006; Lagarde 2007; Patouillard 2007; Akbari 2008; an earlier version of Luiza 2015 ), although of these, we included only Akbari 2008 and Luiza 2015. We excluded Patouillard 2007 because of major methodological limitations; however, another included review did cover the financial arrangement (i.e. the use of voucher schemes) it assessed (Brody 2013). We also excluded Lagarde 2006, Lagarde 2007, and Petersen 2006 because we found a more relevant review. Lewin 2008 concluded that incentives can have positive influences on provider and patient behaviours, and user fees reduce the use of both essential and non-essential health services. The wording of the conclusions in Lewin 2008 suggests that the authors rated the certainty of the evidence on the benefits of financial arrangements higher than us; otherwise, their findings are consistent with ours.

Bambra and co-workers conducted an overview of systematic reviews that reported the effects of organisational and financial arrangements on equity impacts in 15 pre-specified high-income countries: Australia, Canada, Denmark, France, Germany, Iceland, Italy, Japan, the Netherlands, New Zealand, Norway, Sweden, Switzerland, the UK, and the USA (Bambra 2014). The authors included nine systematic reviews: four on general system financing (i.e. increasing use of private insurance and change in user fees), three on organisation of services (i.e. marketisation and privatisation of healthcare services), and two on integration of health and social care systems. The overview shows that the removal of user fees may improve equity in access to health care. However, the following interventions may have negative impacts on equity: use of private insurance, introduction of user fees, and marketisation and privatisation of healthcare services. In addition, the effect of health and social care integration on equity is uncertain (Bambra 2014). Although systematic reviews included in our overview hardly described effects on equity, the applicability of Bambra and colleagues' findings to low-income countries is uncertain, as some of the financial arrangements are peculiar to high-income countries.

\section{AUTHORS' CONCLUSIONS}

\section{Implications for practice}

There is moderate-certainty evidence that the following financial arrangements have desirable effects in low-income countries, with no reported undesirable effects.
- One-time only incentives probably increase the number of people who return to a clinic to start or continue TB prophylaxis

- Conditional cash transfer programmes in low- and middleincome countries probably lead to an increase in health service utilisation

There is low or very-low certainty evidence of the effects of other financial arrangements. Policymakers must make decisions about these, despite uncertainty about their effects. Because it is not possible to be confident about the effects of most financial arrangements, monitoring is needed, and impact evaluations are warranted when these interventions are implemented in lowincome countries. In the light of the substantial uncertainties about the effects of financial arrangements, consideration should be given to pilot testing these, and their effects should be rigorously evaluated.

\section{Implications for research}

Included reviews rarely reported social outcomes, resource use, impacts on equity, and undesirable effects. Systematic reviews and updates of reviews should include all outcomes that are relevant to decision-makers and people affected by changes in financial arrangements.

Based on the included reviews, we have identified gaps in primary research due to uncertainty about the applicability of the available evidence to low-income countries (Table 8). Most of the evidence of effects was of low to very low certainty (Table 6). Thus, in addition to limitations in applicability, we also identified priorities for primary research based on the (very) low certainty of the available evidence for important outcomes such as patient outcomes, access, coverage, utilisation, quality of care, and resource use (Table 9). Financial arrangements for which the effects are uncertain include user fees, external funding, social health insurance, increasing salaries of health professionals in the public sector, caps and co-payments, pay-for-performance, and provider incentives to practise in underserved areas. Further studies evaluating the effects of these interventions are needed, particularly in low-income countries.

Finally, systematic reviews are needed for many types of financial arrangements for which we did not find a relevant eligible systematic review (Table 10). However, we are aware of systematic reviews that are in progress for some of these interventions (Mathes 2014; Motaze 2015; Jia 2015).

\section{A C K N O WLEDGEMENTS}

We would like to thank the following editors and peer referees who provided comments to improve the overview: Sasha Shepperd (editor), Beibei Yuan, Kent Ranson and to Meggan Harris for copyediting the overview.

We would also like to acknowledge the following colleagues who helped to produce the SUPPORT Summaries upon which this overview is based: Peter Steinmann, Leila H Abdullahi, Lucy KuhnBarrientos, Sebastián García Martí, Lilian Dudley, Nkengafac V Motaze, and Charles I Okwundu.

We would also like to thank Susan Munabi-Babigumira, Atle Fretheim, Simon Goudie, and Hanna Bergman for editing some of 
the SUPPORT Summaries, as well as the review authors and others who have provided feedback on them.

Charles S Wiysonge's work is supported by the South African Medical Research Council and the National Research Foundation of South Africa (Grant numbers: 106035 and 108571).

The Norwegian Satellite of the Effective Practice and Organisation of Care (EPOC) Group receives funding from the Norwegian Agency for Development Co-operation (Norad), via the Norwegian Institute of Public Health to support review authors in the production of their reviews.

This overview is a product of the Effective Health Care Research Consortium, which provided funding to make this overview open access. The Consortium is funded by UK aid from the UK Government for the benefit of developing countries (Grant: 5242). The views expressed in this overview do not necessarily reflect UK government policy. 


\section{RE F E R E N C E S}

\section{References to included reviews}

\section{Acharya 2012}

Acharya A, Vellakkal S, Taylor F, Masset E, Satija A, Burke M, Ebrahim S. Impact of National Health Insurance for the Poor and the Informal Sector in Low- and Middle-income Countries: a Systematic Review. London: EPPI-Centre, Social Science Research Unit, Institute of Education, University of London, 2012.

\section{Acosta 2014}

Acosta A, Ciapponi A, Aaserud M, Vietto V, AustolDahlgren A, Kosters JP, Vacca C, Machado M, Diaz D, Oxman AD. Pharmaceutical policies: effects of reference pricing, other pricing, and purchasing policies. Cochrane Database of Systematic Reviews 2014, Issue 10. [DOI: 10.1002/14651858.CD005979.pub2]

\section{Akbari 2008 \\ Akbari A, Mayhew A, Al-Alawi MA, Grimshaw J, Winkens R, Glidewell E, et al. Interventions to improve outpatient referrals from primary care to secondary care. Cochrane Database of Systematic Reviews 2008, Issue 4. [DOI: 10.1002/14651858.CD005471.pub2]}

\section{Brody 2013}

Brody CM, Bellows N, Campbell M, Potts M. The Impact of vouchers on the use and quality of health care in developing countries: a systematic review. Global Public Health 2013;8(4):363-88.

\section{Carr 2011}

Carr SC, Leggatt-Cook C, Clarke M, MacLachlan M, Papola TS, Pais J, et al. What is the Evidence of the Impact of Increasing Salaries on Improving the Performance of Public Servants, Including Teachers, Doctors/Nurses, and Mid-level Occupations, in Low and Middle-income Countries: Is it Time to Give Pay a Chance?. London: EPPI Centre, Social Science Research Unit, Institute of Education, University of London, 2011.

\section{Grobler 2015}

Grobler LA, Marais BJ, Mabunda S. Interventions for increasing the proportion of health professionals practising in rural and other underserved areas. Cochrane Database of Systematic Reviews 2015, Issue 6. [DOI: 10.1002/14651858.CD005314.pub3]

\section{Hayman 2011}

Hayman R, Taylor EM, Crawford F, Jeffery P, Smith J, Harper I. The Impact of Aid on Maternal and Reproductive Health: A Systematic Review to Evaluate the Effect of Aid on the Outcomes of Millennium Development Goal 5. London: EPPICentre, Social Science Research Unit, Institute of Education, University of London, 2011.

\section{Haynes 2008}

Haynes RB, Ackloo E, Sahota N, McDonald HP, Yao X. Interventions for enhancing medication adherence. Cochrane Database of Systematic Reviews 2008, Issue 2. [DOI: 10.1002/14651858.CD000011.pub3]

\section{Lagarde 2009}

Lagarde M, Haines A, Palmer N. The impact of conditional cash transfers on health outcomes and use of health services in low and middle income countries. Cochrane Database of Systematic Reviews 2009, Issue 4. [DOI: 10.1002/14651858.CD008137]

\section{Lagarde 2011}

Lagarde M, Palmer N. The impact of user fees on access to health services in low- and middle-income countries. Cochrane Database of Systematic Reviews 2011, Issue 4. [DOI: 10.1002/14651858.CD009094]

\section{Luiza 2015}

Luiza VL, Chaves LA, Silva RM, Emmerick ICM, Chaves GC, Fonseca de Araújo SC, et al. Pharmaceutical policies: effects of cap and co-payment on rational use of medicines. Cochrane Database of Systematic Reviews 2015, Issue 5. [DOI: 10.1002/14651858.CD007017.pub2]

\section{Lutge 2015}

Lutge EE, Wiysonge CS, Knight SE, Sinclair D, Volmink J. Incentives and enablers to improve adherence in tuberculosis. Cochrane Database of Systematic Reviews 2015, Issue 9. [DOI: 10.1002/14651858.CD007952.pub3]

\section{Rutebemberwa 2014}

Rutebemberwa E, Kinengyere AA, Ssengooba F, Pariyo GW, Kiwanuka SN. Financial interventions and movement restrictions for managing the movement of health workers between public and private organizations in low- and middleincome countries. Cochrane Database of Systematic Reviews 2014, Issue 2. [DOI: 10.1002/14651858.CD009845.pub2]

\section{Scott 2011}

Scott A, Sivey P, Ait Ouakrim D, Willenberg L, Naccarella L, Furler J, Young D. The effect of financial incentives on the quality of health care provided by primary care physicians. Cochrane Database of Systematic Reviews 2011, Issue 9. [DOI: 10.1002/14651858.CD008451.pub2]

\section{Witter 2012}

Witter S, Fretheim A, Kessy FL, Lindahl AK. Paying for performance to improve the delivery of health interventions in low- and middle-income countries. Cochrane Database of Systematic Reviews 2012, Issue 2. [DOI: 10.1002/14651858.CD007899.pub2]

\section{References to excluded reviews}

\section{Attree 2006}

Attree, P. The social costs of child poverty: a systematic review of the qualitative evidence. Children \& Society 2006;20:54-66. [DOI: $10.1002 / \mathrm{CHI} .854]$

\section{Barnighausen 2009}

Bärnighausen T, Bloom DE. Financial incentives for return of service in underserved areas: a systematic review. BMC Health Services Research 2009 May 29;9:86. 


\section{Bellows 2011}

Bellows NM, Bellows BW, Warren C. The use of vouchers for reproductive health services in developing countries: systematic review. Tropical Medicine \& International Health 2011;16(1):84-96.

\section{Bhutta 2009}

Bhutta ZA, Darmstadt GL, Haws RA, Yakoob MY, Lawn JE. Delivering interventions to reduce the global burden of stillbirths: improving service supply and community demand. BMC Pregnancy Childbirth 2009;9(Suppl 1):S7. [DOI: 10.1186/1471-2393-9-S1-S7]

\section{Bock 2001}

Bock NN, Sales RM, Rogers T, DeVoe B. A spoonful of sugar: improving adherence to tuberculosis treatment using financial incentives. International Journal of Tuberculosis and Lung Disease 2001;5(1):96-8.

\section{Borghi 2006}

Borghi J, Ensor T, Somanathan A, Lissner C, Mills A, Lancet Maternal Survival Series steering group. Mobilising financial resources for maternal health. Lancet 2006;368(9545):1457-65.

\section{Bosch-Capblanch 2007}

Bosch-Capblanch X, Abba K, Prictor M, Garner P. Contracts between patients and healthcare practitioners for improving patients' adherence to treatment, prevention and health promotion activities. Cochrane Database of Systematic Reviews 2007, Issue 2. [DOI: 10.1002/14651858.CD004808.pub3]

\section{Buchmueller 2005}

Buchmueller TC, Grumbach K, Kronick R, Kahn JG. The effect of health insurance on medical care utilization and implications for insurance expansion: a review of the literature. Medical Care Research and Review 2005;62(1):3-30.

\section{Chaix-Couturier 2000}

Chaix-Couturier C, Durand-Zaleski I, Jolly D, Durieux P. Effects of financial incentives on medical practice: results from a systematic review of the literature and methodological issues. International Journal for Quality in Health Care 2000;12(2):133-42.

\section{De Janvry 2006}

De Janvry A, Sadoulet E. Making conditional cash transfer programs more efficient: designing for maximum effect of the conditionality. World Bank Economic Review 2006;20:1-29.

\section{Doran 2006}

Doran T, Fullwood C, Gravelle H, Reeves D, Kontopantelis E, Hiroeh U, Roland M. Pay-for-performance programs in family practices in the United Kingdom. New England Journal of Medicine 2006;355(4):375-84. [DOI: 10.1056/NEJMsa055505]

\section{Eichler 2006}

Eichler R. Can "pay for performance" increase utilization by the poor and improve the quality of health services? Discussion paper for the first meeting of the Working Group on Performance-Based Incentives Center for Global
Development, 2006. Available from www.cgdev.org/doc/ghprn/ PBI\%20Background\%20Paper.pdf.

\section{Ekman 2004}

Ekman B. Community-based health insurance in low-income countries: a systematic review of the evidence. Health Policy and Planning 2004;19(5):249-70.

\section{Ensor 2004}

Ensor T, Cooper S. Overcoming barriers to health service access and influencing the demand side through purchasing. Washington (DC): Health, Nutrition, and Population Family (HNP) Discussion Paper. World Bank's Human Development Network 2004.

\section{Faden 2011}

Faden L, Vialle-Valentin C, Ross-Degnan D, Wagner A. Active pharmaceutical management strategies of health insurance systems to improve cost-effective use of medicines in lowand middle-income countries: a systematic review of current evidence. Health Policy 2011;100(2-3):134-43. [DOI: 10.1016/ j.healthpol.2010.10.020]

\section{Forbes 2002}

Forbes CA, Jepson RG, Martin-Hirsch PPL. Interventions targeted at women to encourage the uptake of cervical screening. Cochrane Database of Systematic Reviews 2002, Issue 3. [DOI: 10.1002/14651858.CD002834]

\section{Fournier 2009}

Fournier P, Dumont A, Tourigny C, Dunkley G, Dramé S. Improved access to comprehensive emergency obstetric care and its effect on institutional maternal mortality in rural Mali. Bulletin of the World Health Organization 2009;87:30-8. [DOI: 10.2471/BLT.07.047076]

\section{Gemmill 2008}

Gemmill MC, Thomson S, Mossialos E. What impact do prescription drug charges have on efficiency and equity? Evidence from high-income countries. International Journal for Equity in Health 2008;7(May 2):12. [DOI: 10.1186/1475-9276-7-12]

\section{Giuffrida 1997}

Giuffrida A, Torgerson DJ. Should we pay the patient? Review of financial incentives to enhance patient compliance. BMJ 1997;315(7110):703-7.

\section{Giuffrida 1999}

Giuffrida A, Gosden T, Forland F, Kristiansen I, Sergison M, Leese $B$, et al. Target payments in primary care: effects on professional practice and health care outcomes. Cochrane Database of Systematic Reviews 1999, Issue 4. [DOI: 10.1002/14651858.CD000531]

\section{Giuffrida 2000}

Giuffrida A, Gosden T, Forland F, Kristiansen IS, Sergison M, Leese $B$, et al. Target payments in primary care: effects on professional practice and health care outcomes. Cochrane Database of Systematic Reviews 2000, Issue 3. [DOI: 10.1002/14651858.CD000531] 


\section{Gosden 2000}

Gosden T, Forland F, Kristiansen IS, Sutton M, Leese B, Giuffrida A, et al. Capitation, salary, fee-for-service and mixed systems of payment: effects on the behaviour of primary care physicians. Cochrane Database of Systematic Reviews 2000, Issue 3. [DOI: 10.1002/14651858.CD002215]

\section{Gosden 2001}

Gosden T, Forland F, Kristiansen IS, Sutton M, Leese B, Giuffrida A, et al. Impact of payment method on behaviour of primary care physicians: a systematic review. Journal of Health Services Research and Policy 2001;6(1):44-55.

\section{Handa 2006}

Handa S, Davis B. The experience of conditional cash transfers in Latin America and the Caribbean. Development Policy Review 2006;24:513-36. [DOI: 10.1111/j.1467-7679.2006.00345.x]

\section{Kane 2004}

Kane RL, Johnson PE, Town RJ, Butler M. A structured review of the effect of economic incentives on consumers' preventive behavior. American Journal of Preventive Medicine 2004;27(4):327-52.

\section{Lagarde 2006}

Lagarde M, Palmer N. Evidence from systematic reviews to inform decision making regarding financing mechanisms that improve access to health services for poor people. A policy brief prepared for the International Dialogue on Evidence-Informed Action to Achieve Health Goals in Developing Countries (IDEAHealth). Geneva: Alliance for Health Policy and Systems Research; 2006. Available from www.who.int/rpc/meetings/ HealthFinancingBrief.pdf.

\section{Lagarde 2007}

Lagarde M, Haines A, Palmer N. Conditional cash transfers for improving uptake of health interventions in low- and middle-income countries: a systematic review. JAMA 2007;298(16):1900-10.

\section{Lagarde 2008}

Lagarde M, Palmer N. The impact of user fees on health service utilization in low- and middle-income countries: how strong is the evidence?. Bulletin of the World Health Organization 2008;86:839-48.

\section{Lawn 2009}

Lawn JE, Lee AC, Kinney M, Sibley L, Carlo WA, Paul VK, et al. Two million intrapartum-related stillbirths and neonatal deaths: where, why, and what can be done?. International Journal of Gynecology \& Obstetrics 2009;107(Suppl 1):S5-18, S19. [DOI: 10.1016/j.ijgo.2009.07.016]

\section{Lee 2009}

Lee AC, Lawn JE, Cousens S, Kumar V, Osrin D, Bhutta ZA, et al. Linking families and facilities for care at birth: what works to avert intrapartum-related deaths?. International Journal of Gynecology \& Obstetrics 2009 Oct;107(Suppl 1):S65-85, S86-8.

\section{Lucas 2008}

Lucas P, McIntosh K, Petticrew M, Roberts HM, Shiell A. Financial benefits for child health and well-being in low-income or socially disadvantaged families in developed world countries. Cochrane Database of Systematic Reviews 2008, Issue 2. [DOI: 10.1002/14651858.CD006358.pub2]

\section{Mannion 2008}

Mannion R, Davies HT. Payment for performance in health care. BMJ 2008;336(7639):306-8.

\section{Meyer 2011}

Meyer C, Bellows N, Campbell M, Potts M. The Impact of Vouchers on the Use and Quality of Health Goods and Services in Developing Countries: a Systematic Review. London: EPPICentre, Social Science Research Unit, Institute of Education, University of London, 2011.

\section{Oxman 2008}

Oxman AD, Fretheim A. An overview of research on the effects of results-based financing. Oslo: Nasjonalt kunnskapssenter for helsetjenesten; 2008. Report Nr 16-2008.

\section{Patouillard 2007}

Patouillard E, Goodman CA, Hanson KG, Mills AJ. Can working with the private for-profit sector improve utilization of quality health services by the poor? A systematic review of the literature. International Journal for Equity in Health 2007 Nov 7;6:17.

\section{Petersen 2006}

Petersen LA, Woodard LD, Urech T, Daw C, Sookanan S. Does pay-for-performance improve the quality of health care?. Annals of Internal Medicine 2006;145(4):265-72.

\section{Petry 2012}

Petry NM, Rash CJ, Byrne S, Ashraf S, White WB. Financial reinforcers for improving medication adherence: findings from a meta-analysis. American Journal of Medicine 2012;125(9):888-96. [DOI: 10.1016/j.amjmed.2012.01.003]

\section{Rosenthal 2006}

Rosenthal MB, Frank RG. What is the empirical basis for paying for quality in health care?. Medical Care Research and Review 2006;63(2):135-57.

\section{Siddiqi 2007}

Siddiqi A, Irwin L, Hertzman C, World Health Organization's Commission on the Social Determinants of Health. Total Environment Assessment Model for Early Childhood Development: Evidence Report. Geneva: World Health Organization, 2007.

\section{Sutherland 2008}

Sutherland K, Leatherman S, Christianson J. Paying the patient: does it work? A review of patient-targeted incentives. London: Quest for quality and improved performance. The Health Foundation, UK 2008. 


\section{Van Herck 2010}

Van Herck P, De Smedt D, Annemans L, Remmen R, Rosenthal MB, Sermeus W. Systematic review: effects, design choices, and context of pay-for-performance in health care. BMC Health Services Research 2010 Aug 23;10:247. [DOI: 10.1186/1472-6963-10-247]

\section{WHO 1996}

Maternal and Newborn Health/Safe Motherhood Unit. Division of Reproductive Health. Maternity Waiting Homes: A Review of Experiences. Geneva: World Health Organization, 1996.

\section{WHO 2003}

World Health Organization. Adherence to Long-term Therapies: Evidence for Action. Geneva: World Health Organization, 2003.

\section{WHO 2010b}

World Health Organization. Increasing Access to Health Workers in Remote and Rural Areas through Improved Retention: Global Policy Recommendations. Geneva: World Health Organization, 2010.

\section{Yoong 2012}

Yoong J, Rabinovich L, Diepeveen S. The Impact of Economic Resource Transfers to Women versus Men: A Systematic Review. London: EPPI-Centre, Social Science Research Unit, Institute of Education, University of London, 2012.

\section{Additional references}

\section{Adebayo 2015}

Adebayo EF, Uthman OA, Wiysonge CS, Stern EA, Lamont KT, Ataguba JE. A systematic review of factors that affect uptake of community-based health insurance in low-income and middleincome countries. BMC Health Services Research 2015;15(1):543.

\section{Althabe 2008}

Althabe F, Bergel E, Cafferata ML, Gibbons L, Ciapponi A, Alemán $A$, et al. Strategies for improving the quality of health care in maternal and child health in low- and middle-income countries: an overview of systematic reviews. Paediatric and Perinatal Epidemiology 2008;22(Suppl 1):42-60.

\section{Bambra 2014}

Bambra C, Garthwaite K, Hunter D. All things being equal: does it matter for equity how you organize and pay for health care? A review of the international evidence. International Journal of Health Services: Planning, Administration, Evaluation 2014;44(3):457-77.

\section{Carrin 2002}

Carrin G. Social health insurance in developing countries: a continuing challenge. International Social Security Review 2002;55:57-69.

\section{Carrin 2004}

Carrin G, James C, WHO Dept of Health System Financing, Expenditure, Resource Allocation. Reaching Universal Coverage via Social Health Insurance: Key Design Features in the Transition Period. Geneva: World Health Organization, 2004.

\section{Ciapponi 2014}

Ciapponi A, Lewin S, Bastías G, Dudley L, Flottorp S, Gagnon MP, et al. Delivery arrangements for health systems in lowincome countries: an overview of systematic reviews. Cochrane Database of Systematic Reviews 2014, Issue 5. [DOI: 10.1002/14651858.CD011083]

\section{Drechsler 2005}

Drechsler D, Jutting J. Private Health Insurance in Low and Middle-Income Countries. Scope, Limitations, and Policy Response; March 2005. OECD Development Centre. Available from www.eldis.org/vfile/upload/1/document/0708/ DOC19897.pdf.

\section{EPOC 2017}

Cochrane Effective Practice, Organisation of Care (EPOC). EPOC Resources for review authors, 2017. Available from http:// epoc.cochrane.org/resources/epoc-resources-review-authors.

\section{Guyatt 2008}

Guyatt GH, Oxman AD, Kunz R, Vist GE, Falck-Ytter Y, Schünemann HJ, et al. What is "quality of evidence" and why is it important to clinicians?. BMJ 2008;336(7651):995-8.

\section{Herrera 2014}

Herrera CA, Ciapponi A, Bastías G, Lewin S, Garcia Marti S, Okwundu $\mathrm{Cl}$, et al. Governance arrangements for health systems in low-income countries: an overview of systematic reviews. Cochrane Database of Systematic Reviews 2014, Issue 4. [DOI: 10.1002/14651858.CD011085]

\section{Jia 2014}

Jia L, Yuan B, Lu Y, Garner P, Meng Q, Huang F. Strategies for expanding health insurance coverage in vulnerable populations. Cochrane Database of Systematic Reviews 2014, Issue 11. [DOI: 10.1002/14651858.CD008194.pub2]

\section{Jia 2015}

Jia L, Yuan B, Meng Q, Scott A. Payment methods for ambulatory care health professionals. Cochrane Database of Systematic Reviews 2015, Issue 9. [DOI: 10.1002/14651858.CD011865]

\section{Kutzin 2001}

Kutzin J. A descriptive framework for country-level analysis of health care financing arrangements. Health Policy 2001;56(3):171-204.

\section{Lavis 2015}

Lavis JN, Wilson MG, Moat KA, Hammill AC, Boyko JA, Grimshaw JM, et al. Developing and refining the methods for a 'one-stop shop' for research evidence about health systems. Health Research Policy and Systems 2015;13:10. [DOI: 10.1186/1478-4505-13-10]

\section{Lewin 2008}

Lewin S, Lavis JN, Oxman AD, Bastías G, Chopra M, Ciapponi A, et al. Supporting the delivery of cost-effective interventions in primary health-care systems in low-income and middleincome countries: an overview of systematic reviews. Lancet 2008;372(9642):928-39. 


\section{Mathes 2014}

Mathes T, Pieper D, Mosch CG, Jaschinski T, Eikermann M. Payment methods for hospitals. Cochrane Database of Systematic Reviews 2014, Issue 6. [DOI: 10.1002/14651858.CD011156]

\section{Motaze 2015}

Motaze NV, Chi CP, Ongolo-Zogo P, Ndongo JS, Wiysonge CS. Government regulation of private health insurance. Cochrane Database of Systematic Reviews 2015, Issue 4. [DOI: 10.1002/14651858.CD011512]

\section{Murray 2000}

Murray CJL, Frenk J. A framework for assessing the performance of health systems. Bulletin of the World Health Organization 2000;78(6):717-31.

\section{Pantoja 2014}

Pantoja T, Opiyo N, Ciapponi A, Dudley L, Gagnon MP, Herrera CA, et al. Implementation strategies for health systems in low-income countries: an overview of systematic reviews. Cochrane Database of Systematic Reviews 2014, Issue 5. [DOI: 10.1002/14651858.CD011086]

\section{Paris Declaration 2005}

Paris High-Level Forum. Paris declaration on aid effectiveness. www.oecd.org/dac/effectiveness/34428351.pdf (accessed 23 April 2015)

\section{Rada 2013}

Rada G, Pérez D, Capurro D. Epistemonikos: A free, relational, collaborative, multilingual database of health evidence. Studies in Health Technology and Informatics 2013;192:486-90.

\section{Ranji 2007}

Ranji SR, Auerbach AD, Hurd CJ, O'Rourke K, Shojania KG. Effects of rapid response systems on clinical outcomes: systematic review and meta-analysis. Journal of Hospital Medicine 2007;2(6):422-32.

\section{Ravishankar 2009}

Ravishankar N, Gubbins P, Cooley RJ, Leach-Kemon K, Michaud CM, Jamison DT, et al. Financing of global health: tracking development assistance for health from 1990 to 2007. Lancet 2009;373(9681):2113-24.

\section{Rosenbaum 2011}

Rosenbaum SE, Glenton C, Wiysonge CS, Abalos E, Mignini L, Young T, et al. Evidence summaries tailored to health policymakers in low- and middle-income countries. Bulletin of the World Health Organization 2011;89:54-61.

\section{Schieber 2006}

Schieber G, Baeza C, Kress D, Maier M. Chapter 12: Financing Health Systems in the 21st Century. In: Jamison DT, Breman JG, Measham AR, Alleyne G, Claeson M, Evans DB, et al. editor(s). Disease Control Priorities in Developing Countries. 2nd Edition. Washington DC: World Bank, 2006.

\section{Schünemann 2011a}

Schünemann HJ, Oxman AD, Higgins JPT, Vist GE, Glasziou P, Guyatt GH. Chapter 11: Presenting results and 'Summary of findings' tables. In: Higgins JPT, Green S (editors), Cochrane Handbook for Systematic Reviews of Interventions Version 5.1.0 (updated March 2011). The Cochrane Collaboration, 2011. Available from www.cochrane-handbook.org.

\section{Schünemann 2011b}

Schünemann HJ, Oxman AD, Vist GE, Higgins JPT, Deeks JJ, Glasziou P, et al. Chapter 12: Interpreting results and drawing conclusions. In: Higgins JPT, Green S (editors), Cochrane Handbook for Systematic Reviews of Interventions Version 5.1.0 (updated March 2011). The Cochrane Collaboration, 2011. Available from www.cochrane-handbook.org.

\section{Town 2005}

Town R, Kane R, Johnson P, Butler M. Economic incentives and physicians' delivery of preventive care: a systematic review. American Journal of Preventive Medicine 2005;28 (2):234-40.

\section{UN 2012}

United Nations. Global Health and Foreign Policy [A/67/L.36]. New York: United Nations, 2012.

\section{Van Olmen 2010}

Van Olmen J, Criel B, van Damme W, Marchal B, van Belle S, van Dormael M, et al. Analysing health systems to make them stronger. Studies in Health Services Organisation \& Policy 2010; Vol. 27:1-102. Available from www.strengtheninghealthsystems.be/doc/SHSO\&P27_HS \%20ANALYSIS_FINAL.pdf.

\section{Wensing 1998}

Wensing M, Weijen T, Grol R. Implementing guidelines and innovations in general practice: which interventions are effective?. British Journal of General Practice 1998;48(427):991-7.

\section{WHO 2000}

World Health Organization. The World Health Report 2000 Health Systems: Improving Performance. Geneva: World Health Organization, 2000.

\section{WHO 2005}

World Health Organization. Sustainable Health Financing, Universal Coverage and Social Health Insurance. WHO: Geneva, 2005.

\section{WHO 2007}

World Health Organization. Everybody's Business: Strengthening Health Systems to Improve Health Outcomes: WHO's Framework for Action. 2007: World Health Organization, 2007.

\section{WHO 2010a}

World Health Organization. The World Health Report: Health Systems Financing: the Path to Universal Coverage. Geneva: WHO, 2010. 


\section{WHO 2015}

World Health Organization. Sustainable Development Goal 3: Ensure healthy lives and promote wellbeing for all at all ages. 2015. www.who.int/sdg/targets/en/ (accessed 12 June 2017).

\section{Wiysonge 2012}

Wiysonge CS, Ngcobo NJ, Jeena PM, Madhi SA, Schoub BD, Hawkridge A, Shey MS, Hussey GD. Advances in childhood immunisation in South Africa - where to now? Programme managers' views and evidence from systematic reviews. $B M C$ Public Health 2012 Jul 31;12:578.

\section{World Bank 2016}

The World Bank Group. Data. Countries and Economies, 2016. Available from data.worldbank.org/country (accessed prior to 30 June 2017).

\section{References to other published versions of this review Wiysonge 2014}

Wiysonge CS, Herrera CA, Ciapponi A, Lewin S, Garcia Marti S, Opiyo N, et al. Financial arrangements for health systems in low-income countries: an overview of systematic reviews. Cochrane Database of Systematic Reviews 2014, Issue 4. [DOI: 10.1002/14651858.CD011084]

ADDITIONAL TABLES

Table 1. Types of financial arrangements

\section{Financial arrangement Definition}

\section{Collection of funds}

\begin{tabular}{ll}
\hline User fees & Charges levied on any aspect of health services at the point of delivery \\
\hline Prepaid funding & $\begin{array}{l}\text { Collection of funds through general tax revenues versus earmarked tax revenues versus employer } \\
\text { payments versus direct payments }\end{array}$
\end{tabular}

Community loan funds $\quad$ Funds generated from contributions of community members that families can borrow to pay for emergency transportation and hospital costs

\begin{tabular}{ll}
\hline Health savings accounts & Prepayment schemes for individuals or families without risk pooling \\
\hline External funding & $\begin{array}{l}\text { Financial contributions such as donations, loans, etc. from public or private entities from outside } \\
\text { the national or local health financing system }\end{array}$ \\
\hline
\end{tabular}

\section{Insurance schemes (pooling of funds)}

\begin{tabular}{ll}
\hline Social health insurance & Compulsory insurance that aims to provide universal coverage \\
\hline $\begin{array}{l}\text { Community-based health in- } \\
\text { surance }\end{array}$ & $\begin{array}{l}\text { A scheme managed and operated by an organisation, other than a government or private for-profit } \\
\text { company, that provides risk pooling to cover all or part of the costs of health care services }\end{array}$ \\
\hline
\end{tabular}

Private health insurance Private for-profit health insurance

\section{Purchasing of services}

Funding of health service organisations
Fee-for-service versus capitation versus prospective payment versus line item budgets versus global budgets versus case-based reimbursement (including diagnostic related group payment schemes) versus mixed methods of paying for health service organisations

\section{Payment methods for health Fee for service versus capitation versus salary versus mixed methods of paying health workers} workers

\section{Financial incentives for recipients of care}

Financial incentives for recipients of care
Financial or monetary incentives or removal of disincentives to change specified behaviours of recipients of care 


\section{Table 1. Types of financial arrangements (Continued)}
Conditional cash transfers
Monetary transfers to households on the condition that they comply with pre-defined require- ments

\begin{tabular}{ll}
\hline Voucher schemes & Provision of vouchers that can be redeemed for health services at specified facilities \\
\hline Caps and co-payments & Direct patient payments for part of the cost of drugs or health services
\end{tabular}

\section{Financial incentives for providers of care}

\begin{tabular}{ll}
\hline Pay-for-performance & Transfer of money or material goods to healthcare providers conditional on taking a measurable \\
action or achieving a predetermined performance target
\end{tabular}

$\begin{array}{ll}\text { Budgets } & \text { Funds that are allocated by payers to a group or individual physicians to purchase services (includ- } \\ \text { ing fund holding and indicative budgets) }\end{array}$

Incentives to practice in un- Financial or material rewards for practicing in underserved areas
derserved areas
derserved areas

Table 2. Included reviews

FINANCIAL ARRANGEMENT INCLUDED REVIEWS

\section{Collection of funds}

\begin{tabular}{ll}
\hline Financing of insurance & No eligible systematic review found \\
\hline User fees & $\begin{array}{l}\text { The impact of user fees on access to health services in low- and middle-income countries } \\
(\text { Lagarde 2011) }\end{array}$ \\
\hline Community loan funds & No eligible systematic review found \\
\hline Health savings accounts & No eligible systematic review found \\
\hline External funding & $\begin{array}{l}\text { The impact of aid on maternal and reproductive health: a systematic review to evaluate the } \\
\text { effect of aid on the outcomes of Millennium Development Goal 5 (Hayman 2011) }\end{array}$ \\
\hline
\end{tabular}

\section{Insurance schemes}

Social health insurance Impact of national health insurance for the poor and the informal sector in low- and middle-income countries: a systematic review (Acharya 2012)

Community based health insurance Impact of national health insurance for the poor and the informal sector in low- and middle-income countries: a systematic review (Acharya 2012)

\begin{tabular}{ll}
\hline Private health insurance $\quad$ No eligible systematic review found \\
\hline
\end{tabular}

\section{Purchasing of services}

Funding of health service organisa- No eligible systematic review found
tions 
Table 2. Included reviews (Continued)
Payment methods for health workers
What is the evidence of the impact of increasing salaries on improving the performance
- primary care physicians of public servants, including teachers, nurses and mid-level occupations, in low- and mid- dle-income countries: is it time to give pay a chance? (Carr 2011)
Payment methods for health workers
- specialist physicians

No eligible systematic review found
Payment methods for health workers No eligible systematic review found
- non-physician health workers

\title{
Financial incentives and disincentives for recipients of care
}

\author{
Financial incentives for recipients of Interventions for enhancing medication adherence (Haynes 2008) \\ care \\ - medication adherence
}
Financial incentives for recipients of Incentives and enablers to improve adherence in tuberculosis(Lutge 2015) care
- TB adherence

\begin{tabular}{ll}
\hline Conditional cash transfers & $\begin{array}{l}\text { The impact of conditional cash transfers on health outcomes and use of health services in } \\
\text { low and middle income countries (Lagarde 2009) }\end{array}$ \\
\hline Non-conditional financial benefits & No eligible systematic review found \\
\hline Voucher schemes & $\begin{array}{l}\text { The Impact of vouchers on the use and quality of health care in developing countries: a sys- } \\
\text { tematic review (Brody 2013) }\end{array}$ \\
\hline Caps and co-payments & $\begin{array}{l}\text { Pharmaceutical policies: effects of cap and co-payment on rational use of medicines (Luiza } \\
\text { - drugs }\end{array}$ \\
\hline Reference pricing & $\begin{array}{l}\text { Pharmaceutical policies: effects of reference pricing, other pricing, and purchasing policies } \\
\text { (Acosta 2014) }\end{array}$ \\
\hline
\end{tabular}

\section{Financial incentives and disincentives for providers of care}

Pay-for-performance

- effects on delivery of health interventions

Pay-for-performance

- effects on outpatient referrals from primary care to secondary care

Pay-for-performance

- effects on the quality of health care provided by primary care physicians

Budgets
Paying for performance to improve the delivery of health interventions in low- and middle-income countries (Witter 2012)

Interventions to improve outpatient referrals from primary care to secondary care (Akbari 2008)

The effect of financial incentives on the quality of health care provided by primary care physicians (Scott 2011)

No eligible systematic review found 
Table 2. Included reviews (Continued) $\begin{aligned} & \text { Incentives to practice in underserved } \\ & \text { areas }\end{aligned}$
communities (Grobler 2015)

Managing the movement of health workers

Financial interventions and movement restrictions for managing the movement of health workers between public and private organisations in low and middle-income countries (Rutebemberwa 2014)

Incentives for career choices

No eligible systematic review found

TB: tuberculosis.

Table 3. Excluded reviews

\begin{tabular}{|c|c|c|}
\hline Review ID & Excluded reviews & Reasons for exclusion \\
\hline Attree 2006 & $\begin{array}{l}\text { The social costs of child poverty: a systematic review of the qualitative evi- } \\
\text { dence }\end{array}$ & Major limitations \\
\hline Barnighausen 2009 & $\begin{array}{l}\text { Financial incentives for return of service in underserved areas: a systematic re- } \\
\text { view }\end{array}$ & $\begin{array}{l}\text { More relevant review } \\
\text { found }\end{array}$ \\
\hline Bellows 2011 & $\begin{array}{l}\text { The use of vouchers for reproductive health services in developing countries: } \\
\text { systematic review }\end{array}$ & Major limitations \\
\hline Bhutta 2009 & $\begin{array}{l}\text { Delivering interventions to reduce the global burden of stillbirths: improving } \\
\text { service supply and community demand }\end{array}$ & Major limitations \\
\hline Bock 2001 & $\begin{array}{l}\text { A spoonful of sugar: improving adherence to tuberculosis treatment using fi- } \\
\text { nancial incentives }\end{array}$ & Out of date \\
\hline Borghi 2006 & Mobilising financial resources for maternal health & $\begin{array}{l}\text { More relevant review } \\
\text { found }\end{array}$ \\
\hline Bosch-Capblanch 2007 & $\begin{array}{l}\text { Contracts between patients and healthcare practitioners for improving pa- } \\
\text { tients' adherence to treatment, prevention and health promotion activities }\end{array}$ & $\begin{array}{l}\text { More relevant review } \\
\text { found }\end{array}$ \\
\hline Buchmueller 2005 & $\begin{array}{l}\text { The effect of health insurance on medical care utilization and implications for } \\
\text { insurance expansion }\end{array}$ & Major limitations \\
\hline Chaix-Couturier 2000 & Effects of financial incentives on medical practice & $\begin{array}{l}\text { More relevant review } \\
\text { found }\end{array}$ \\
\hline De Janvry 2006 & Making conditional cash transfer programs more efficient & Major limitations \\
\hline Doran 2006 & Pay-for-performance programs in family practices in the United Kingdom & $\begin{array}{l}\text { More relevant review } \\
\text { found }\end{array}$ \\
\hline Eichler 2006 & $\begin{array}{l}\text { Can "pay for performance" increase utilization by the poor and improve the } \\
\text { quality of health services? }\end{array}$ & $\begin{array}{l}\text { More relevant review } \\
\text { found }\end{array}$ \\
\hline Ekman 2004 & $\begin{array}{l}\text { Community-based health insurance in low-income countries: a systematic re- } \\
\text { view of the evidence }\end{array}$ & Major limitations \\
\hline Ensor 2004 & $\begin{array}{l}\text { Overcoming barriers to health service access and influencing the demand side } \\
\text { through purchasing }\end{array}$ & Major limitations \\
\hline
\end{tabular}

Financial arrangements for health systems in low-income countries: an overview of systematic reviews (Review) 
Table 3. Excluded reviews (Continued)

\begin{tabular}{lll} 
Faden 2011 & $\begin{array}{l}\text { Active pharmaceutical management strategies of health insurance systems to } \\
\text { improve cost-effective use of medicines in low- and middle-income countries }\end{array}$ & Major limitations \\
\hline Forbes 2002 & $\begin{array}{l}\text { Interventions targeted at women to encourage the uptake of cervical screen- } \\
\text { ing }\end{array}$ & Out of date \\
\hline Fournier 2009 & Whproved access to comprehensive emergency obstetric care and its effect on & $\begin{array}{l}\text { More relevant review } \\
\text { found }\end{array}$ \\
\hline Gemmill 2008 & Should we pay the patient? & $\begin{array}{l}\text { More relevant review } \\
\text { found }\end{array}$ \\
\hline Giuffrida 1997 & $\begin{array}{l}\text { Target payments in primary care: effects on professional practice and health } \\
\text { care outcomes }\end{array}$ & Out of date
\end{tabular}

\begin{tabular}{|c|c|c|}
\hline Gosden 2000 & $\begin{array}{l}\text { Capitation, salary, fee-for-service and mixed systems of payment: effects on } \\
\text { the behaviour of primary care physicians }\end{array}$ & $\begin{array}{l}\text { More relevant review } \\
\text { found }\end{array}$ \\
\hline Gosden 2001 & $\begin{array}{l}\text { Impact of payment method on behaviour of primary care physicians: a system- } \\
\text { atic review }\end{array}$ & Out of date \\
\hline Handa 2006 & $\begin{array}{l}\text { The experience of conditional cash transfers in Latin America and the } \\
\text { Caribbean }\end{array}$ & $\begin{array}{l}\text { More relevant review } \\
\text { found }\end{array}$ \\
\hline Yoong 2012 & The impact of economic resource transfers to women versus men & $\begin{array}{l}\text { More relevant review } \\
\text { found }\end{array}$ \\
\hline Kane 2004 & $\begin{array}{l}\text { A structured review of the effect of economic incentives on consumers' pre- } \\
\text { ventive behavior }\end{array}$ & Out of date \\
\hline Giuffrida 2000 & $\begin{array}{l}\text { Target payments in primary care: effects on professional practice and health } \\
\text { care outcomes }\end{array}$ & $\begin{array}{l}\text { More relevant review } \\
\text { found }\end{array}$ \\
\hline Lagarde 2006 & $\begin{array}{l}\text { Evidence from systematic reviews to inform decision making regarding financ- } \\
\text { ing mechanisms that improve access to health services for poor people }\end{array}$ & $\begin{array}{l}\text { More relevant review } \\
\text { found }\end{array}$ \\
\hline Lagarde 2007 & $\begin{array}{l}\text { Conditional cash transfers for improving uptake of health interventions in low- } \\
\text { and middle-income countries }\end{array}$ & $\begin{array}{l}\text { More relevant review } \\
\text { found }\end{array}$ \\
\hline Lagarde 2008 & $\begin{array}{l}\text { The impact of user fees on health service utilization in low- and middle-income } \\
\text { countries: how strong is the evidence? }\end{array}$ & Major limitations \\
\hline Lawn 2009 & $\begin{array}{l}\text { Two million intrapartum-related stillbirths and neonatal deaths: where, why, } \\
\text { and what can be done? }\end{array}$ & $\begin{array}{l}\text { More relevant review } \\
\text { found }\end{array}$ \\
\hline Lee 2009 & $\begin{array}{l}\text { Linking families and facilities for care at birth: what works to avert intra- } \\
\text { partum-related deaths? }\end{array}$ & Major limitations \\
\hline Lucas 2008 & $\begin{array}{l}\text { Financial benefits for child health and well-being in low-income or socially dis- } \\
\text { advantaged families in developed world countries }\end{array}$ & $\begin{array}{l}\text { Not transferable to low- } \\
\text { income countries }\end{array}$ \\
\hline Mannion 2008 & Payment for performance in health care & $\begin{array}{l}\text { More relevant review } \\
\text { found }\end{array}$ \\
\hline
\end{tabular}


Table 3. Excluded reviews (Continued)
Meyer 2011
The impact of vouchers on the use and quality of health goods and services in
Major limitations developing countries: a systematic review

\begin{tabular}{|c|c|c|}
\hline Oxman 2008 & An overview of research on the effects of results-based financing & $\begin{array}{l}\text { More relevant review } \\
\text { found }\end{array}$ \\
\hline Petersen 2006 & Does pay-for-performance improve the quality of health care? & $\begin{array}{l}\text { More relevant review } \\
\text { found }\end{array}$ \\
\hline Patouillard 2007 & $\begin{array}{l}\text { Can working with the private for-profit sector improve utilization of quality } \\
\text { health services by the poor? }\end{array}$ & Major limitations \\
\hline Petry 2012 & $\begin{array}{l}\text { Financial reinforcers for improving medication adherence: findings from a } \\
\text { meta-analysis }\end{array}$ & $\begin{array}{l}\text { More relevant review } \\
\text { found }\end{array}$ \\
\hline Rosenthal 2006 & What is the empirical basis for paying for quality in health care? & $\begin{array}{l}\text { More relevant review } \\
\text { found }\end{array}$ \\
\hline Siddiqi 2007 & Towards environment assessment model for early childhood development & Major limitations \\
\hline Sutherland 2008 & Paying the patient: does it work? A review of patient-targeted incentives & $\begin{array}{l}\text { More relevant review } \\
\text { found }\end{array}$ \\
\hline Van Herck 2010 & $\begin{array}{l}\text { Systematic review: effects, design choices, and context of pay-for-performance } \\
\text { in health care }\end{array}$ & $\begin{array}{l}\text { More relevant review } \\
\text { found }\end{array}$ \\
\hline WHO 1996 & Maternity waiting homes: a review of experiences & $\begin{array}{l}\text { More relevant review } \\
\text { found }\end{array}$ \\
\hline WHO 2003 & Adherence to long-term therapies: evidence for action & $\begin{array}{l}\text { More relevant review } \\
\text { found }\end{array}$ \\
\hline WHO 2010b & $\begin{array}{l}\text { Increasing access to health workers in remote and rural areas through im- } \\
\text { proved retention: global policy recommendations }\end{array}$ & $\begin{array}{l}\text { More relevant review } \\
\text { found }\end{array}$ \\
\hline
\end{tabular}




\begin{tabular}{|c|c|c|c|c|c|c|c|c|c|c|c|c|c|c|}
\hline \multirow[t]{2}{*}{ Review } & \multicolumn{6}{|c|}{$\begin{array}{l}\text { A. Identification, selection and critical appraisal of stud- } \\
\text { ies }^{a}\end{array}$} & \multicolumn{6}{|c|}{ B. Analysisb } & \multicolumn{2}{|c|}{ C. Overallc } \\
\hline & $\begin{array}{l}1 . \\
\text { Selec- } \\
\text { tion } \\
\text { crite- } \\
\text { ria }\end{array}$ & $\begin{array}{l}2 . \\
\text { Search }\end{array}$ & $\begin{array}{l}\text { 3. Up- } \\
\text { to- } \\
\text { date }\end{array}$ & $\begin{array}{l}4 . \\
\text { Study } \\
\text { selec- } \\
\text { tion }\end{array}$ & $\begin{array}{l}\text { 5. Risk } \\
\text { of bias }\end{array}$ & $\begin{array}{l}6 . \\
\text { Over- } \\
\text { all }\end{array}$ & $\begin{array}{l}1 . \\
\text { Study } \\
\text { char- } \\
\text { acter- } \\
\text { istics }\end{array}$ & $\begin{array}{l}\text { 2. An- } \\
\text { alytic } \\
\text { meth- } \\
\text { ods }\end{array}$ & $\begin{array}{l}\text { 3. Het- } \\
\text { ero- } \\
\text { gene- } \\
\text { ity }\end{array}$ & $\begin{array}{l}\text { 4. Ap- } \\
\text { pro- } \\
\text { priate } \\
\text { syn- } \\
\text { thesis }\end{array}$ & $\begin{array}{l}\text { 5. Ex- } \\
\text { plorato- } \\
\text { ry fac- } \\
\text { tors }\end{array}$ & $\begin{array}{l}6 . \\
\text { Over- } \\
\text { all }\end{array}$ & $\begin{array}{l}\text { 1. Oth- } \\
\text { er con- } \\
\text { sidera- } \\
\text { tions }\end{array}$ & $\begin{array}{l}\text { 2. Reli- } \\
\text { ability } \\
\text { of the } \\
\text { review }\end{array}$ \\
\hline Acharya 2012 & + & $?$ & + & + & + & + & + & + & + & + & + & + & + & + \\
\hline Acosta 2014 & + & + & + & + & + & + & + & + & + & + & + & + & + & + \\
\hline Akbari 2008 & + & + & + & + & + & + & + & + & + & + & + & + & + & + \\
\hline Brody 2013 & + & + & + & + & + & + & + & + & + & + & $?$ & + & + & + \\
\hline Carr 2011 & + & + & + & + & + & + & $?$ & + & + & + & $?$ & + & + & + \\
\hline Grobler 2015 & + & + & + & + & + & + & + & + & + & + & + & + & + & + \\
\hline Hayman 2011 & + & + & + & + & $?$ & + & + & + & + & + & + & + & + & + \\
\hline Haynes 2008 & + & + & + & + & + & + & + & + & + & + & + & + & + & + \\
\hline Lagarde 2009 & + & + & + & + & + & + & + & + & + & + & + & + & + & + \\
\hline Lagarde 2011 & + & + & + & + & + & + & + & + & + & + & + & + & + & + \\
\hline Luiza 2015 & + & + & + & + & + & + & + & + & + & + & + & + & + & + \\
\hline Lutge 2015 & + & + & + & + & + & + & + & + & + & + & + & + & + & + \\
\hline Rutebemberwa 2014 & + & $?$ & + & + & + & + & NA & NA & NA & NA & NA & + & + & + \\
\hline Scott 2011 & + & + & + & + & + & + & + & + & + & + & + & + & + & + \\
\hline Witter 2012 & + & + & + & + & + & + & + & + & + & + & + & + & + & + \\
\hline $\begin{array}{l}\text { Identification, select } \\
\text { 1. Selection criteria: } \\
\text { 2. Search: was the sear }\end{array}$ & $\begin{array}{l}\text { Ind critic } \\
\text { e criteric } \\
\text { evidenc }\end{array}$ & $\begin{array}{l}\text { appraisa } \\
\text { used for } \mathrm{d} \\
\text { reasonabl }\end{array}$ & $\begin{array}{l}\text { of studi } \\
\text { ciding w } \\
\text { compre }\end{array}$ & $\begin{array}{l}\text { ch studie } \\
\text { ensive? (+ }\end{array}$ & $\begin{array}{l}\text { to include } \\
\text { es; ? can't }\end{array}$ & $\begin{array}{l}\text { in the rev } \\
\text { tell/parti }\end{array}$ & $\begin{array}{l}\text { w report } \\
\text { ly; - no) }\end{array}$ & (+ yes; & . & tially & & & & \\
\hline
\end{tabular}


3. Up-to-date: is the review reasonably up-to-date? (+ yes; ? can't tell/partially; - no)

4. Study selection: was bias in the selection of articles avoided? (+ yes; ? can't tell/partially; - no)

5. Risk of bias: did the authors use appropriate criteria to assess the risk for bias in analysing the studies that are included? (+ yes; ? can't tell/partially; - no)

6. Overall: how would you rate the methods used to identify, include and critically appraise studies? (+ only minor limitations, - important limitations)

${ }^{b}$ Analysis

1. Study characteristics: were the characteristics and results of the included studies reliably reported? (+ yes; ? can't tell/partially; - no, NA: Not applicable; e.g. no studies or data)

2. Analytic methods: were the methods used by the review authors to analyse the findings of the included studies reported? (+ yes; ? can't tell/partially; - no, NA = Not applicable;

e.g. no studies or data)

3. Heterogeneity: did the review describe the extent of heterogeneity? (+ yes; ? can't tell/partially; - no, NA: not applicable; e.g. no studies or data)

4. Appropriate synthesis: were the findings of the relevant studies combined (or not combined) appropriately relative to the primary question the review addresses and the available data? (+ yes; ? can't tell/partially; - no, NA: not applicable; e.g. no studies or data)

5. Exploratory factors: did the review examine the extent to which specific factors might explain differences in the results of the included studies? (+ yes; ? can't tell/partially; - no, NA: not applicable; e.g. no studies or data)

6. Overall: how would you rate the methods used to analyse the findings relative to the primary question addressed in the review? (+ only minor limitations, - important limitations)

\section{c Overall}

1. Other considerations: are there any other aspects of the review not mentioned before which lead you to question the results? (+ yes; ? can't tell/partially; - no)

2. Reliability of the review: based on the above assessments of the methods how would you rate the reliability of the review? (+ only minor limitations, - important limitations) 
Table 5. Key messages of included reviews

\section{FINANCIAL ARRANGEMENT KEY MESSAGES}

\section{Collection of funds}

$\begin{array}{ll}\text { User fees } & \Rightarrow \text { The effects for the following are uncertain. } \\ \text { Lagarde } 2011 & \text { - Introducing or increasing user fees. } \\ & \text { - The combination of user fees and quality improvement. } \\ & \text { Removing or reducing user fees. }\end{array}$

$\Rightarrow$ The impacts of changes in user fees on utilisation may depend on whether they are for preventive or curative services, whether increases are combined with quality improvement efforts, and the size of the change in fees.

The impact of changes in user fees on equity are uncertain. However, poorer people may be more sensitive to changes in user fees.

Changes to user fees should be carefully planned and monitored, and the impacts of changes to user fees should be rigorously evaluated.

\section{External funding}

Hayman 2011
It is uncertain whether aid delivered under the Paris Principles improves maternal and reproductive health outcomes.

Aid-supported interventions to improve maternal and reproductive health should include an evaluation plan.

\section{Insurance schemes}

\section{Social health insurance/ \\ Community-based health in- surance}

Acharya 2012
$\Rightarrow$ Community health insurance may increase utilisation of health services, but it is uncertain if it improves health outcomes or changes out-of-pocket expenditure among those insured in low-income countries.

$\Rightarrow$ It is uncertain if social health insurance improves utilisation of health services and health outcomes, leads to changes in out-of-pocket expenditure, or improves equity among those insured in low-income countries.

Most of the included studies were conducted in low- and middle-income countries in Latin America, Asia, and Africa.

\section{Purchasing of services}

\section{Payment methods for prima- ry care physicians}

Carr 2011
$\Rightarrow$ It is uncertain whether increasing the salaries of health professionals or other professionals in the public sector improves either the quantity or quality of their work.

Rather than making assumptions about the intended or unintended effects of fixed salary reforms that increase the salaries of health professionals, such policies should be evaluated, if possible using randomised trials or interrupted time series studies.

\section{Financial incentives and disincentives for recipients of care}

\section{Financial incentives for re- cipients of care}

- medication adherence

Haynes 2008
It is uncertain whether interventions to increase adherence to short-term treatments improve adherence or patient outcomes.

Interventions aimed at increasing adherence to long-term treatments may improve adherence, but it is uncertain whether they improve patient outcomes.

Most of the included studies assessed complex interventions with multiple components in highincome countries. Adherence interventions may be difficult to implement in low-income countries where health systems face greater challenges. 


\section{Table 5. Key messages of included reviews (Continued)}

Financial incentives for recipients of care

- TB adherence

Lutge 2015
Sustained material incentives may lead to little or no difference in cure or completion of treatment for active TB, compared to no incentive.

It is not clear if sustained material incentives improve completion of TB prophylaxis, compared to no incentive, because findings varied across studies.

A one-time-only incentive may increase the number of people who return to a clinic for reading of their tuberculin skin test, compared to no incentive.

A one-time-only incentive probably increases the number of people who return to a clinic to start or continue TB prophylaxis, compared to no incentive.

Compared to a non-cash incentive, cash incentives may slightly increase the number of people who return to a clinic for reading of their tuberculin skin test and may increase the number of people who complete TB prophylaxis.

Compared to counselling or education interventions, material incentives may increase the number of people who return to a clinic for reading of their tuberculin skin test.

$\Rightarrow$ Compared to counselling or education interventions, material incentives may lead to little or no difference in the number of people who return to a clinic to start or continue TB prophylaxis or in the number of people who complete TB prophylaxis.

Higher cash incentives may slightly improve the number of people who return to a clinic for reading of their tuberculin skin test, compared to lower cash incentives.

\section{Conditional cash transfers}

Lagarde 2009

$\Rightarrow$ Conditional cash transfer programmes in low- and middle-income countries probably lead to an increase in the use of health services and mixed effects on immunisation coverage and health status.

The capacity of each health system to deal with the increased demand should be considered, particularly in low-income countries where the capacity of health systems may not be sufficient.

The cost-effectiveness of conditional cash transfer programmes, compared with supply-side strategies and other policy options, has not been evaluated.

\section{Voucher schemes}

Brody 2013
$\Rightarrow$ Vouchers may improve the utilisation of reproductive health services, targeting specific populations, quality of care, and health outcomes.

Vouchers may improve the utilisation of insecticide-treated bed nets and targeting specific populations.

The effect of vouchers for insecticide-treated bed nets on quality of care and health outcomes is uncertain.

The cost-effectiveness of voucher programmes is uncertain for both reproductive health services and insecticide-treated bed nets.

All the included studies were conducted in low- and middle-income countries.

Restrictive caps may decrease use of medicines for symptomatic conditions and overall use of medicines and insurers' expenditures on medicines, and they may have uncertain effects on health service utilisation.

A combination of a cap, co-insurance, and a ceiling may increase the use of medicines overall and for symptomatic and asymptomatic conditions, and decrease the cost of medicines for both patients and insurers.

A combination of a cap and fixed co-payments may increase the use of medicines for symptomatic conditions, and it has uncertain effects on the insurer's cost of medicines.

Fixed co-payments may decrease the use of medicines for symptomatic and asymptomatic conditions and the insurer's expenditures on medicines. 
Table 5. Key messages of included reviews (Continued) $\Rightarrow$ Fixed and tier co-payments have uncertain effects on the use of medicines and the insurer's ex-
penditures on medicines.

$\Rightarrow$ A combination of a ceiling and fixed co-payments may slightly decrease the use of medicines and lead to little or no difference in health service utilisation.

$\Rightarrow$ A combination of a ceiling and co-insurance probably slightly decreases the overall use of medicines, may decrease the use of medicines for symptomatic conditions, may slightly decrease the insurer's short-term expenditures on medicines, and may increase health service utilisation.

None of the included studies were conducted in a low-income country or reported health outcomes.

\section{Caps and co-payments for health services}

Acosta 2014
Reference pricing may reduce insurers' cumulative drug expenditures by shifting drug use from cost-share drugs to reference drugs.

$\Rightarrow$ Index pricing may increase the use of the generic drugs, may reduce the use of brand drugs, slightly reduce the price of generic drugs, and may have little or no effect on the price of brand drugs.

It is uncertain whether maximum pricing affects drug expenditures.

The effects of these policies on healthcare utilisation or health outcomes are uncertain.

None of the included studies were conducted in a low-income country.

The effects of other pharmaceutical pricing and purchasing policies are uncertain.

\section{Financial incentives and disincentives for providers of care}

\section{Paying for performance}

- effects on delivery of health interventions

Witter 2012
We are very uncertain whether pay-for-performance improves provider performance, the utilisation of services, patient outcomes or resource use in low- and middle-income countries.

$\rightarrow$ Unintended effects of pay-for-performance schemes may include:

- adverse selection (for example, excluding high-risk people from care in order to obtain better performance);

- gaming (i.e. inaccurate or false reporting);

- distortion (i.e. ignoring important tasks that are not rewarded with incentives).

There is a lack of evidence about the economic consequences of pay-for-performance schemes in low- and middle-income countries.

It is uncertain whether pay-for-performance improves provider performance, the utilisation of services, patient outcomes, or resource use in low- and middle-income countries.

\section{Paying for performance}

- effects on outpatient referrals from primary care to secondary care

\section{Akbari 2008.}

\section{Pay-for-performance}

- effects on the quality of health care provided by primary care physicians

\section{Scott 2011}

The effects of financial incentives on referral rates are uncertain. 


\section{Table 5. Key messages of included reviews (Continued)}

Financial incentives to practice in underserved areas

Grobler 2015

It is uncertain whether any of the following types of interventions to recruit or retain health professionals increase the number of health professionals practising in underserved areas,

- Educational interventions (e.g. student selection criteria, undergraduate and postgraduate teaching curricula, exposure to rural and urban underserved areas).

- Financial interventions (e.g. undergraduate and postgraduate bursaries or scholarships linked to future practice location, rural allowances, increased public sector salaries).

- Regulatory strategies (e.g. compulsory community service, relaxing work regulations imposed on foreign medical graduates who are willing to work in rural or urban underserved areas).

- Personal and professional support strategies (e.g. providing adequate professional support and attending to the needs of the practitioners family).

\section{Managing the movement of} health workers

Rutebemberwa 2014
No rigorous studies have evaluated the effects of interventions to manage the movement of health workers between public and private organisations.

There is a need for well-designed studies to evaluate the impact of interventions that attempt to regulate health worker movement between public and private organisations in low-income countries.

TB: tuberculosis. 


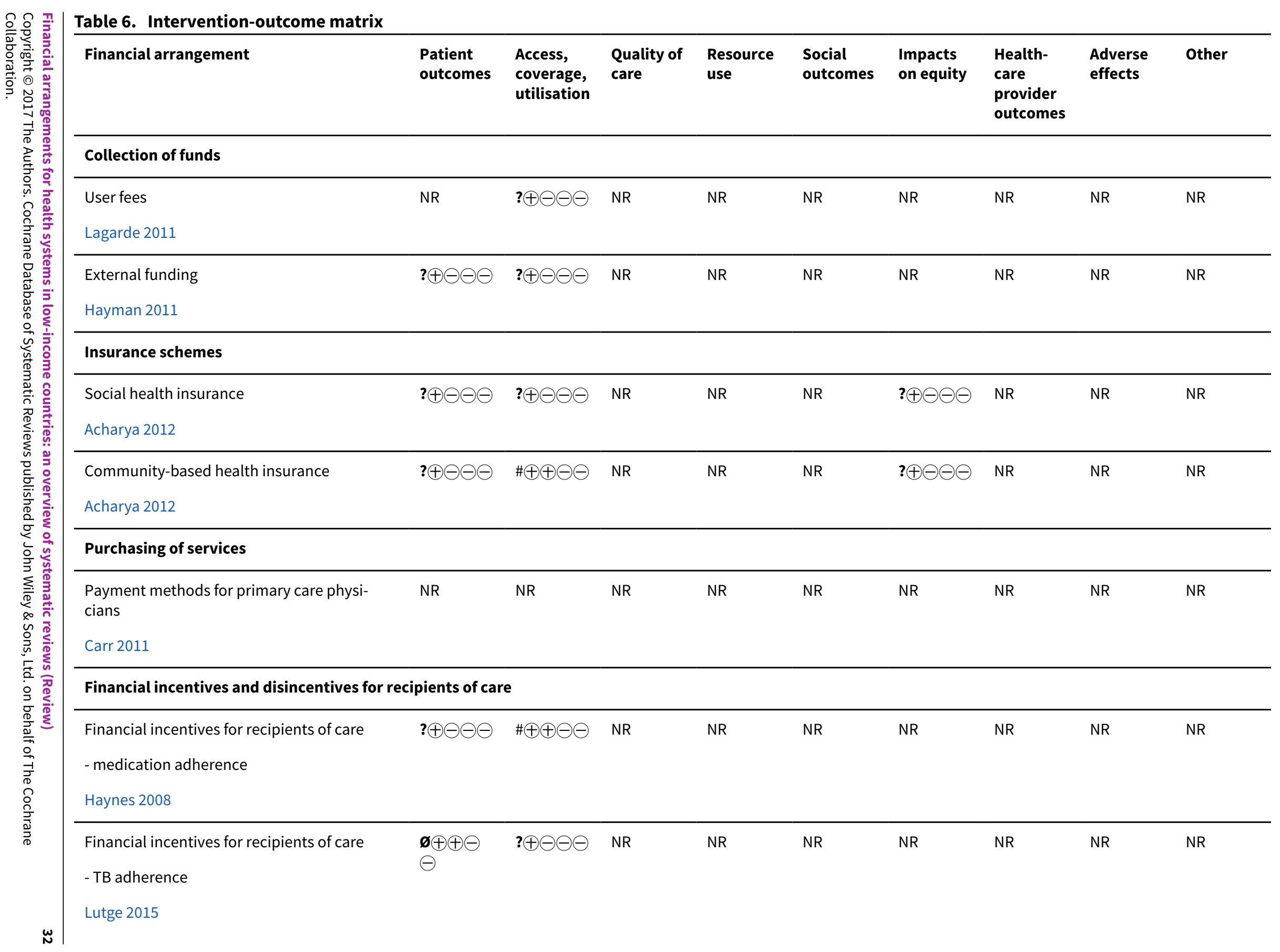




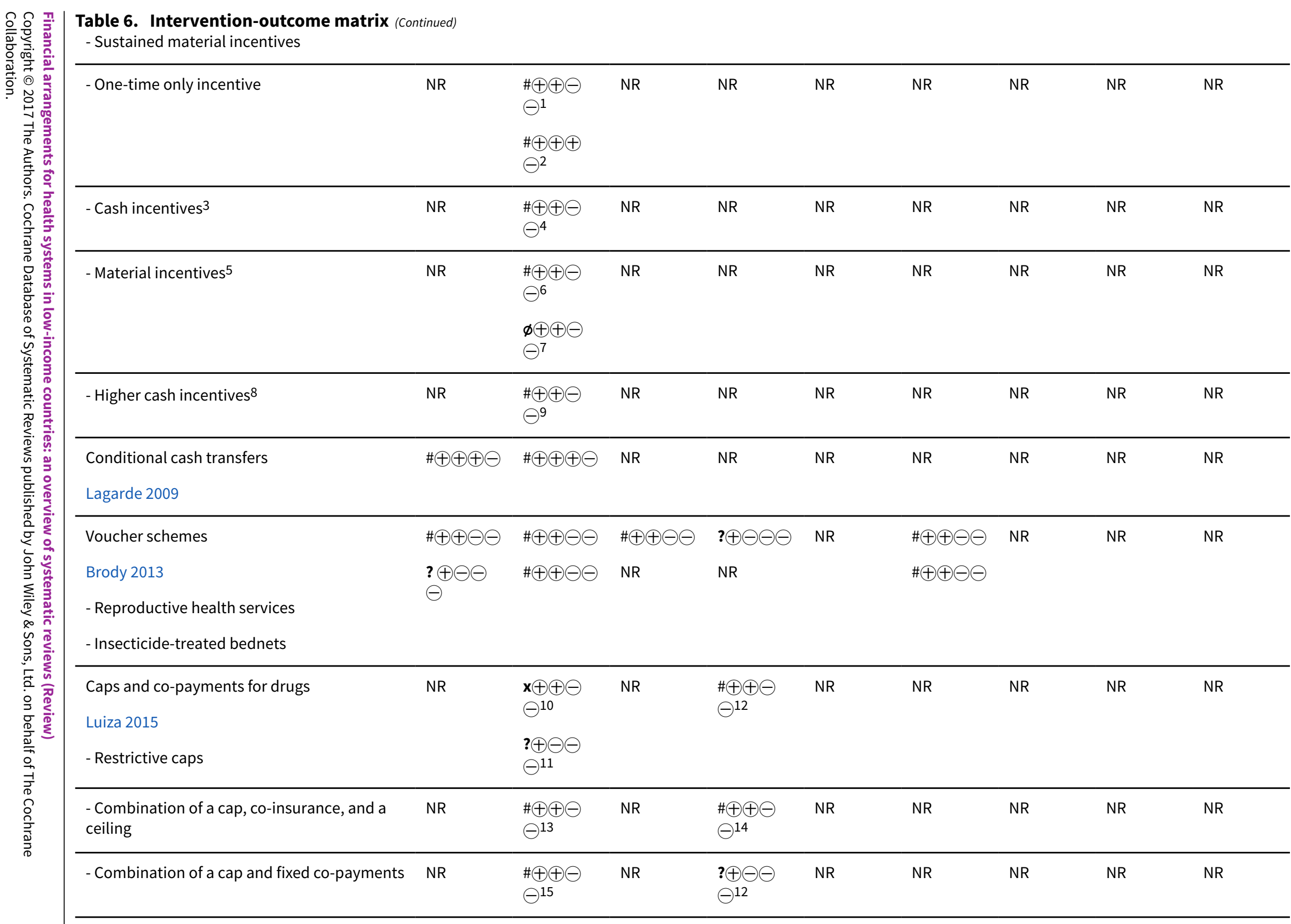




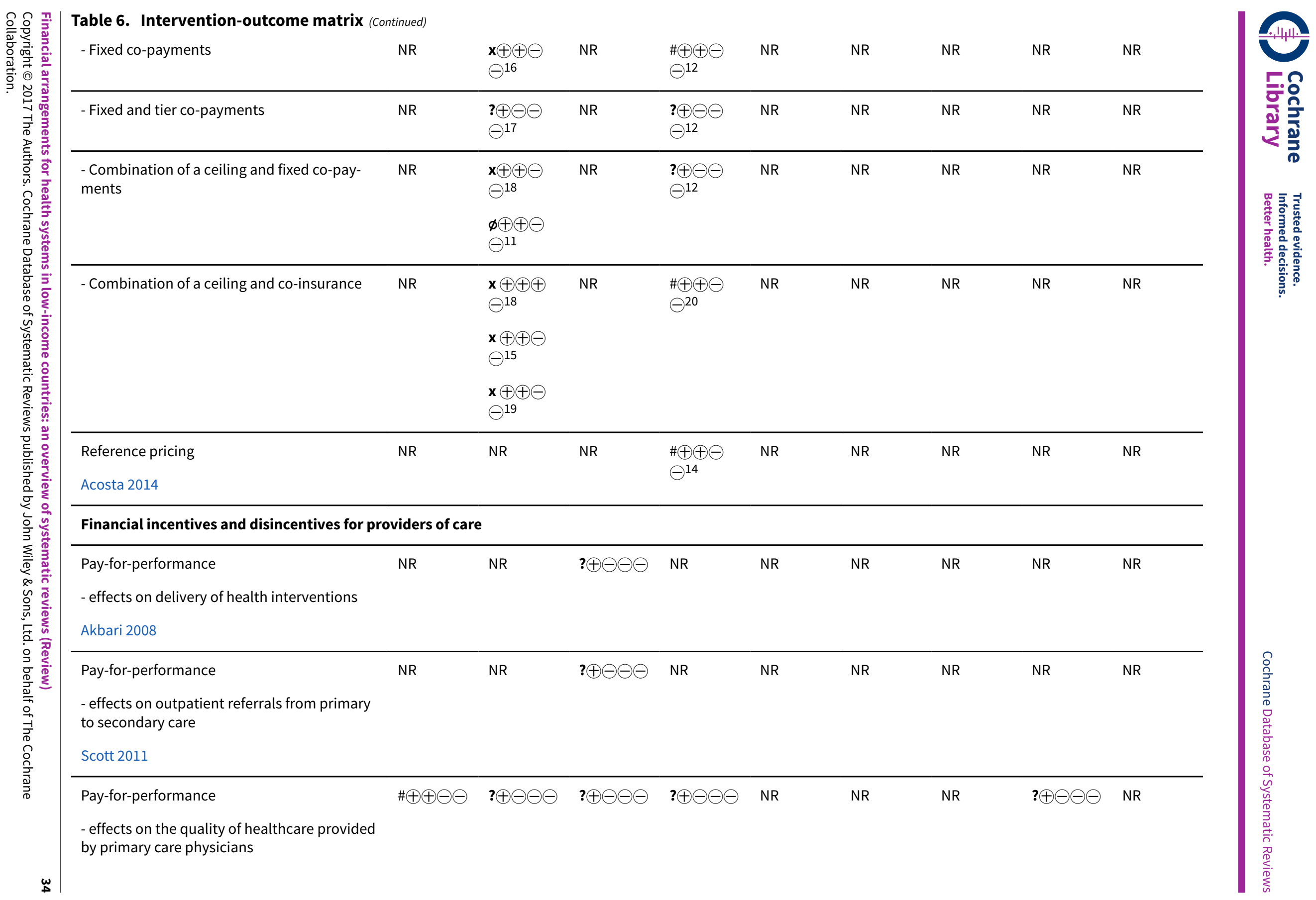




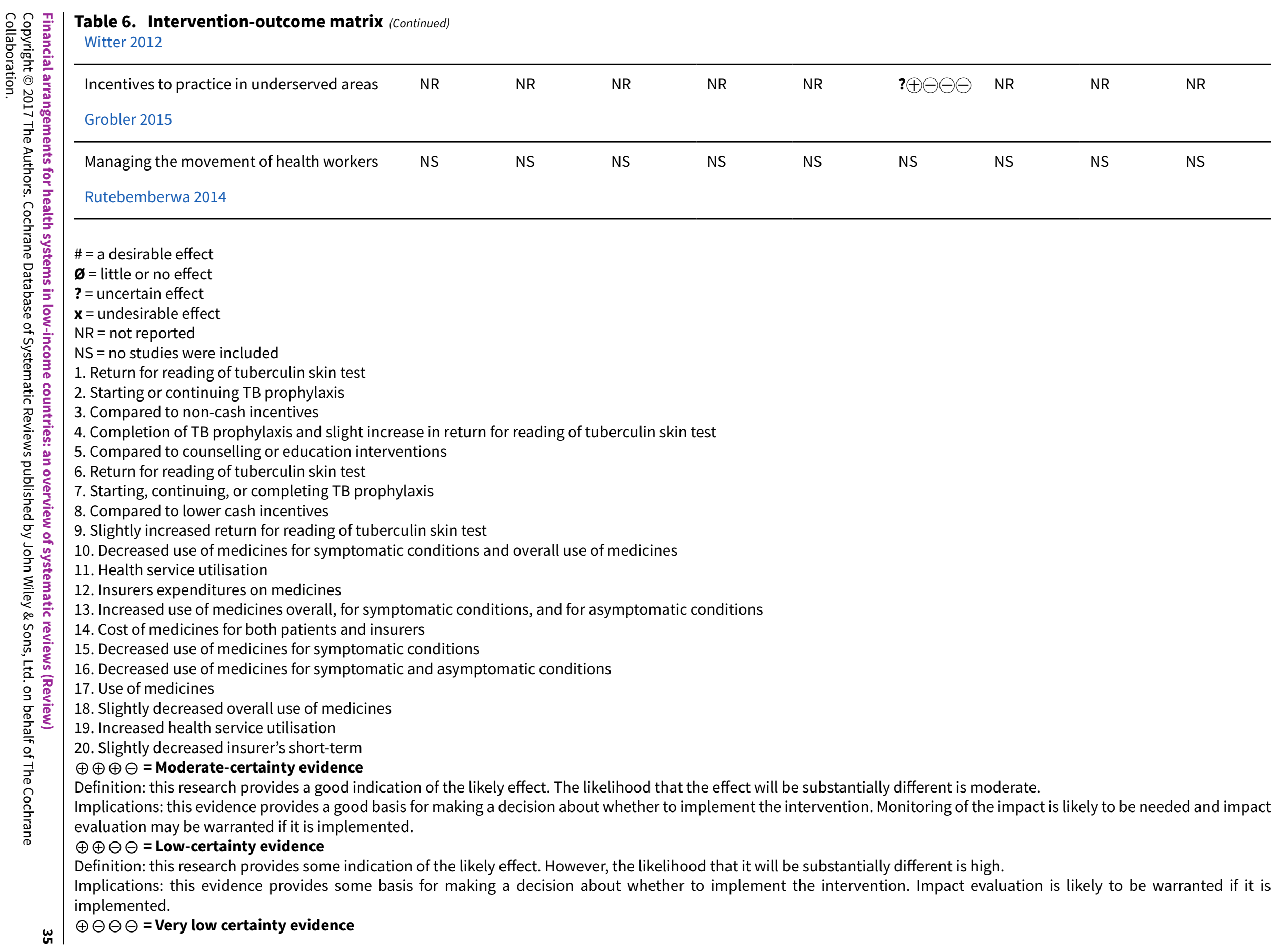




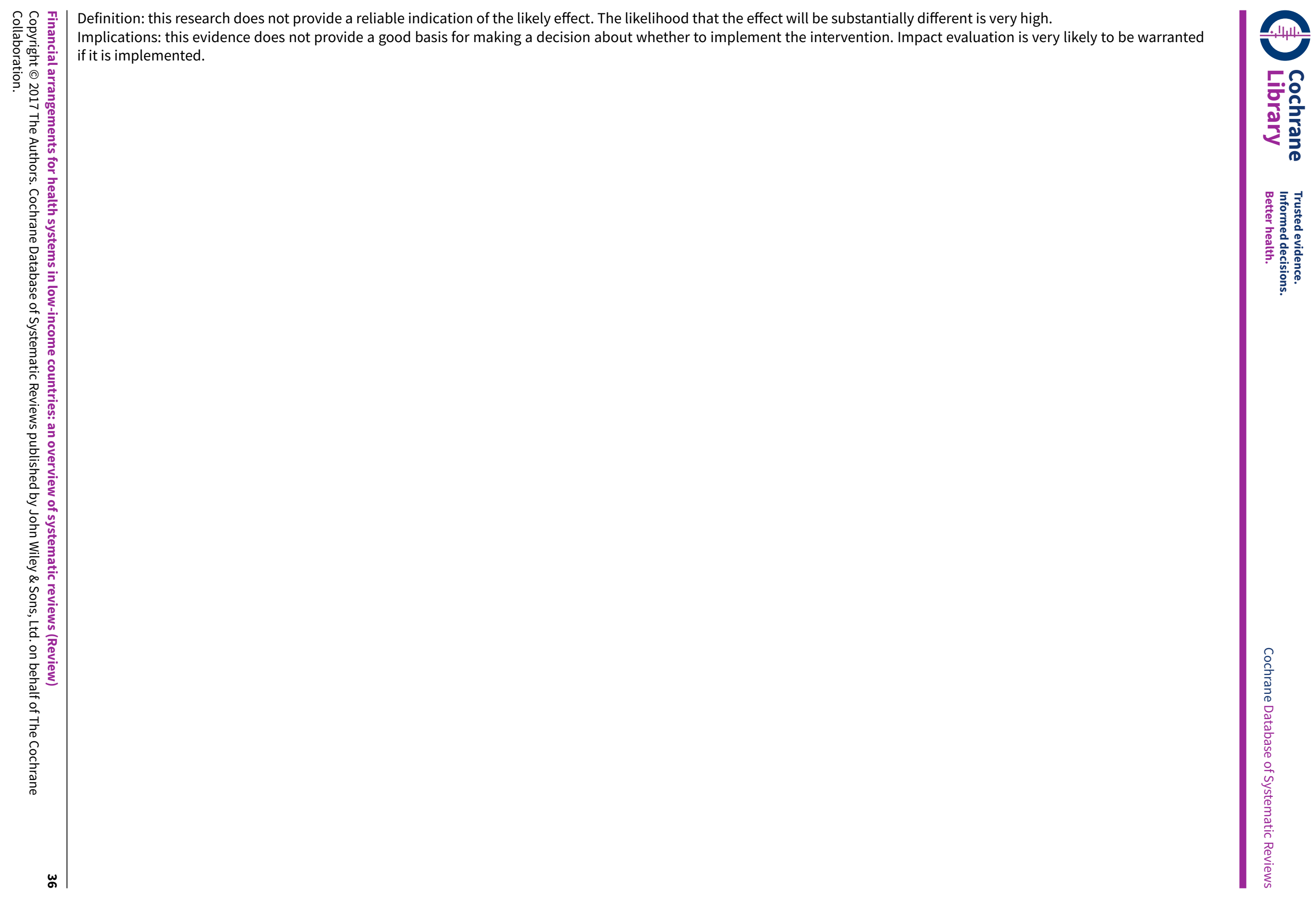




\section{Table 7. Summary of effects of interventions and certainty of evidence}

Interventions found to have desirable effects on at least one outcome with moderate- or high-certainty evidence and no moderate- or high-certainty evidence of undesirable effects

\section{Financial incentives and disincentives for recipients of care}

- Conditional cash transfers (Lagarde 2009)

- One-time only incentives (Lutge 2015)

Interventions found to have moderate or high certainty evidence of at least one outcome with an undesirable effect and no moderate or high certainty evidence of desirable effects

\section{Financial incentives and disincentives for recipients of care}

- Combination of a ceiling and co-insurance (Luiza 2015)

Interventions for which the certainty of the evidence was low or very low (or no studies were found) for all outcomes examined

\section{Collection of funds}

- User fees (Lagarde 2011)

- External funding (Hayman 2011)

\section{Insurance schemes}

- Social health insurance (Acharya 2012)

- Community-based health insurance (Acharya 2012)

\section{Purchasing of services}

- Payment methods for primary care physicians (Carr 2011)

\section{Financial incentives and disincentives for recipients of care}

- Financial incentives for recipients of care - medication adherence (Haynes 2008)

- Sustained material, cash, higher cash, and material incentives for recipients of care - TB adherence (Lutge 2015)

- Voucher schemes (Brody 2013)

- Restrictive caps; combination of a cap, co-insurance, and a ceiling; combination of a cap and fixed co-payments, fixed co-payments, fixed and tier co-payments; and a combination of a ceiling and fixed co-payments for drugs (Luiza 2015)

- Reference pricing for drugs (Acosta 2014)

\section{Financial incentives and disincentives for providers of care}

- Pay-for-performance - effects on delivery of health interventions (Akbari 2008)

- Pay-for-performance - effects on outpatient referrals from primary to secondary care (Scott 2011)

- Pay-for-performance - effects on the quality of healthcare provided by primary care physicians (Witter 2012)

- Incentives to practice in underserved areas (Grobler 2015)

- Managing the movement of health workers (Rutebemberwa 2014)

Table 8. Priorities for primary research based on applicability limitationsa

\begin{tabular}{lll} 
Financial arrangement & \multicolumn{2}{l}{ Applicability limitations } \\
\cline { 2 - 3 } & Findings & Interpretation
\end{tabular}

Financial arrangements for health systems in low-income countries: an overview of systematic reviews (Review) 
Table 8. Priorities for primary research based on applicability limitationsa (Continued)

\section{Purchasing of services}

$\begin{array}{lll}\begin{array}{l}\text { Payment methods for } \\ \text { primary care physicians }\end{array} & \begin{array}{l}\text { We found only one before-af- } \\ \text { ter study from Brazil of the ef- } \\ \text { fects of increases in teachers' } \\ \text { wages. }\end{array} & \begin{array}{l}\text { - It is uncertain whether raising the salaries of health professionals in the } \\ \text { public sector in low-income countries improves their performance. }\end{array} \\ & \begin{array}{l}\text { - Rather than making assumptions about the intended or unintended ef- } \\ \text { fects of fixed salary reforms that increase the salaries of health profes- } \\ \text { sionals, such policies should be evaluated, if possible using randomised } \\ \text { trials or interrupted time series studies. }\end{array}\end{array}$

\section{Financial incentives and disincentives for recipients of care}

Financial incentives for recipients of care

Haynes 2008
- 72 of the 78 included studies were conducted in highincome countries.

- The studies differed according to the type of setting, the conditions targeted, the type of medication and the duration of treatment. Almost all the interventions that were effective were complex and included combinations of interventions.

- Even the most effective interventions did not lead to large improvements in treatment outcomes.
- The findings indicate that interventions to improve medication adherence should be used with caution given that there is a high degree of uncertainty about both their effects and costs outcomes.

- Adherence interventions may be difficult to implement in low-income countries where health systems face greater challenges.

\section{Incentives in the man- agement of tuberculo- sis \\ Lutge 2015 \\ - Most studies were conduct- ed in the USA. \\ - Most studies were conduct- ed among population sub- groups of patients, such as injection drug users.}

\section{- The findings need to be applied with caution in low-income countries considering the structural and qualitative differences in health systems, health care provision, resources and health care-seeking behaviour.}

- The findings may therefore not be applicable in the general population.

\section{Caps and co-payments for drugs}

Luiza 2015
All the 33 included studies were conducted high-income countries: USA (18 studies), Canada (9 studies), Australia (4 studies), and Sweden (2 studies).

Factors that need to be considered in assessing whether the intervention effects are likely to be transferable to other settings where health subsidies are competitive to food and other essentials include:

- the extent to which increased cost sharing for drugs may present a financial barrier to poor households or to patients with chronic conditions who need a high volume of pharmaceuticals; and

- the extent to which any deterioration of health in these vulnerable populations may result in increased use of healthcare services and increased overall healthcare expenditures.

All of the 18 included studies were in high-income countries.
The effectiveness of reference pricing in low-income countries may depend on factors such as:

- health systems financial arrangements, such as co-payments, reimbursements, and cost sharing;

- access to data sources for prices; 
Table 8. Priorities for primary research based on applicability limitations ${ }^{\mathbf{a}}$ (Continued)

- availability of adequate incentives for healthcare providers, patients, physicians, pharmacists and pharmaceutical companies to comply with the reference pricing policy;

- significant price differences between the drugs in the intervention group before reference pricing is introduced;

- clear information for managers, clinicians and patients;

- availability and access to drugs in the reference group;

- a regulatory framework that allows generic substitution or prescribing

by International Non-Proprietary Name (INN)

- appropriate exemptions (Exemptions that are too limited could lead to higher co-payments for appropriate use of more expensive drugs and incentives to use a less effective drug.

\section{Financial incentives and disincentives for providers of care}

Pay-for-performance effects on outpatient referrals from primary care to secondary care

Akbari 2008
16 of the 17 included studies were conducted in highincome countries and within particular health systems. These systems included, for example, the publicly funded National Health System in the UK and Medicaid in the USA.
The studies were based in well-resourced environments in which primary care services were provided by an adequate number of practitioners, and people had relatively easy access to specialist services. Such scenarios are not necessarily available or possible in many low-income countries. The study findings therefore need to be interpreted with caution when applied to low-income countries.
The 7 studies included in this systematic review were all from high-income countries.
The impacts of financial incentives for primary care physicians are likely to vary depending on clinical, demographic, and organisational factors, as well as on the magnitude of the incentives and payment methods.

Some payment methods require sophisticated information and billing systems that are not available in some settings.

No other studies meeting the review's inclusion criteria were found for any of the following types of financial interventions for recruiting and retaining health professionals in underserved areas: undergraduate and postgraduate bursaries or scholarships linked to future practice location, rural allowances, increased public sector salaries, etc.
Financial incentives to practice in underserved areas

Grobler 2015
We did not find any ran-

domised trials.

The only included study was an interrupted time series study from Taiwan on the effects of national health insurance on the equality of distribution of health care professionals

apriorities for primary research based on applicability limitations to low-income countries of financial arrangement interventions identified by the included reviews.

Table 9. Priorities for primary research based on insufficient evidence for important outcomes

\begin{tabular}{lll}
\hline Financial arrangement & No studies & Certainty of evidence \\
\cline { 2 - 3 } & Very low Low \\
\hline
\end{tabular}

\section{Collection of funds}


Table 9. Priorities for primary research based on insufficient evidence for important outcomes (Continued)
User fees
Patient outcomes, quality of care, re-
Access, coverage, source use utilisation

Lagarde 2011

\section{External funding}

Hayman 2011

\section{Insurance schemes}

Social health insurance

Acharya 2012

Quality of care, resource use

Quality of care, resource use

Community-based health insurance

Acharya 2012

Quality of care, resource use

\section{Purchasing of services}

Patient outcomes, access, coverage, utilisation

\author{
Patient outcomes, \\ access, coverage, \\ utilisation
}

Patient outcomes, access, coverage, utilisation

\section{Financial incentives and disincentives for recipients of care}

\begin{tabular}{|c|c|c|c|}
\hline $\begin{array}{l}\text { Financial incentives for recipients of care } \\
\text { - medication adherence } \\
\text { Haynes } 2008\end{array}$ & Quality of care, resource use & $\begin{array}{l}\text { Access, coverage, } \\
\text { utilisation }\end{array}$ & Patient outcomes \\
\hline $\begin{array}{l}\text { Financial incentives for recipients of care } \\
\text { - TB adherence } \\
\text { Lutge } 2015\end{array}$ & $\begin{array}{l}\text { Patient outcomes, quality of care, re- } \\
\text { source use }\end{array}$ & - & $\begin{array}{l}\text { Access, coverage, } \\
\text { utilisation }\end{array}$ \\
\hline $\begin{array}{l}\text { Conditional cash transfers } \\
\text { Lagarde } 2009\end{array}$ & Quality of care, resource use & - & \\
\hline $\begin{array}{l}\text { Voucher schemes } \\
\text { Brody } 2013\end{array}$ & - & - & $\begin{array}{l}\text { Patient outcomes, } \\
\text { quality of care, re- } \\
\text { source use }\end{array}$ \\
\hline $\begin{array}{l}\text { Caps and co-payments for drugs } \\
\text { Luiza } 2015\end{array}$ & Patient outcomes, quality of care & Resource use & $\begin{array}{l}\text { Access, coverage, } \\
\text { utilisation }\end{array}$ \\
\hline $\begin{array}{l}\text { Reference pricing } \\
\text { Acosta } 2014\end{array}$ & $\begin{array}{l}\text { Patient outcomes, access, coverage, } \\
\text { utilisation, quality of care }\end{array}$ & - & Resource use \\
\hline
\end{tabular}

\section{Financial incentives and disincentives for providers of care}

Pay-for-performance - effects on outpatient Patient outcomes, access, coverage, Quality of care
referrals from primary care to secondary care utilisation, resource use 
Table 9. Priorities for primary research based on insufficient evidence for important outcomes (Continued) Akbari 2008

\begin{tabular}{lll}
\hline $\begin{array}{l}\text { Pay-for-performance - effects on the quality } \\
\text { of health care provided by primary care }\end{array}$ & $\begin{array}{l}\text { Patient outcomes, access, coverage, } \\
\text { utilisation, resource use }\end{array}$ & Quality of care \\
Scott 2011 & - & $\begin{array}{l}\text { Access, coverage, } \\
\text { utilisation, quali- } \\
\text { ty of care, resource } \\
\text { use }\end{array}$ \\
\hline $\begin{array}{l}\text { Pay-for-performance - effects on the quality } \\
\text { of healthcare provided by primary care physi- } \\
\text { cians }\end{array}$ & $\begin{array}{l}\text { Patient outcomes, access, coverage, } \\
\text { utilisation, quality of care, resource } \\
\text { use }\end{array}$ & - \\
\hline $\begin{array}{l}\text { Incentives to practice in underserved areas } 2012 \\
\text { Grobler } 2015\end{array}$ & $\begin{array}{l}\text { Patient outcomes, access, coverage, } \\
\text { utilisation, quality of care, resource } \\
\text { use }\end{array}$ \\
\hline Managing the movement of health workers & - \\
Rutebemberwa 2014 &
\end{tabular}

Priorities for primary research based on the absence of evidence or low certainty of evidence for important outcomes: Patient outcomes, access, coverage, utilisation, quality of care, and resource use.

\section{Table 10. Priorities for systematic reviews}

\begin{tabular}{ll}
\hline Financial arrangement & Systematic reviews needed $^{\star}$ \\
\hline Collection of funds & No eligible systematic review found \\
\hline Financing of insurance & No eligible systematic review found \\
\hline Community loan funds & No eligible systematic review found \\
\hline Health savings accounts &
\end{tabular}

\section{Insurance schemes}

Private health insurance No eligible systematic review found

\section{Purchasing of services}

\begin{tabular}{ll} 
Funding of health service organisations & No eligible systematic review found \\
\hline Payment methods for specialist physicians & No eligible systematic review found \\
\hline Payment methods for non-physician health workers & No eligible systematic review found
\end{tabular}

\section{Financial incentives for recipients of care}

Non-conditional financial benefits No eligible systematic review found

\section{Financial incentives for providers of care}

Budgets No eligible systematic review found


* Priorities for systematic reviews are based on subcategories of financial arrangements (Table 1) for which we did not find an eligible systematic review.

\section{AP PE N DICES}

\section{Appendix 1. Search strategies}

\section{PubMed}

\section{From 2000 to present. Update: weekly}

\#1. MEDLINE[Title/Abstract]

\#2. (systematic[Title/Abstract] AND review[Title/Abstract])

\#3. meta analysis[Publication Type]

\#4. \#1 OR \#2 OR \#3 (Methods filter for systematic reviews -Clinical Queries-Max Specificity)

\#5. overview[Title] AND (reviews[Title] OR systematic[Title]

\#6. meta-review[Title]

\#7. review of reviews[Title]

\#8. review[Title] AND systematic reviews[Title]

\#9. umbrella[Title] AND (review[Title] OR reviews[Title] OR systematic[Title])

\#10. policy[Title] AND (brief[Title] OR evidence[Title])

\#11. \#5 OR \#6 OR \#7 OR \#8 OR \#9 OR \#10 (Methods filter for overviews)

\#12. \#4 OR \#11 (Methods filter for systematic reviews and for overviews)

\section{LILACS}

\section{From 2000 to present. Update: monthly}

(TW:"revision sistematica" OR TW:"revisao sistematica" OR TW:"systematic review" OR MH:"review literature as topic" OR MH:"metaanalysis as topic" OR PT:"meta-analysis")

\section{OR}

(PT:revision AND (TW:metaanal\$ OR TW:"meta-analysis" OR TW:"metaanalise" OR TW:"meta-analisis" OR TI:overview\$ OR TW:"estudio sistematico" OR TW:"systematic study" OR TW:"estudo sistematico" OR TI:review OR TI:revisao OR TI:revision OR TI:systematic OR TI:sistematico))

\section{OR}

((TW:overview OR TW:"estudio sistematico" OR TW:"systematic study" OR TW:"estudo sistematico") AND (TI:review OR TI:revisao OR TI:revision OR TI:systematic OR TI:sistematico))

\section{CINAHL (EBSCO)}

From 2000 to present. Update: monthly

((TI meta analys ${ }^{\star}$ or AB meta analys $\left.{ }^{\star}\right)$ or (TI systematic review or AB systematic review))

\section{PsyciNFO (EBSCO)}

\section{From 2000 to present. Update: monthly}

meta-analysis OR search*

\section{EMBASE (Ovid)}

\section{From 2000 to present. Update: monthly}

Financial arrangements for health systems in low-income countries: an overview of systematic reviews (Review) 
meta-analysis.tw. OR systematic review.tw

Appendix 2. SUPPORT Summaries checklist for making judgments about how much confidence to place in a systematic review

\section{Review:}

\section{Assessed by:}

\section{Date:}

Section A: Methods used to identify, include and critically appraise studies

\begin{tabular}{l}
\hline A.1 Were the criteria used for deciding which studies to include in the review reported?_ Y Yes \\
Did the authors specify: \\
_ Types of studies \\
_ Participants \\
_ Intervention(s) \\
_ Outcome(s) \\
Coding guide - check the answers above \\
YES: All four should be yes
\end{tabular}

Comments (note important limitations or uncertainty)

\section{A.2 Was the search for evidence reasonably comprehensive?}

Were the following done:

_ Language bias avoided (no restriction of inclusion based on language)

_ No restriction of inclusion based on publication status

_ Relevant databases searched (including MEDLINE + Cochrane Library)

_ Reference lists in included articles checked

_ Authors/experts contacted

Coding guide - check the answers above:

YES: All five should be yes

PARTIALLY: Relevant databases and reference lists are both ticked off

\section{Comments (note important limitations or uncertainty)}

\section{A.3 Is the review reasonably up-to-date?}

Were the searches done recently enough that more recent research is unlikely to be found or to change the results of the review?

Coding guide - consider how many years since the last search (e.g. if more than 10 years the review is unlikely to be up-to-date) and whether there is ongoing research

_ Yes
_ Can't tell/partially
_ No

- Yes

_ Can't tell/not sure

- No

Comments (note important limitations or uncertainty)

Financial arrangements for health systems in low-income countries: an overview of systematic reviews (Review) 
(Continued)
A.4 Was bias in the selection of articles avoided?
_Yes
Did the authors specify:
_ Can't tell/partially
_ Explicit selection criteria
_ Independent screening of full text by at least 2 reviewers
_ List of included studies provided
_ List of excluded studies provided
Coding guide - check the above
YES: All four should be yes

Comments (note important limitations or uncertainty)

\section{A.5 Did the authors use appropriate criteria to assess the risk for bias in analysing the studies that are included? ${ }^{\dagger}$ (See Appendix for an example of criteria - Assessing Risk of Bias Criteria for EPOC Reviews)}

_ The criteria used for assessing the risk of bias were reported

_A table or summary of the assessment of each included study for each criterion was reported

_ Sensible criteria were used that focus on the risk of bias (and not other qualities of the studies, such as precision or applicability)

Coding guide - check the above

YES: All four should be yes
- Yes

_ Can't tell/partially

- No

Comments (note important limitations or uncertainty)

\section{A. 6 Overall - how would you rate the methods used to identify, include and critically appraise studies?}

Summary assessment score A relates to the 5 questions above.

If the "No" or "Partial" option is used for any of the questions above, the review is likely to have important limitations.

Examples of major limitations might include not reporting explicit selection criteria, not providing a list of included studies or not assessing the risk of bias in included studies.

\begin{abstract}
_ Major limitations (limitations that are important enough that the results of the review are not reliable and they should not be used in the policy brief)
\end{abstract}

\begin{abstract}
_ Important limitations (limitations that are important enough that it would be worthwhile to search for another systematic review and to interpret the results of this review cautiously, if a better review cannot be found)
\end{abstract}

_ Reliable (only minor limitations)

Comments (note any major limitations or important limitations).

Section B: Methods used to analyse the findings

$\begin{array}{lc}\text { B.1 Were the characteristics and results of the included studies reliably reported? } & \text { - Yes } \\ \text { Was there: } & \text { - Partially } \\ \text { _Independent data extraction by at least } 2 \text { reviewers } & \text { - No }\end{array}$

Financial arrangements for health systems in low-income countries: an overview of systematic reviews (Review) 
(Continued)

_. A table or summary of the characteristics of the participants, interventions and outcomes for the included studies

_ Not applicable (e.g. no included studies)

_A table or summary of the results of the included studies.

Coding guide - check the answers above

YES: All three should be yes

Comments (note important limitations or uncertainty)

B. 2 Were the methods used by the review authors to analyse the findings of the included stud- _ _ Yes ies reported?

_ Partially

- No

_ Not applicable (e.g. no studies or no data)

Comments (note important limitations or uncertainty)

\section{B.3 Did the review describe the extent of heterogeneity?}

_ Did the review ensure that included studies were similar enough that it made sense to combine them, sensibly divide the included studies into homogeneous groups, or sensibly conclude that it did not make sense to combine or group the included studies?

_ Did the review discuss the extent to which there were important differences in the results of the included studies?

_ If a meta-analysis was done, was the $\mathrm{I}^{2}$, Chi² test for heterogeneity or other appropriate statistic reported?

\section{- Yes}

_ Can't tell/partially

- No

_ Not applicable (e.g. no studies or no data)

Comments (note important limitations or uncertainty)

\section{B.4 Were the findings of the relevant studies combined (or not combined) appropriately rela-} tive to the primary question the review addresses and the available data?

How was the data analysis done?

_ Descriptive only

_ Vote counting based on direction of effect

_ Vote counting based on statistical significance

_ Description of range of effect sizes

_ Meta-analysis

_ Meta-regression

_ Other: specify

_ Not applicable (e.g. no studies or no data)

How were the studies weighted in the analysis?

_ Equal weights (this is what is done when vote counting is used)

_ By quality or study design (this is rarely done)

_ Inverse variance (this is what is typically done in a meta-analysis)
- Yes

_ Can't tell/partially

- No

_ Not applicable (e.g. no studies or no data) 
(Continued)

_ Number of participants

_ Other, specify:

- Not clear

_ Not applicable (e.g. no studies or no data)

Did the review address unit of analysis errors?

_ Yes - took clustering into account in the analysis (e.g. used intra-cluster correlation coefficient)

_ No, but acknowledged problem of unit of analysis errors

_ No mention of issue

_ Not applicable - no clustered trials or studies included

Coding guide - check the answers above

If narrative $O R$ vote counting (where quantitative analyses would have been possible) OR inappropriate table, graph or meta-analyses OR unit of analyses errors not addressed (and should have been) the answer is likely NO.

If appropriate table, graph or meta-analysis AND appropriate weights AND the extent of heterogeneity was taken into account, the answer is likely YES.

If no studies/no data: NOT APPLICABLE

If unsure: CAN'T TELL/PARTIALLY

Comments (note important limitations or uncertainty)

\section{B.5 Did the review examine the extent to which specific factors might explain differences in the results of the included studies?}

_- Were factors that the review authors considered as likely explanatory factors clearly described?

_ Was a sensible method used to explore the extent to which key factors explained heterogeneity?

_ Descriptive/textual

_ Graphical

- Meta-regression

_ Other
- Yes

_ Can't tell/partially

- No

_ Not applicable (e.g. too few studies, no important differences in the results of the included studies, or the included studies were so dissimilar that it would not make sense to explore heterogeneity of the results)

Comments (note important limitations or uncertainty)

B.6 Overall - how would you rate the methods used to analyse the findings relative to the primary question addressed in the review?

Summary assessment score $B$ relates to the 5 questions in this section, regarding the analysis.

If the "No" or "Partial" option is used for any of the 5 preceding questions, the review is likely to have important limitations.

Examples of major limitations might include not reporting critical characteristics of the included studies or not reporting the results of the included studies.
_ Major limitations (limitations that are important enough that the results of the review are not reliable and they should not be used in the policy brief)

\section{_Important limitations}

(limitations that are important enough that it would be worthwhile to search for another systematic review and to interpret the results of this re- 
Use comments to specify if relevant, to flag uncertainty or need for discussion

Section C: Overall assessment of the reliability of the review

\begin{tabular}{|c|c|}
\hline $\begin{array}{l}\text { C.1 Are there any other aspects of the review not mentioned before which lead you to ques- } \\
\text { tion the results? }\end{array}$ & $\begin{array}{l}\text { _ Additional methodological } \\
\text { concerns } \\
\text { _ Robustness } \\
\text { _ Interpretation } \\
\text { _ Conflicts of interest (of the } \\
\text { review authors or for included } \\
\text { studies) } \\
\text { _ Other } \\
\text { _ No other quality issues iden- } \\
\text { tified }\end{array}$ \\
\hline
\end{tabular}

\section{C.2 Based on the above assessments of the methods how would you rate the reliability of the review?}

Major limitations (exclude); briefly (and politely) state the reasons for excluding the review by completing the following sentence: This review was not included in this policy brief for the following reasons: Comments (briefly summarise any key messages or useful information that can be drawn from the review for policy makers or managers):

_Important limitations; briefly (and politely) state the most important limitations by editing the following sentence, if needed, and specifying what the important limitations are: This review has important limitations.

Reliable; briefly note any comments that should be noted regarding the reliability of this review by editing the following sentence, if needed: This is a good quality systematic review with only minor limitations.

\section{Appendix 3. Characteristics of included reviews}

\section{Collection of funds}

\section{User fees}

\section{Lagarde 2011}

Review objective: to assess the effects of introducing, removing, or changing user fees on the access of different populations to care in low- and middle-income countries

\begin{tabular}{lll}
\hline Types of & What the review authors searched for & What the review authors found \\
\hline $\begin{array}{ll}\text { Study designs and in- } \\
\text { terventions }\end{array}$ & $\begin{array}{l}\text { Randomised trials, interrupted time se- } \\
\text { ries studies, and controlled before-af- } \\
\text { ter studies of introducing, removing, or } \\
\text { changing user fees }\end{array}$ & $\begin{array}{l}\text { Randomised trials (2 studies), interrupted time series stud- } \\
\text { ies (9 studies), and controlled before-after studies (6 studies) } \\
\text { evaluating the introduction of user fees (8 studies), the re- } \\
\text { moval of fees (5 studies), and increasing or decreasing fees (5 } \\
\text { studies). }\end{array}$ \\
\hline
\end{tabular}


(Continued)

Participants People living in low- and middle-income countries
Users or potential users of outpatient facilities (8 studies), hospitals ( 3 studies), both ( 5 studies), or preventive drugs (school children) (1 study)

\begin{tabular}{lll}
\hline Settings & $\begin{array}{l}\text { Any setting where health services are } \\
\text { provided }\end{array}$ & $\begin{array}{l}\text { Kenya (4 studies), Ecuador (2 studies), Uganda (2 studies), and } \\
1 \text { study each from Burkina Faso, Cameroon, Colombia, Gabon, } \\
\text { Lesotho, Niger, Papa New Guinea, South Africa, and Sudan }\end{array}$ \\
\hline Outcomes & $\begin{array}{l}\text { Use of health services, healthcare costs, } \\
\text { health outcomes, and equity }\end{array}$ & $\begin{array}{l}\text { Utilisation of services (14 studies), number of new patients (2 } \\
\text { studies), health-seeking behaviour (2 studies) }\end{array}$ \\
\hline
\end{tabular}

Date of most recent search: February 2011

Limitations: this is a well-conducted systematic review with only minor limitations.

\section{External funding}

Hayman 2011

Review objective: to compare the effects on Millennium Development Goal 5 outcomes of aid delivered under the Paris Principles and aid delivered outside this framework

\section{Types of What the review authors searched for What the review authors found}

Study designs and in- Studies had to present empirical reterventions search (qualitative or quantitative), i.e. contain primary data

Interventions: aid delivered under the Paris Principles, aid in general, or directly comparing both

Donors and receiving developing countries

Interrupted time series (1 study), pre-test post-test (17 studies), secondary data analysis (5 studies), process-training methodology (1 study), retrospective analyses ( 3 studies), unclear ( 1 study), and qualitative components (3 studies)

10 studies for aid delivered under the Paris Principles, and 20 for aid in general

Bilateral donor agencies: USAID (8 studies); Canadian International Development Agency (1 study); DFID (4 studies)

Multilateral agencies: World Bank (8 studies); large number of donors (5 studies)

Non-governmental organisations: CARE (1 study); Bill and Melinda Gates Foundation (2 studies); Save the Children Australia (1 study); PEPFAR (1 study); MotherCare (1 study)

\section{Settings}

Studies had to refer to developing countries or regions
China (3 studies), Honduras (2 studies), Indonesia (3 studies), Uzbekistan (1 study), Egypt (3 studies), Nicaragua (1 study), Botswana (1 study), South Africa (1 study), People's Democratic Republic of Lao (1 study), Tanzania (2 studies), Cameroon (1 study), Bangladesh (2 studies), Nepal (2 studies), Ghana (2 studies), Uganda (1 study), Madagascar (1 study), India (1 study), Pakistan (1 study), Guinea (1 study), Burkina Faso (1 study), Timor Leste (1 study), Rwanda (1 study), Zimbabwe (1 study)

Maternal mortality ratio or rate (MDG 5.1): 12 studies

Births attended by skilled birth personnel (MDG 5.2): 17 studies

Contraceptive prevalence (MDG 5.3): 15 studies

Adolescent birth rate (MDG 5.4): 1 study 
Date of most recent search: August 2010

Limitations: this review has important limitations.

\title{
Insurance schemes
}

\section{Social health insurance/community-based health insurance}

Acharya 2012

Review objective: to systematically examine studies that show the impact of nationally or sub-nationally sponsored health insurance schemes on the poor and near poor

\begin{tabular}{ll}
\hline Types of & What the review authors searched for \\
\hline $\begin{array}{l}\text { Study designs and In- } \\
\text { terventions }\end{array}$ & $\begin{array}{l}\text { Randomised trials, non-randomised tri- } \\
\text { als, controlled before-after studies, re- } \\
\text { gression studies and qualitative studies } \\
\text { that measured the impact of national } \\
\text { health insurance }\end{array}$ \\
\hline
\end{tabular}

Participants People taking up health insurance

Settings Low- and middle-income countries

\section{What the review authors found}

24 studies were included: 4 randomised trials, 10 non-randomised trials and 10 observational studies. 16 studies reported on social health insurance and 3 on community health insurance. 19 studies strongly met the review inclusion criteria and 5 partially met the inclusion criteria

People who enrolled in social and community health insurance schemes

Burkina Faso, China (6 studies), Colombia (2 studies), Costa Rica, Egypt, Georgia, India (2 studies), Mexico (3 studies), Nicaragua, Philippines, Tanzania and Vietnam (3 studies). 1 study was done in Senegal, Mali and Ghana.

Access or utilisation, healthcare expenditure and health status

\section{Outcomes}

Access or utilisation, healthcare expenditure and health status

Date of most recent search: July 2010

Limitations: this is a well-conducted systematic review. However, the methods for assessing the risk of bias of included studies were unclear.

\section{Purchasing of services}

\section{Payment methods for health workers}

\author{
Primary care physicians
}

\section{Carr 2011}

Review objective: to assess the available evidence of the impact of increasing salaries on the performance of public sectors employees in the health, education and judicial sectors in low- and middle-income countries

\begin{tabular}{lll}
\hline Types of & What the review authors searched for & What the review authors found \\
\hline $\begin{array}{l}\text { Study designs and in- } \\
\text { terventions }\end{array}$ & $\begin{array}{l}\text { Empirical research that used qualitative } \\
\text { or quantitative methods to assess the } \\
\text { effects of a change in salary or remuner- }\end{array}$ & $\begin{array}{l}1 \text { controlled before-after ("differences-in-differences") study } \\
\text { of increases in teachers' wages }\end{array}$
\end{tabular}


(Continued)

ation packages (pay and benefits com-

bined)

\begin{tabular}{lll}
\hline Participants & $\begin{array}{l}\text { Public sector employees in the health } \\
\text { (nurses, doctors, and other cadres), edu- } \\
\text { cation (teachers), or justice (judges) }\end{array}$ & Teachers \\
\hline Settings & Low- and middle-income countries & Brazil \\
\hline Outcomes & $\begin{array}{l}\text { Measures of work performance includ- } \\
\text { ing the quantity or quality of work }\end{array}$ & Student grades
\end{tabular}

Date of most recent search: 2010

Limitations: this was a well-conducted review, but the authors only found 1 study that met their inclusion criteria.

\section{Financial incentives and disincentives for recipients of care}

\section{Financial incentives for recipients of care}

Medication adherence

Haynes 2008

Review objective: to summarise the effects of interventions to help patients follow prescriptions for medications

\begin{tabular}{lll}
\hline Types of & What the review authors searched for & What the review authors found \\
\hline $\begin{array}{l}\text { Study designs and in- } \\
\text { terventions }\end{array}$ & $\begin{array}{l}\text { Randomised trials evaluating interven- } \\
\text { tions to improve adherence with pre- } \\
\text { scribed, self-administered medications }\end{array}$ & 78 trials evaluating 93 diverse interventions \\
\hline Participants & $\begin{array}{l}\text { Patients who were prescribed medica- } \\
\text { tion for a medical disorder (including } \\
\text { psychiatric), but not for addictions }\end{array}$ & $\begin{array}{l}\text { Patients with several different chronic conditions including } \\
\text { hypertension (12 studies), schizophrenia or acute psychosis } \\
\text { (10 studies), asthma or chronic obstructive pulmonary disease } \\
\end{array}$ \\
& $\begin{array}{l}\text { (COPD) (11 studies), rheumatoid arthritis (2 studies), hyperlipi- } \\
\text { demia (3 studies), depression (4 studies) and HIV (12 studies) }\end{array}$
\end{tabular}

Settings Any setting

Many different settings and venues were included. Trials were conducted in the USA ( 30 studies), the UK (14 studies), Spain ( 5 studies), Canada (8 studies), Australia (3 studies), the Netherlands (3 studies), China (3 studies), France (2 studies), Mexico (1 study), Norway (1 study), Italy (1 study), Sweden (1 study), Ghana (1 study), Denmark (1 study), Republic of Ireland (1 study), United Arab Emirates (1 study), Switzerland (1 study) and Malaysia (1 study)

$\begin{array}{ll}\text { Outcomes } & \begin{array}{l}\text { Medication adherence and patient out- } \\ \text { comes }\end{array}\end{array}$

9 studies on short-term and 71 on long-term treatments measuring adherence and patient outcomes

Date of most recent search: February 2007

Limitations: this is a systematic review with moderate limitations related to how the results were synthesised.

\section{Financial incentives for recipients of care}

TB adherence

Financial arrangements for health systems in low-income countries: an overview of systematic reviews (Review) 
(Continued)

Lutge 2015

Review objective: to evaluate the effects of material incentives and enablers given to people undergoing diagnostic testing for TB, or receiving drug therapy to prevent or cure TB.

\section{Types of What the review authors searched for What the review authors found}

Study designs and In- Randomised trials of any form of mateterventions rial inducement to return for TB test results, or adhere to or complete anti-TB preventive or curative treatment
12 randomised trials were included, assessing incentives for adherence to different stages of TB management: returning for reading of tuberculin skin test results ( 2 studies); clinic attendance for initiation of preventive therapy (1 study); clinic attendance for continuation of preventive therapy ( 2 studies); adherence to preventive treatment (5 studies); adherence to treatment for active TB ( 2 studies). The incentives used included cash, vouchers that could be redeemed for various products and food.

Adolescents (11-19 years)( 1 study); injection drug or cocaine users (4 studies); homeless or marginally housed adults ( 3 studies); prisoners (2 studies); and studies on the general adult population ( 2 studies)

- Participants
for TB
- Patients receiving preventative thera-
py for TB
- Patients suspected of TB who are un-
dergoing, and collecting results of, diag-
nostic tests

\begin{tabular}{lll}
\hline Settings & No restrictions & South Africa (1 study), Timor Leste (1 study), USA (10 studies) \\
\hline Outcomes & $\begin{array}{l}\text { For treatment of active TB: cure and/or } \\
\text { completion of treatment and/or suc- } \\
\text { cessful treatment }\end{array}$ & - Return for tuberculin skin test reading \\
& $\begin{array}{l}\text { For prophylaxis: cases of active TB; com- } \\
\text { pletion of prophylactic treatment }\end{array}$ & - Return to clinic for continuation of treatment \\
& $\begin{array}{l}\text { For diagnostics: number returning to } \\
\text { collect test results }\end{array}$ & - Time needed to track participants who missed appointments \\
& Also adverse events and costs &
\end{tabular}

Date of most recent search: June 2015

Limitations: this is a well-conducted systematic review with only minor limitations.

\section{Conditional cash transfers}

Lagarde 2009

Review objective: to assess the effectiveness of conditional monetary transfers in improving access to and use of health services and health outcomes in low- and middle-income countries

\begin{tabular}{lll}
\hline Types of & What the review authors searched for & What the review authors found \\
\hline $\begin{array}{l}\text { Study designs and in- } \\
\text { terventions }\end{array}$ & $\begin{array}{l}\text { Programmes in which money was trans- } \\
\text { ferred directly to households, condition- } \\
\text { al on some requirements, at least 1 of } \\
\text { which had to be related to health-seek- } \\
\text { ing behaviour }\end{array}$ \\
\hline
\end{tabular}


(Continued)

Participants Users and non-users of health services in low- and middle-income countries
Disadvantaged households in low-income areas of selected Latin American countries, and individuals who underwent HIV testing in rural areas in Malawi

Low- and middle-income countries as
defined by the World Bank

Low- and middle-income countries: 5 in Latin America (Mexico, Nicaragua, Honduras, Brazil and Colombia) and 1 in Africa (Malawi)

$\begin{array}{lll}\text { Outcomes } & \begin{array}{l}\text { Healthcare utilisation or access to } \\ \text { healthcare, household health expen- } \\ \text { diture, health or anthropometric out- } \\ \text { comes }\end{array} & \begin{array}{l}\text { Care-seeking behaviour (5 studies); immunisation coverage } \\ \text { (4 studies); anthropometric outcomes (4 studies); and health } \\ \text { status (3 studies) }\end{array}\end{array}$

Date of most recent search: January 2011

Limitations: this is a well-conducted systematic review with only minor limitations.

\section{Voucher schemes}

\section{Brody 2013}

Review objective: to assess the effects of vouchers on health goods and services utilisation, quality, efficiency in delivery, targeting and health outcomes in low- and middle-income countries

\section{Types of What the review authors searched for What the review authors found}

Study designs and in- Studies of voucher programmes for terventions health goods and services in low- and middle-income countries with a comparison such as before and after programme implementation, control groups, control programmes or comparison with accepted benchmarks of success

$\begin{array}{ll}\text { Participants } & \text { Populations that would potentially use } \\ \text { vouchers for health goods and services } \\ \text { in low- and middle-income countries }\end{array}$
in low- and middle-income countries
24 studies of 16 health voucher programmes; including 19 observational studies (pre/post design, cross-sectional intervention/comparison or before-after with controls design), 1 case control study, 2 economic modelling studies, 1 clinical record review, and 1 evaluation using a simulated patient
Reproductive health programmes for pregnant women and adolescents that provided maternity services, family planning (FP) and treatment for sexually transmitted infections (STI) (9 studies); Insecticide-treated bed net (ITN) distribution programmes for households, pregnant women and infants (6 studies); general health services payment programme (1 study)

Settings All studies conducted in low- and middle-income countries
Bangladesh ( 3 maternity studies), Cambodia (1 maternity study), India (2 maternity studies), Mozambique (1 ITN study), Nicaragua (5 reproductive health and 2 STI studies), Niger (1 ITN study), Senegal (1 ITN study), Taiwan (1 FP study), Tanzania (4 ITN studies), Uganda (1 STI study), Zambia (1 ITN and 1 health services)

Studies provided data on targeting specific groups (6 studies), utilisation (16 studies), quality of goods/services ( 6 studies), efficiency in delivery ( 1 study), and health impact ( 6 studies) tion and quality of health goods/services, efficiency in delivery of health services and health outcomes

Date of most recent search: October 2010 
(Continued)

Limitations: this review has important limitations due to uncertainty in risk of bias assessments and how the results were synthesised.

\section{Caps and co-payments}

\section{Drugs}

Luiza 2015

Review objective: to determine the effects of cap and co-payment policies on rational use of medicines.

\section{Types of What the review authors searched for What the review authors found}

Study designs and in- Randomised trials, non-randomised terventions trials, repeated measures studies, interrupted time series studies, and controlled before-after studies of policies that regulate out-of-pocket payments for medicines by patients, including changes in the amount paid directly by patients or limits on the amount reimbursed, including caps, fixed co-payments, co-insurance, maximum co-payment ceilings and tier co-payments
32 studies reporting on 39 interventions, including: 1 randomised trial, 8 repeated measures studies, 21 interrupted time series studies, and 2 controlled before-after studies

Pharmaceutical policies included cap policies (5 studies); cap with co-insurance and a ceiling policy ( 6 studies); fixed co-payments policies ( 6 studies); tier co-payment with fixed co-payment policies ( 2 studies); fixed co-payment with ceiling policies (10 studies); and co-insurance with ceiling policies (10 studies)

$\begin{array}{ll}\text { Participants } & \text { Healthcare consumers and providers } \\ & \text { within a regional, national or interna- } \\ \text { tional jurisdiction or system of care, and } & \text { organisations, such as multi-site health } \\ & \text { maintenance organisations, serving a } \\ \text { large population }\end{array}$

Australia: pharmaceutical benefits scheme (PBM) (4 studies); Canada: British Columbia PharmaCare Program (4 studies), Canada, Ontario/Quebec medicine/health insurance program (4 studies), Vancouver Residents of British Columbia (1 study); Swedish population (2 studies); USA: Medicare (6 studies), Medicaid ( 7 studies) a large PBM ( 1 study), 6 cities (1 study), 3 nation-wide pharmacy chains (1 study)

$\begin{array}{lll}\text { Settings } & \text { Any } & \text { USA (18 studies), Canada (9 studies), Australia (4 studies), and } \\ & \text { Sweden ( } 2 \text { studies) }\end{array}$

Outcomes

Objectively measured outcomes:

The studies provided data on medicine use (19 studies), costs (17 studies) and health service utilisation ( 6 studies). The data

1. Medicine use on costs were reported as medicine expenditures from the in-

2. Health service utilisation

3. Health outcomes surer's perspective (10 studies), medicine expenditures from the patient's perspective (6 studies), healthcare expenditures ( 1 study), and intervention costs (1 study). None of the included studies reported health outcomes.

4. Costs (medicine expenditures and other healthcare and policy administration expenditures)

Date of most recent search: February 2013

Limitations: this is a well-conducted systematic review with only minor limitations.

\section{Reference pricing}

Health services 
(Continued)

Review objective: to determine the effects of pharmaceutical pricing and purchasing policies on drug use, healthcare utilisation, health outcomes and costs (expenditures)

\section{Types of What the review authors searched for What the review authors found}

Study designs and in- Randomised trials, non-randomised terventions

trials, controlled repeated measures studies (CRM), interrupted time series (ITS) studies and controlled before-after (CBA) studies of pharmaceutical pricing and purchasing policies

Participants Healthcare users and providers

18 studies were included. Some used more than one design: 14 ITS, 1 ITS/CBA/CRM, 1 CRM/RM and 2 CBA/RM studies. 17 studies evaluated reference pricing, 1 of which also assessed maximum prices, and 1 study evaluated index pricing.

$\begin{array}{ll}\text { Settings } & \text { Large jurisdictions or systems of care. } \\ & \text { Jurisdictions could be regional, nation- } \\ & \text { al or international. Studies within organ- } \\ \text { isations, such as health maintenance } & \\ \text { organisations were included if the or- } \\ \text { ganisation was multi-sited and served a } \\ \text { large population. }\end{array}$

Outcomes

Drug use, healthcare utilisation, health outcomes, costs (expenditures), including drug costs and prices, other healthcare costs and administration costs
In 8 Canadian studies, the patients were Pharmacare beneficiaries in British Columbia: senior citizens aged 65 years and older. The other studies included all beneficiaries of national drug insurance plans, including vulnerable groups of people from all ages. 1 German and 1 Spanish study did not provide information about the participants.

Canada (8 studies), USA ( 2 studies), Spain ( 2 studies), Germany ( 2 studies), Norway ( 2 studies), Australia (1 study) and Sweden (1 study)
Drug use (10 studies), third party (insurance) drug expenditures (9 studies), drug prices (4 studies), drug expenditures savings ( 5 studies), and patient costs

Date of most recent search: December 2012

Limitations: this is well-conducted systematic review with only minor limitations.

\section{Financial incentives and disincentives for providers of care}

\section{Pay for performance}

Effects on delivery of health interventions

\section{Witter 2012}

Review objective: to assess the current evidence for the effects of pay-for-performance schemes on the provision of healthcare and health outcomes in low- and middle-income countries

\begin{tabular}{lll}
\hline Types of & What the review authors searched for & What the review authors found \\
\hline $\begin{array}{ll}\text { Study designs and In- } \\
\text { terventions }\end{array}$ & $\begin{array}{l}\text { Randomised trials, non-randomised tri- } \\
\text { als, controlled before-after studies, and } \\
\text { interrupted time series studies evaluat- } \\
\text { ing paying for performance in the form } \\
\text { of conditional cash payments, the con- } \\
\text { ditional provision of material goods, or } \\
\text { target payments }\end{array}$ & $\begin{array}{l}\text { and } 2 \text { interrupted time series studies. The interventions were } \\
\text { target payments linked to quality of care or coverage indica- } \\
\text { tors conditional cash transfers, with and without quality mea- } \\
\text { suremts and a mix of targeted payments and conditional }\end{array}$ \\
& & \\
\hline
\end{tabular}


(Continued)

Participants

Providers of healthcare services, sub-national organisations, national governments, and combinations of these, in the public or private sector
4 studies were conducted at public facilities and facilities run by faith-based organisations; 2 focused on primary care facilities alone; 2 focused on hospitals; and 1 on individual private practitioners

Included studies were conducted in Rwanda (2 studies), Vietnam, China, Zambia, Tanzania, the Democratic Republic of the Congo, the Philippines, and Burundi. 8 studies were conducted in rural or rural and urban areas.

Patient health indicators, utilisation or coverage changes, and changes in resource use
Outcomes

Measures of provider performance (e.g. the delivery or utilisation of healthcare services, or patient outcomes), unintended effects, and changes in resource use
Any setting in which explicit financial incentives have been used to improve the provision of healthcare in low- and middle-income countries

Date of most recent search: June 2011

Limitations: this is a well-conducted systematic review with only minor limitations.

\section{Pay for performance}

Effects on outpatient referrals from primary to secondary care

Akbari 2008

Review objective: to assess the effects of interventions to change primary care outpatient referral rates or improve outpatient referral appropriateness

\section{Types of What the review authors searched for What the review authors found}

Study designs and In- Randomised trials, non-randomised triterventions als, controlled before-after studies, and interrupted time series studies of interventions to change outpatient referral rates or improve outpatient referral appropriateness.

$\begin{array}{ll}\text { Participants } & \text { Primary care physicians, including gen- } \\ & \text { eral practitioners, family doctors, fami- } \\ & \text { ly physicians, family practitioners, and } \\ & \text { other physicians working in primary } \\ \text { healthcare settings, who fulfil primary } \\ \text { healthcare tasks }\end{array}$

Specialist physicians working in hospitals or community outpatient settings

\begin{tabular}{lll}
\hline Settings & Primary care and hospitals & $\begin{array}{l}\text { Studies conducted in the UK (12 studies), the USA (2 studies), } \\
\text { and 1 each in the Netherlands, Palestine, and Finland }\end{array}$ \\
\hline Outcomes & $\begin{array}{l}\text { Objectively measured provider perfor- } \\
\text { mance in a healthcare setting (for exam- } \\
\text { ple, referral rates or appropriateness of } \\
\text { referral) or health outcomes }\end{array}$ & $\begin{array}{l}\text { Number of primary care visits, referral rates, appropriateness } \\
\text { of referrals, case mix of referrals, appropriateness of specialist } \\
\text { investigations, costs of prescriptions }\end{array}$ \\
\hline
\end{tabular}

Date of most recent search: October 2007
17 studies were found, of which 9 evaluated professional educational interventions, 4 evaluated organisational interventions, and 4 evaluated financial interventions. Of the 17 studies identified, 10 were randomised trials, 1 was a non-randomised trial, 5 were controlled before-after studies, and 1 was an interrupted time series study

Primary care physicians and specialist physicians 
(Continued)

Limitations: this is a well-conducted systematic review with only minor limitations.

\section{Pay for performance}

Effects on the quality of healthcare provided by primary care physicians

Scott 2011

Review objective: to examine the effect of changes in the method and level of payment on the quality of care provided by primary care physicians (PCPs)

\section{Types of What the review authors searched for What the review authors found}

Study designs and Interventions
Randomised trials, controlled before-after studies (CBA), and interrupted time series studies (ITS) evaluating the impact of changes in the method or level of payment for primary care physicians
7 studies, including: cluster-randomised trials ( 3 studies), controlled before-after studies ( 2 studies), interrupted time series study ( 1 study), and controlled interrupted time series study (1 study). The studies evaluated: single-threshold target payments ( 3 studies); a fixed fee per patient achieving a specified outcome (1 study); payments based on the relative ranking of medical groups' performance (tournament-based pay) (1 study); a mix of tournament-based pay and threshold payments ( 1 study); and changing from a blended payments scheme to salaried payment (1 study)

5 studies took place in large private health plans in the USA; 1 study in 20 primary care provider medical groups in England; and 1 study in 82 medical practices in Germany

The studies were from USA ( 5 studies), the UK ( 1 study), and Germany (1 study)

Studies examined: smoking cessation (3 studies); patients' assessment of the quality of care (1 study); cervical cancer screening, mammography screening, and glycated haemoglobin (2 studies, 1 of them also childhood immunisation, chlamydia screening, and appropriate asthma medication); and 4 outcomes in diabetes ( 1 study).

Date of most recent search: August 2009

Limitations: this is a well-conducted systematic review with only minor limitations.

\section{Incentives to practice in underserved areas}

Grobler 2015

Review objective: to assess the effectiveness of interventions to increase the proportion of healthcare professionals working in rural and other underserved areas

\section{Types of What the review authors searched for What the review authors found}

Study designs and In- Randomised trials, non-randomised triterventions

als, controlled before-after studies and interrupted time series studies of any intervention to increase the recruitment or retention of health professionals in underserved areas
1 interrupted time series study from Taiwan of the effects of national health insurance on the equality of distribution of healthcare professionals 
(Continued)
Participants
Qualified healthcare professionals of
Physicians, doctors of Chinese medicine and dentists any cadre or specialty

\begin{tabular}{lll}
\hline Settings & All settings & Taiwan \\
\hline Outcomes & $\begin{array}{l}\text { Recruitment of health professionals: the } \\
\text { proportion of health professionals who } \\
\text { initially choose to work in rural or urban } \\
\text { underserved communities as a result of } \\
\text { being exposed to the intervention. Re- } \\
\text { tention: the proportion of healthcare } \\
\text { professionals who continue to work in } \\
\text { rural or urban underserved communi- } \\
\text { ties as a consequence of the interven- } \\
\text { tion }\end{array}$ \\
\hline
\end{tabular}

Date of most recent search: April 2014

Limitations: this is a well-conducted systematic review with only minor limitations.

\section{Managing the movement of health workers}

\section{Rutebemberwa 2014}

Review objective: to assess the effects of financial incentives and movement restriction interventions to manage the movement of health workers between public and private organizations in low- and middle-income countries

\begin{tabular}{lll}
\hline Types of & What the review authors searched for & What the review authors found \\
\hline $\begin{array}{l}\text { Study designs and In- } \\
\text { terventions }\end{array}$ & $\begin{array}{l}\text { Randomised trials and non-randomised } \\
\text { trials; controlled before-after studies; } \\
\text { controlled interrupted time series and } \\
\text { interrupted time series studies without } \\
\text { controls. }\end{array}$ & $\begin{array}{l}\text { No studies were found eligible for inclusion in the review. } 9 \\
\text { surveys, 1 review of government reports, } 1 \text { study of speeches } \\
\text { in the national assembly, and 1 policy analysis paper }\end{array}$ \\
\hline Participants & All health professionals & No studies were found eligible for inclusion in the review \\
\hline Settings & $\begin{array}{l}\text { Any public or private sector organisa- } \\
\text { tions }\end{array}$ & No studies were found eligible for inclusion in the review \\
\hline Outcomes & $\begin{array}{l}\text { 1. Change in the numbers or proportion } \\
\text { of health workers entering or leaving the } \\
\text { public or private sectors }\end{array}$ & No studies were found eligible for inclusion in the review \\
& $\begin{array}{l}\text { 2. Duration of stay in a particular sector } \\
\end{array}$ & \\
\hline
\end{tabular}

Date of most recent search: November 2012

Limitations: this is a well-conducted systematic review with only minor limitations.

\section{Appendix 4. Reviews awaiting classification}

\section{Likely included reviews}

Bowman LR, Donegan S, McCall PJ. Is dengue vector control deficient in effectiveness or evidence?: Systematic review and meta-analysis. PLOS Neglected Tropical Diseases 2016;10(3):e0004551. 
Abdel-Aleem H, El-Gibaly OMH, El-Gazzar AFS, Al-Attar GST. Mobile clinics for women's and children's health. Cochrane Database of Systematic Reviews. 2016;8:CD009677.

Akl EA, El-Jardali F, Bou Karroum L, El-Eid J, Brax H, Akik C, et al. Effectiveness of Mechanisms and Models of Coordination between Organizations, Agencies and Bodies Providing or Financing Health Services in Humanitarian Crises: A Systematic Review. PloS one. 2015;10(9):e0137159.

Algie CM, Mahar RK, Wasiak J, Batty L, Gruen RL, Mahar PD. Interventions for reducing wrong-site surgery and invasive clinical procedures. The Cochrane database of systematic reviews. 2015;3(3):CD009404.

Ambia J, Mandala J. A systematic review of interventions to improve prevention of mother-to-child HIV transmission service delivery and promote retention. Journal of the International AIDS Society. 2016;19(1):20309.

Barnard S, Kim C, Park MH, Ngo TD. Doctors or mid-level providers for abortion. The Cochrane database of systematic reviews. 2015;7(7):CD011242.

Basu S, Andrews J, Kishore S, Panjabi R, Stuckler D. Comparative performance of private and public healthcare systems in low- and middleincome countries: a systematic review. PLoS medicine. 2012;9(6):e1001244.

Blacklock C, Gonçalves Bradley DC, Mickan S, Willcox M, Roberts N, Bergström A, et al. Impact of Contextual Factors on the Effect of Interventions to Improve Health Worker Performance in Sub-Saharan Africa: Review of Randomised Clinical Trials. PloS one. 2016;11(1):e0145206.

Byrne A, Hodge A, Jimenez-Soto E, Morgan A. What works? Strategies to increase reproductive, maternal and child health in difficult to access mountainous locations: a systematic literature review. PloS one. 2014;9(2):e87683.

Coast E, Jones E, Lattof SR, Portela A. Effectiveness of interventions to provide culturally appropriate maternity care in increasing uptake of skilled maternity care: a systematic review. Health policy and planning. 2016;31(10):1479-91.

Cornish F, Priego-Hernandez J, Campbell C, Mburu G, McLean S. The impact of Community Mobilisation on HIV Prevention in Middle and Low Income Countries: A Systematic Review and Critique. AIDS and behavior. 2014;18(11):2110-34.

Dawson A, Tran NT, Westley E, Mangiaterra V, Festin M. Improving access to emergency contraception pills through strengthening service delivery and demand generation: a systematic review of current evidence in low and middle-income countries. PloS one. 2014;9(10):e109315.

de Jongh TE, Gurol-Urganci I, Allen E, Zhu NJ, Atun R. Integration of antenatal care services with health programmes in low- and middleincome countries: systematic review. Journal of global health. 2016;6(1):010403.

Dyer TA, Brocklehurst P, Glenny AM, Davies L, Tickle M, Issac A, et al. Dental auxiliaries for dental care traditionally provided by dentists. The Cochrane database of systematic reviews. 2014;8(8):CD010076.

Ehiri JE, Gunn JK, Center KE, Li Y, Rouhani M, Ezeanolue EE. Training and deployment of lay refugee/internally displaced persons to provide basic health services in camps: a systematic review. Global health action. 2014;7:23902.

Emdin CA, Chong NJ, Millson PE. Non-physician clinician provided HIV treatment results in equivalent outcomes as physician-provided care: a meta-analysis. Journal of the International AIDS Society. 2013;16(no pagination):18445.

Fernandez Turienzo C, Sandall J, Peacock JL. Models of antenatal care to reduce and prevent preterm birth: a systematic review and metaanalysis. BMJ open. 2016;6(1):e009044.

Feyissa GT, Lockwood C, Munn Z. The effectiveness of home-based HIV counseling and testing in reducing stigma and risky sexual behavior among adults and adolescents: a systematic review and meta-analysis. JBI Database of Systematic Reviews and Implementation Reports. 2015;13(6):318-72.

Fiander M, McGowan J, Grad R, Pluye P, Hannes K, Labrecque M, et al. Interventions to increase the use of electronic health information by healthcare practitioners to improve clinical practice and patient outcomes. The Cochrane database of systematic reviews. 2015;3(3):CD004749.

Flodgren G, Rachas A, Farmer AJ, Inzitari M, Shepperd S. Interactive telemedicine: effects on professional practice and health care outcomes. The Cochrane database of systematic reviews. 2015;9(9):CD002098.

Gaitonde R, Oxman AD, Okebukola PO, Rada G. Interventions to reduce corruption in the health sector. Cochrane Database of Systematic Reviews. 2016;8:CD008856. 
George AS, Branchini C, Portela A. Do Interventions that Promote Awareness of Rights Increase Use of Maternity Care Services? A Systematic Review. PloS one. 2015;10(10):e0138116.

Ghada Abou El S, Therese D, Hatem AM. Planned home versus hospital care for preterm prelabour rupture of the membranes (PPROM) prior to 37 weeks' gestation. Cochrane Database of Systematic Reviews. 2014;4(4):CD008053.

Giedion U, Alfonso EA, Diaz Y. The Impact of Universal Coverage Schemes in the Developing World: A Review of the Existing Evidence. Universal Health Coverage (UNICO) studies series; no. 25. Washington D.C.: The Worldbank. 2013.

Handford CD, Tynan AM, Agha A, Rzeznikiewiz D, Glazier RH. Organization of care for persons with HIV-infection: a systematic review. AIDS care. 2016:1-10.

Health Quality Ontario. Interventions to Improve Access to Primary Care for People Who Are Homeless: A Systematic Review. Ontario health technology assessment series. 2016;16(9):1-50.

Hensen B, Taoka S, Lewis JJ, Weiss HA, Hargreaves J. Systematic review of strategies to increase men's HIV-testing in sub-Saharan Africa. AIDS (London, England). 2014;28(14):2133-45.

Hernández AV, Pasupuleti V, Benites-Zapata V, Velásquez-Hurtado E, Loyola-Romaní J, Rodríguez-Calviño Y, et al. [Systematic review of the efectiveness of community-based interventions to decrease neonatal mortality]. Revista peruana de medicina experimental y salud pública. 2015;32(3):532-45.

Hesselink G, Berben S, Beune T, Schoonhoven L. Improving the governance of patient safety in emergency care: a systematic review of interventions. BMJ open. 2016;6(1):e009837.

Hopkins U, Itty AS, Nazario H, Pinon M, Slyer J, Singleton J. The effectiveness of delegation interventions by the registered nurse to the unlicensed assistive personnel and their impact on quality of care, patient satisfaction, and RN staff satisfaction: a systematic review. JBI Library of Systematic Reviews. 2012;10(15):895-934.

Hoyler M, Hagander L, Gillies R, Riviello R, Chu K, Bergström S, et al. Surgical care by non-surgeons in low-income and middle-income countries: a systematic review. Lancet (London, England). 2015;385 Suppl 2:S42.

Joshi R, Alim M, Kengne AP, Jan S, Maulik PK, Peiris D, et al. Task shifting for non-communicable disease management in low and middle income countries--a systematic review. PloS one. 2014;9(8):e103754.

Kien C, Reichenpfader U, Nußbaumer B, Rohleder S, Punz P, Christof C, et al. [Comparative effectiveness and safety of screening and counselling interventions conducted by non-physicians and physicians: A systematic review]. Zeitschrift für Evidenz, Fortbildung und Qualität im Gesundheitswesen. 2015;109(1):18-27.

Kilpatrick K, Kaasalainen S, Donald F, Reid K, Carter N, Bryant-Lukosius D, et al. The effectiveness and cost-effectiveness of clinical nurse specialists in outpatient roles: a systematic review. Journal of evaluation in clinical practice. 2014;20(6):1106-23.

Kim K, Choi JS, Choi E, Nieman CL, Joo JH, Lin FR, et al. Effects of Community-Based Health Worker Interventions to Improve Chronic Disease Management and Care Among Vulnerable Populations: A Systematic Review. American journal of public health. 2016;106(4):e1-e26.

Kredo T, Adeniyi FGB, Bateganya M, Pienaar ED. Task shifting from doctors to non-doctors for initiation and maintenance of antiretroviral therapy. Cochrane Database of Systematic Reviews. 2014;7(7):CD007331.

Lassi ZS, Musavi NB, Maliqi B, Mansoor N, de Francisco A, Toure K, et al. Systematic review on human resources for health interventions to improve maternal health outcomes: evidence from low- and middle-income countries. Human resources for health. 2016;14(1):10.

Lavender T, Richens Y, Milan SJ, Smyth RMD, Dowswell T. Telephone support for women during pregnancy and the first six weeks postpartum. Cochrane Database of Systematic Reviews. 2013;7(7):CD009338.

Lawrence D, Fedorowicz Z, van Zuuren EJ. Day care versus in-patient surgery for age-related cataract. The Cochrane database of systematic reviews. 2015;11(11):CD004242.

Liu G, Jack H, Piette A, Mangezi W, Machando D, Rwafa C, et al. Mental health training for health workers in Africa: a systematic review. The lancet Psychiatry. 2016;3(1):65-76.

MacPherson P, Munthali C, Ferguson J, Armstrong A, Kranzer K, Ferrand RA, et al. Service delivery interventions to improve adolescents' linkage, retention and adherence to antiretroviral therapy and HIV care. Tropical medicine \& international health : TM \& IH. 2015;20(8):1015-32.

Mbuagbaw L, Medley N, Darzi AJ, Richardson M, Habiba Garga K, Ongolo-Zogo P. Health system and community level interventions for improving antenatal care coverage and health outcomes. The Cochrane database of systematic reviews. 2015;12(12):CD010994. 
Mdege ND, Chindove S. Bringing antiretroviral therapy (ART) closer to the end-user through mobile clinics and home-based ART: systematic review shows more evidence on the effectiveness and cost effectiveness is needed. The International journal of health planning and management. 2013;29(1):e31-47.

Moraros J, Lemstra M, Nwankwo C. Lean interventions in healthcare: do they actually work? A systematic literature review. International journal for quality in health care : journal of the International Society for Quality in Health Care / ISQua. 2016;28(2):150-65.

Nunan M, Duke T. Effectiveness of pharmacy interventions in improving availability of essential medicines at the primary healthcare level. Tropical medicine \& international health : TM \& IH. 2011;16(5):647-58.

Oluoch T, Santas X, Kwaro D, Were M, Biondich P, Bailey C, et al. The effect of electronic medical record-based clinical decision support on HIV care in resource-constrained settings: a systematic review. International journal of medical informatics. 2012;81(10):e83-92.

Palmer KS, Agoritsas T, Martin D, Scott T, Mulla SM, Miller AP, et al. Activity-based funding of hospitals and its impact on mortality, readmission, discharge destination, severity of illness, and volume of care: a systematic review and meta-analysis. PloS one. 2014;9(10):e109975.

Pega F, Liu SY, Walter S, Lhachimi SK. Unconditional cash transfers for assistance in humanitarian disasters: effect on use of health services and health outcomes in low- and middle-income countries. The Cochrane database of systematic reviews. 2015;9(9):CD011247.

Penazzato M, Davies MA, Apollo T, Negussie E, Ford N. Task shifting for the delivery of pediatric antiretroviral treatment: a systematic review. Journal of acquired immune deficiency syndromes (1999). 2014;65(4):414-22.

Pollaris G, Sabbe M. Reverse triage: more than just another method. European journal of emergency medicine : official journal of the European Society for Emergency Medicine. 2015;23(4):240-7.

Polus S, Lewin S, Glenton C, Lerberg PM, Rehfuess E, Gülmezoglu AM. Optimizing the delivery of contraceptives in low- and middle-income countries through task shifting: a systematic review of effectiveness and safety. Reproductive health. 2015;12(1):27.

Rashidian A, Omidvari AH, Vali Y, Sturm H, Oxman AD. Pharmaceutical policies: effects of financial incentives for prescribers. The Cochrane database of systematic reviews. 2015;8(8):CD006731.

Reichow B, Servili C, Yasamy MT, Barbui C, Saxena S. Non-specialist psychosocial interventions for children and adolescents with intellectual disability or lower-functioning autism spectrum disorders: a systematic review. PLoS medicine. 2013;10(12):e1001572.

Reisman J, Arlington L, Jensen L, Louis H, Suarez-Rebling D, Nelson BD. Newborn Resuscitation Training in Resource-Limited Settings: A Systematic Literature Review. Pediatrics. 2016;138(2):1-16.

Robyn PJ, Sauerborn R, Bärnighausen T. Provider payment in community-based health insurance schemes in developing countries: a systematic review. Health policy and planning. 2013;28(2):111-22.

Salam RA, Das JK, Lassi ZS, Bhutta ZA. Impact of community-based interventions for the prevention and control of malaria on intervention coverage and health outcomes for the prevention and control of malaria. Infectious diseases of poverty. 2014;3(1):25.

Schmidt E, Goldhaber-Fiebert SN, Ho LA, McDonald KM. Simulation exercises as a patient safety strategy: a systematic review. Annals of internal medicine. 2013;158(5 Pt 2):426-32.

Sharon RL, Amanda N, Andrew FS, Phil A. Physician anaesthetists versus non-physician providers of anaesthesia for surgical patients. Cochrane Database of Systematic Reviews. 2014;7(7):CD010357.

Sondaal SF, Browne JL, Amoakoh-Coleman M, Borgstein A, Miltenburg AS, Verwijs M, et al. Assessing the Effect of mHealth Interventions in Improving Maternal and Neonatal Care in Low- and Middle-Income Countries: A Systematic Review. PloS one. 2016;11(5):e0154664.

Spaan E, Mathijssen J, Tromp N, McBain F, ten Have A, Baltussen R. The impact of health insurance in Africa and Asia: a systematic review. Bulletin of the World Health Organization. 2012;90(9):685-92.

Sunguya BF, Poudel KC, Mlunde LB, Urassa DP, Yasuoka J, Jimba M. Nutrition training improves health workers' nutrition knowledge and competence to manage child undernutrition: a systematic review. Frontiers in public health. 2013;1:37.

Susan FM, Benjamin MH, Ramila B, Tim E, Debra B. Demand-side financing measures to increase maternal health service utilisation and improve health outcomes: a systematic review of evidence from low- and middle-income countries. JBI Library of Systematic Reviews. 2012;10(58):4165-567.

Thomas SM, Jeyaraman M, Hodge WG, Hutnik C, Costella J, Malvankar-Mehta MS. The effectiveness of teleglaucoma versus in-patient examination for glaucoma screening: a systematic review and meta-analysis. PloS one. 2014;9(12):e113779. 
Tibingana-Ahimbisibwe B, Katabira C, Mpalampa L, Harrison RA. The effectiveness of adolescent-specific prenatal interventions on improving attendance and reducing harm during and after birth: a systematic review. International journal of adolescent medicine and health. 2016.

Till SR, Everetts D, Haas DM. Incentives for increasing prenatal care use by women in order to improve maternal and neonatal outcomes. Cochrane Database of Systematic Reviews. 2015;12(12):CD009916.

Watterson JL, Walsh J, Madeka I. Using mHealth to Improve Usage of Antenatal Care, Postnatal Care, and Immunization: A Systematic Review of the Literature. BioMed research international. 2015;2015(no pagination):153402.

Weeks G, George J, Maclure K, Stewart D. Non-medical prescribing versus medical prescribing for acute and chronic disease management in primary and secondary care. The Cochrane database of systematic reviews. 2016;11:CD011227.

Wiysonge CS, Abdullahi LH, Ndze VN, Hussey GD. Public stewardship of private for-profit healthcare providers in low- and middle-income countries. Cochrane Database of Systematic Reviews. 2016;8(8):CD009855.

Wong WC, Luk CW, Kidd MR. Is there a role for primary care clinicians in providing shared care in HIV treatment? A systematic literature review. Sexually transmitted infections. 2012;88(2):125-31.

Yuan B, He L, Meng Q, Jia L. Payment methods for outpatient care facilities. Cochrane Database of Systematic Reviews 2017, Issue 3. Art. No.: CD011153. DOI: 10.1002/14651858.CD011153.pub2.

\section{Likely excluded reviews}

Bassili A, Fitzpatrick C, Qadeer E, Fatima R, Floyd K, Jaramillo E. A systematic review of the effectiveness of hospital- and ambulatory-based management of multidrug-resistant tuberculosis. The American journal of tropical medicine and hygiene. 2013;89(2):271-80.

Bhageerathy R, Nair S, Bhaskaran U. A systematic review of community-based health insurance programs in South Asia. The International journal of health planning and management. 2016.

Blaya JA, Fraser HS, Holt B. E-health technologies show promise in developing countries. Health affairs (Project Hope). 2010;29(2):244-51.

Callese TE, Richards CT, Shaw P, Schuetz SJ, Paladino L, Issa N, et al. Trauma system development in low- and middle-income countries: a review. The Journal of surgical research. 2015;193(1):300-7.

Davy C, Bleasel J, Liu H, Tchan M, Ponniah S, Brown A. Effectiveness of chronic care models: opportunities for improving healthcare practice and health outcomes: a systematic review. BMC health services research. 2015;15(1):194.

Dawson AZ, Walker RJ, Campbell JA, Egede LE. Effective Strategies for Global Health Training Programs A Systematic Review of Training Outcomes in Low and Middle Income Countries. Global journal of health science. 2016;8(11):56719.

Higgs ES, Goldberg AB, Labrique AB, Cook SH, Schmid C, Cole CF, et al. Understanding the role of mHealth and other media interventions for behavior change to enhance child survival and development in low- and middle-income countries: an evidence review. Journal of health communication. 2014;19 Suppl 1:164-89.

Hubert GJ, Müller-Barna P, Audebert HJ. Recent advances in TeleStroke: a systematic review on applications in prehospital management and Stroke Unit treatment or TeleStroke networking in developing countries. International journal of stroke: official journal of the International Stroke Society. 2014;9(8):968-73.

Margaret Elizabeth K, Denis P, Peter CR, Wim Van L. The contribution of primary care to health and health systems in low- and middleincome countries: A critical review of major primary care initiatives. 2010.

Pannick S, Davis R, Ashrafian H, Byrne BE, Beveridge I, Athanasiou T, et al. Effects of Interdisciplinary Team Care Interventions on General Medical Wards: A Systematic Review. JAMA internal medicine. 2015;175(8):1288-98.

Schiavo R, May Leung M, Brown M. Communicating risk and promoting disease mitigation measures in epidemics and emerging disease settings. Pathogens and global health. 2014;108(2):76-94.

Zulfiqar AB, Zohra SL, Nadia M. Systematic review on human resources for health interventions to improve maternal health outcomes: Evidence from developing countries. 2010.

\section{Uncertain reviews}

Acheampong F, Anto BP, Koffuor GA. Medication safety strategies in hospitals--a systematic review. The International journal of risk \& safety in medicine. 2014;26(3):117-31. 
Alkhenizan A, Shaw C. Impact of accreditation on the quality of healthcare services: a systematic review of the literature. Annals of Saudi medicine. 2011;31(4):407-16.

Al-Mallah MH, Farah I, Al-Madani W, Bdeir B, Al Habib S, Bigelow ML, et al. The Impact of Nurse-Led Clinics on the Mortality and Morbidity of Patients with Cardiovascular Diseases: A Systematic Review and Meta-analysis. The Journal of cardiovascular nursing. 2015;31(1):89-95.

Bakitas MA, Elk R, Astin M, Ceronsky L, Clifford KN, Dionne-Odom JN, et al. Systematic Review of Palliative Care in the Rural Setting. Cancer control : journal of the Moffitt Cancer Center. 2015;22(4):450-64.

Balfour J, Abdulcadir J, Say L, Hindin MJ. Interventions for healthcare providers to improve treatment and prevention of female genital mutilation: a systematic review. BMC health services research. 2016;16(1):409.

Bannan DF, Tully MP. Bundle interventions used to reduce prescribing and administration errors in hospitalized children: a systematic review. Journal of clinical pharmacy and therapeutics. 2016;41(3):246-55.

Bashshur RL, Howell JD, Krupinski EA, Harms KM, Bashshur N, Doarn CR. The Empirical Foundations of Telemedicine Interventions in Primary Care. Telemedicine journal and e-health : the official journal of the American Telemedicine Association. 2016;22(5):342-75.

Boccia D, Hargreaves J, Lönnroth K, Jaramillo E, Weiss J, Uplekar M, et al. Cash transfer and microfinance interventions for tuberculosis control: review of the impact evidence and policy implications. The international journal of tuberculosis and lung disease : the official journal of the International Union against Tuberculosis and Lung Disease. 2011;15 Suppl 2:S37-49.

Booth A, Cantrell A, Preston L, Chambers D, Goyder E. What is the evidence for the effectiveness, appropriateness and feasibility of group clinics for patients with chronic conditions? A systematic review2015 2015/12/None.

Brocklehurst P, Mertz B, Jerković-Ćosić K, Littlewood A, Tickle M. Direct access to midlevel dental providers: an evidence synthesis. Journal of public health dentistry. 2014;74(4):326-35.

Candy B, France R, Low J, Sampson L. Does involving volunteers in the provision of palliative care make a difference to patient and family wellbeing? A systematic review of quantitative and qualitative evidence. International journal of nursing studies. 2014;52(3):756-68.

Chapman SM, Wray J, Oulton K, Peters MJ. Systematic review of paediatric track and trigger systems for hospitalised children. Resuscitation. 2016;109:87-109.

Coxeter P, Del Mar CB, McGregor L, Beller EM, Hoffmann TC. Interventions to facilitate shared decision making to address antibiotic use for acute respiratory infections in primary care. The Cochrane database of systematic reviews. 2015;11(11):CD010907.

Damiani G, Pinnarelli L, Sommella L, Vena V, Magrini P, Ricciardi W. The Short Stay Unit as a new option for hospitals: a review of the scientific literature. Medical science monitor : international medical journal of experimental and clinical research. 2011;17(6):SR15-9.

Gentry S, van Velthoven MHMMT, Tudor Car L, Car J. Telephone delivered interventions for reducing morbidity and mortality in people with HIV infection. Cochrane Database of Systematic Reviews. 2013;5(5):CD009189.

Harding R, Albertyn R, Sherr L, Gwyther L. Pediatric palliative care in sub-saharan Africa: a systematic review of the evidence for care models, interventions, and outcomes. Journal of pain and symptom management. 2014;47(3):642-51.

Hastings SE, Armitage GD, Mallinson S, Jackson K, Suter E. Exploring the relationship between governance mechanisms in healthcare and health workforce outcomes: a systematic review. BMC health services research. 2014;14(1):479.

Hines S, Munday J, Kynoch K. Effectiveness of nurse-led preoperative assessment services for elective surgery: a systematic review update. JBI database of systematic reviews and implementation reports. 2015;13(6):279-317.

Hotchkiss DR, Diana ML, Foreit KG. How can routine health information systems improve health systems functioning in low- and middleincome countries? Assessing the evidence base. Advances in health care management. 2012;12:25-58.

Housden L, Wong ST, Dawes M. Effectiveness of group medical visits for improving diabetes care: a systematic review and meta-analysis. CMAJ : Canadian Medical Association journal = journal de l'Association medicale canadienne. 2013;185(13):E635-44.

Ireland S, Kent B. Telephone pre-operative assessment for adults: a comprehensive systematic review. JBI Library of Systematic Reviews. 2012;10(25):1452-503.

Kågesten A, Parekh J, Tunçalp O, Turke S, Blum RW. Comprehensive adolescent health programs that include sexual and reproductive health services: a systematic review. American journal of public health. 2014;104(12):e1-e14.

Lazarus JV, Safreed-Harmon K, Nicholson J, Jaffar S. Health service delivery models for the provision of antiretroviral therapy in subSaharan Africa: a systematic review. Tropical medicine \& international health : TM \& IH. 2014;19(10):1198-215. 
Leidy Johanna Rueda D, Diná Lopes Monteiro da C. The efficacy of telephone use to assist and improve the wellbeing of family caregivers of persons with chronic diseases: a systematic review. JBI Library of Systematic Reviews. 2015;12(12):106-40.

McCormack L, Sheridan S, Lewis M, Boudewyns V, Melvin CL, Kistler C, et al. Communication and dissemination strategies to facilitate the use of health-related evidence. Evidence report/technology assessment. 2013(213):1-520.

Meid AD, Lampert A, Burnett A, Seidling HM, Haefeli WE. The impact of pharmaceutical care interventions for medication underuse in older people: a systematic review and meta-analysis. British journal of clinical pharmacology. 2015;80(4):768-76.

Mengistu TA, Tafere TE. Effect of antenatal care on institutional delivery in developing countries: a systematic review. JBI Library of Systematic Reviews. 2011;9(35):1447-70

Mitchell GK, Burridge L, Zhang J, Donald M, Scott IA, Dart J, et al. Systematic review of integrated models of health care delivered at the primary?secondary interface: how effective is it and what determines effectiveness? Australian journal of primary health. 2015;21(4):391-408.

Palmas W, March D, Darakjy S, Findley SE, Teresi J, Carrasquillo O, et al. Community Health Worker Interventions to Improve Glycemic Control in People with Diabetes: A Systematic Review and Meta-Analysis. Journal of General Internal Medicine. 2015;30:1004-12.

Pérez-Escamilla R, Martinez JL, Segura-Pérez S. Impact of the Baby-friendly Hospital Initiative on breastfeeding and child health outcomes: a systematic review. Maternal \& child nutrition. 2016;12(3):402-17.

Rinke ML, Bundy DG, Velasquez CA, Rao S, Zerhouni Y, Lobner K, et al. Interventions to Reduce Pediatric Medication Errors: A Systematic Review. Pediatrics. 2014;134(2):338-60.

Rudge MV, Lima SA, El Dib RP, Marini G, Magalhães C, Calderon Ide M. Effect of ambulatory versus hospital treatment for gestational diabetes or hyperglycemia on infant mortality rates: a systematic review. São Paulo medical journal = Revista paulista de medicina. 2013;131(5):331-7.

Sabater-Hernández D, Sabater-Galindo M, Fernandez-Llimos F, Rotta I, Hossain LN, Durks D, et al. A Systematic Review of EvidenceBased Community Pharmacy Services Aimed at the Prevention of Cardiovascular Disease. Journal of managed care \& specialty pharmacy. 2016;22(6):699-713.

Salmoiraghi A, Hussain S. A Systematic Review of the Use of Telepsychiatry in Acute Settings. Journal of psychiatric practice. 2015;21(5):389-93.

Santos MT, Moura SC, Gomes LM, Lima AH, Moreira RS, Silva CD, et al. Telehealth application on the rehabilitation of children and adolescents. Revista paulista de pediatria : orgão oficial da Sociedade de Pediatria de São Paulo. 2014;32(1):136-43.

Saxon RL, Gray MA, Oprescu FI. Extended roles for allied health professionals: an updated systematic review of the evidence. Journal of multidisciplinary healthcare. 2014;7((Saxon R.L., robyn.saxon@health.qld.gov.au; Gray M.A.; loprescu F.) School of Health and Sports Sciences, University of the Sunshine Coast, Sippy Downs, Australia):479-88.

Stokes J, Panagioti M, Alam R, Checkland K, Cheraghi-Sohi S, Bower P. Effectiveness of Case Management for 'At Risk' Patients in Primary Care: A Systematic Review and Meta-Analysis. PloS one. 2015;10(7):e0132340.

Suksomboon N, Poolsup N, Nge YL. Impact of phone call intervention on glycemic control in diabetes patients: a systematic review and meta-analysis of randomized, controlled trials. PloS one. 2014;9(2):e89207.

Tao D, Xie L, Wang T, Wang T. A meta-analysis of the use of electronic reminders for patient adherence to medication in chronic disease care. Journal of Telemedicine and Telecare. 2015;21(1).

Tricco AC, Antony J, Ivers NM, Ashoor HM, Khan PA, Blondal E, et al. Effectiveness of quality improvement strategies for coordination of care to reduce use of health care services: a systematic review and meta-analysis. CMAJ : Canadian Medical Association journal = journal de l'Association medicale canadienne. 2014;186(15):E568-78.

Pitt V, Lowe D, Hill S, Prictor M, Hetrick SE, Ryan R, et al. Consumer-providers of care for adult clients of statutory mental health services. Cochrane Database of Systematic Reviews. 2013;3(3):CD004807.

Weaver MS, Lönnroth K, Howard SC, Roter DL, Lam CG. Interventions to improve adherence to treatment for paediatric tuberculosis in lowand middle-income countries: a systematic review and meta-analysis. Bulletin of the World Health Organization. 2015;93(10):700-11B.

Wekesah FM, Mbada CE, Muula AS, Kabiru CW, Muthuri SK, Izugbara CO. Effective non-drug interventions for improving outcomes and quality of maternal health care in sub-Saharan Africa: a systematic review. Systematic reviews. 2016;5(1):137. 
Willey B, Smith Paintain L, Mangham-Jefferies L, Car J, Armstrong Schellenberg J. Effectiveness of interventions to strengthen national health service delivery on coverage, access, quality and equity in the use of health services in low and lower middle income countries. 20132013.

World Health Organization, University of California SF. Task shifting - physicians (doctors) versus non-physicians (nurses or clinical officers) for initiation and maintenance of antiretroviral therapy. World Health Organization. 2013.

Yasmin F, Banu B, Zakir SM, Sauerborn R, Ali L, Souares A. Positive influence of short message service and voice call interventions on adherence and health outcomes in case of chronic disease care: a systematic review. BMC medical informatics and decision making. 2016;16:46.

Zhai YK, Zhu WJ, Hou HL, Sun DX, Zhao J. Efficacy of telemedicine for thrombolytic therapy in acute ischemic stroke: a meta-analysis. Journal of telemedicine and telecare. 2015;21(3):123-30.

Zhou K, Fitzpatrick T, Walsh N, Kim JY, Chou R, Lackey M, et al. Interventions to optimise the care continuum for chronic viral hepatitis: a systematic review and meta-analyses. The Lancet Infectious diseases. 2016.

Zwanikken PA, Dieleman M, Samaranayake D, Akwataghibe N, Scherpbier A. A systematic review of outcome and impact of master's in health and health care. BMC medical education. 2013;13:18.

\section{Likely supplemental reviews}

Abdulwahid MA, Booth A, Kuczawski M, Mason SM. The impact of senior doctor assessment at triage on emergency department performance measures: systematic review and meta-analysis of comparative studies. Emergency medicine journal : EMJ. 2015;33(7):504-13.

Adebayo EF, Uthman OA, Wiysonge CS, Stern EA, Lamont KT, Ataguba JE. A systematic review of factors that affect uptake of communitybased health insurance in low-income and middle-income countries. BMC health services research. 2015;15(1):543.

Alghamdi M, Gashgari H, Househ M. A Systematic Review of Mobile Health Technology Use in Developing Countries. Studies in health technology and informatics. 2015;213:223-6.

Alkhaled L, Kahale L, Nass H, Brax H, Fadlallah R, Badr K, et al. Legislative, educational, policy and other interventions targeting physicians' interaction with pharmaceutical companies: a systematic review. BMJ open. 2014;4(7):e004880.

Altowaijri A, Phillips CJ, Fitzsimmons D. A systematic review of the clinical and economic effectiveness of clinical pharmacist intervention in secondary prevention of cardiovascular disease. Journal of managed care pharmacy : JMCP. 2013;19(5):408-16.

Amouzou A, Morris S, Moulton LH, Mukanga D. Assessing the impact of integrated community case management (iCCM) programs on child mortality: Review of early results and lessons learned in sub-Saharan Africa. Journal of global health. 2014;4(2):020411.

Aziz H, Hatah E, Makmor Bakry M, Islahudin F. How payment scheme affects patients' adherence to medications? A systematic review. Patient preference and adherence. 2016;10:837-50.

Bailey C, Blake C, Schriver M, Cubaka VK, Thomas T, Martin Hilber A. A systematic review of supportive supervision as a strategy to improve primary healthcare services in Sub-Saharan Africa. International journal of gynaecology and obstetrics: the official organ of the International Federation of Gynaecology and Obstetrics. 2015;132(1):117-25.

Baxter PE, Hewko SJ, Pfaff KA, Cleghorn L, Cunningham BJ, Elston D, et al. Leaders' experiences and perceptions implementing activity-based funding and pay-for-performance hospital funding models: A systematic review. Health policy (Amsterdam, Netherlands). 2015;119(8):1096-110.

Bbosa GS, Wong G, Kyegombe DB, Ogwal-Okeng J. Effects of intervention measures on irrational antibiotics/antibacterial drug use in developing countries: A systematic review. Health. 2014;6.

Bellows B, Bulaya C, Inambwae S, Lissner CL, Ali M, Bajracharya A. Family Planning Vouchers in Low and Middle Income Countries: A Systematic Review. Studies in family planning. 2016;47(4):357-70.

Bellows BW, Conlon CM, Higgs ES, Townsend JW, Nahed MG, Cavanaugh K, et al. A taxonomy and results from a comprehensive review of 28 maternal health voucher programmes. Journal of health, population, and nutrition. 2013;31(4 Suppl 2):106-28.

Benishek LA, Dugosh KL, Kirby KC, Matejkowski J, Clements NT, Seymour BL, et al. Prize-based contingency management for the treatment of substance abusers: a meta-analysis. Addiction (Abingdon, England). 2014;109(9):1426-36. 
Beratarrechea A, Lee AG, Willner JM, Jahangir E, Ciapponi A, Rubinstein A. The impact of mobile health interventions on chronic disease outcomes in developing countries: a systematic review. Telemedicine journal and e-health : the official journal of the American Telemedicine Association. 2014;20(1):75-82

Blank L, Baxter S, Woods HB, Goyder E, Lee A, Payne N, et al. What is the evidence on interventions to manage referral from primary to specialist non-emergency care? A systematic review and logic model synthesis. Health services and delivery research. 2015.

Bloomfield GS, Vedanthan R, Vasudevan L, Kithei A, Were M, Velazquez EJ. Mobile health for non-communicable diseases in Sub-Saharan Africa: a systematic review of the literature and strategic framework for research. Globalization and health. 2014;10(1):49.

Boksmati N, Butler-Henderson K, Anderson K, Sahama T. The Effectiveness of SMS Reminders on Appointment Attendance: a Meta-Analysis. Journal of medical systems. 2016;40(4):90.

Borchard A, Schwappach DL, Barbir A, Bezzola P. A systematic review of the effectiveness, compliance, and critical factors for implementation of safety checklists in surgery. Annals of surgery. 2012;256(6):925-33.

Braet A, Weltens C, Sermeus W. Effectiveness of discharge interventions from hospital to home on hospital readmissions: a systematic review. JBI database of systematic reviews and implementation reports. 2016;14(2):106-73.

Brata C, Gudka S, Schneider CR, Clifford RM. A review of the provision of appropriate advice by pharmacy staff for self-medication in developing countries. Research in social \& administrative pharmacy: RSAP. 2014;11(2):136-53.

Byrne A, Morgan A. How the integration of traditional birth attendants with formal health systems can increase skilled birth attendance. International journal of gynaecology and obstetrics: the official organ of the International Federation of Gynaecology and Obstetrics. 2011;115(2):127-34.

Campanella P, Vukovic V, Parente P, Sulejmani A, Ricciardi W, Specchia ML. The impact of Public Reporting on clinical outcomes: a systematic review and meta-analysis. BMC health services research. 2016;16(1):296.

Carter EB, Temming LA, Akin J, Fowler S, Macones GA, Colditz GA, et al. Group Prenatal Care Compared With Traditional Prenatal Care: A Systematic Review and Meta-analysis. Obstetrics and gynecology. 2016;128(3):551-61.

Chhina HK, Bhole VM, Goldsmith C, Hall W, Kaczorowski J, Lacaille D. Effectiveness of academic detailing to optimize medication prescribing behaviour of family physicians. Journal of pharmacy \& pharmaceutical sciences : a publication of the Canadian Society for Pharmaceutical Sciences, Société canadienne des sciences pharmaceutiques. 2013;16(4):511-29.

Chin WY, Lam CL, Lo SV. Quality of care of nurse-led and allied health personnel-led primary care clinics. Hong Kong medical journal = Xianggang yi xue za zhi / Hong Kong Academy of Medicine. 2011;17(3):217-30.

Chishinga N, Godfrey-Faussett P, Fielding K, Ayles H. Effect of home-based interventions on virologic outcomes in adults receiving antiretroviral therapy in Africa: a meta-analysis. BMC public health. 2014;14(1):239.

Clark CE, Smith LF, Taylor RS, Campbell JL. Nurse led interventions to improve control of blood pressure in people with hypertension: systematic review and meta-analysis. BMJ (Clinical research ed). 2010;341(7771):c3995.

Cobos Muñoz D, Merino Amador P, Monzon Llamas L, Martinez Hernandez D, Santos Sancho JM. Decentralization of health systems in low and middle income countries: a systematic review. International journal of public health. 2016.

Conn VS, Ruppar TM, Enriquez M, Cooper PS, Chan KC. Healthcare provider targeted interventions to improve medication adherence: systematic review and meta-analysis. International journal of clinical practice. 2015;69(8):889-99.

Davis R, Parand A, Pinto A, Buetow S. Systematic review of the effectiveness of strategies to encourage patients to remind healthcare professionals about their hand hygiene. The Journal of hospital infection. 2014;89(3):141-62.

Davy C, Bleasel J, Liu H, Tchan M, Ponniah S, Brown A. Factors influencing the implementation of chronic care models: A systematic literature review. BMC family practice. 2015;16:102.

Decroo T, Rasschaert F, Telfer B, Remartinez D, Laga M, Ford N. Community-based antiretroviral therapy programs can overcome barriers to retention of patients and decongest health services in sub-Saharan Africa: a systematic review. International health. 2013;5(3):169-79.

Dempsey E, Pammi M, Ryan AC, Barrington KJ. Standardised formal resuscitation training programmes for reducing mortality and morbidity in newborn infants. The Cochrane database of systematic reviews. 2015;9(9):CD009106.

Devi BR, Syed-Abdul S, Kumar A, Iqbal U, Nguyen PA, Li YC, et al. mHealth: An updated systematic review with a focus on HIV/AIDS and tuberculosis long term management using mobile phones. Computer methods and programs in biomedicine. 2015;122(2):257-65. 
do Amaral JJF, Victora CG. The effect of training in Integrated Management of Childhood Illness (IMCI) on the performance and healthcare quality of pediatric healthcare workers: a systematic review. Revista Brasileira de Saúde Materno Infantil. 2008;8(2):151-62.

Druetz T, Siekmans K, Goossens S, Ridde V, Haddad S. The community case management of pneumonia in Africa: a review of the evidence. Health policy and planning. 2013;30(2):253-66.

Dzakpasu S, Powell-Jackson T, Campbell OM. Impact of user fees on maternal health service utilization and related health outcomes: a systematic review. Health policy and planning. 2014;29(2):137-50.

Eichler R, Agarwal K, Askew I, Iriarte E, Morgan L, Watson J. Performance-based incentives to improve health status of mothers and newborns: what does the evidence show? Journal of health, population, and nutrition. 2013;31(4 Suppl 2):36-47.

Elder E, Johnston AN, Crilly J. Review article: Systematic review of three key strategies designed to improve patient flow through the emergency department. Emergency medicine Australasia : EMA. 2015;27(5):394-404.

Evans BA, Porter A, Gammon B, Mayes RH, Poulden M, Rees N, et al. A systematic review of rapid access models of care and their effects on delays in emergency departments. Emergency medicine journal : EMJ. 2015;32(6):e15-6.

Free C, Phillips G, Galli L, Watson L, Felix L, Edwards P, et al. The effectiveness of mobile-health technology-based health behaviour change or disease management interventions for health care consumers: a systematic review. PLoS medicine. 2013;10(1):e1001362.

Gielen SC, Dekker J, Francke AL, Mistiaen P, Kroezen M. The effects of nurse prescribing: A systematic review. International journal of nursing studies. 2013;51(7):1048-61.

Gillespie BM, Chaboyer W, Thalib L, John M, Fairweather N, Slater K. Effect of Using a Safety Checklist on Patient Complications after Surgery: A Systematic Review and Meta-analysis. Anesthesiology. 2014;120(6):1380-9.

Gilmore B, McAuliffe E. Effectiveness of community health workers delivering preventive interventions for maternal and child health in low- and middle-income countries: a systematic review. BMC public health. 2013;13(1):847.

Gogia S, Sachdev HP. Home-based neonatal care by community health workers for preventing mortality in neonates in low- and middleincome countries: a systematic review. Journal of perinatology : official journal of the California Perinatal Association. 2016;36 Suppl 1(S1):S55-73.

Gogia S, Sachdev HS. Home visits by community health workers to prevent neonatal deaths in developing countries: a systematic review. Bulletin of the World Health Organization. 2010;88(9):658-66B.

Govindasamy D, Meghij J, Kebede Negussi E, Clare Baggaley R, Ford N, Kranzer K. Interventions to improve or facilitate linkage to or retention in pre-ART (HIV) care and initiation of ART in low- and middle-income settings - a systematic review. Journal of the International AIDS Society. 2014;17(1):19032.

Hamine S, Gerth-Guyette E, Faulx D, Green BB, Ginsburg AS. Impact of mHealth Chronic Disease Management on Treatment Adherence and Patient Outcomes: A Systematic Review. Journal of medical Internet research. 2015;17(2):e52.

Hecht L, Buhse S, Meyer G. Effectiveness of training in evidence-based medicine skills for healthcare professionals: a systematic review. BMC medical education. 2016;16(1):103.

Hurt K, Walker RJ, Campbell JA, Egede LE. mHealth Interventions in Low and Middle-Income Countries: A Systematic Review. Global journal of health science. 2016;8(9):54429.

Jia L, Meng Q, Yuan B, Fang L. Effects of drug cost sharing policy on the drug use, financial risks and moral hazard for the health insurance beneficiaries. Value in Health. 2014;17(7):A795.

Kamarudin G, Penm J, Chaar B, Moles R. Educational interventions to improve prescribing competency: a systematic review. BMJ open. 2013;3(8):e003291.

Kanters S, Park JJ, Chan K, Socias ME, Ford N, Forrest JI, et al. Interventions to improve adherence to antiretroviral therapy: a systematic review and network meta-analysis. The lancet HIV. 2016.

Ke KM, Blazeby JM, Strong S, Carroll FE, Ness AR, Hollingworth W. Are multidisciplinary teams in secondary care cost-effective? A systematic review of the literature. Cost effectiveness and resource allocation:C/E. 2013;11(1):7.

Khanal S, Burgon J, Leonard S, Griffiths M, Eddowes LA. Recommendations for the Improved Effectiveness and Reporting of Telemedicine Programs in Developing Countries: Results of a Systematic Literature Review. Telemedicine journal and e-health : the official journal of the American Telemedicine Association. 2015;21(11):903-15. 
Kok MC, Dieleman M, Taegtmeyer M, Broerse JE, Kane SS, Ormel H, et al. Which intervention design factors influence performance of community health workers in low- and middle-income countries? A systematic review. Health policy and planning. 2014;30(9):1207-27.

Kondo KK, Damberg CL, Mendelson A, Motu'apuaka M, Freeman M, O'Neil M, et al. Implementation Processes and Pay for Performance in Healthcare: A Systematic Review. Journal of general internal medicine. 2016;31 Suppl 1:61-9.

Korachais C, Macouillard E, Meessen B. How User Fees Influence Contraception in Low and Middle Income Countries: A Systematic Review. Studies in family planning. 2016;47(4):341-56.

Körner M, Bütof S, Müller C, Zimmermann L, Becker S, Bengel J. Interprofessional teamwork and team interventions in chronic care: A systematic review. Journal of interprofessional care. 2015;30(1):1-14.

Kurtzman ET, Greene J. Effective presentation of health care performance information for consumer decision making: A systematic review. Patient education and counseling. 2015;99(1):36-43.

Lee IH, Bloor K, Hewitt C, Maynard A. International experience in controlling pharmaceutical expenditure: influencing patients and providers and regulating industry - a systematic review. Journal of health services research \& policy. 2014;20(1):52-9.

Lee SH, Nurmatov UB, Nwaru BI, Mukherjee M, Grant L, Pagliari C. Effectiveness of mHealth interventions for maternal, newborn and child health in low- and middle-income countries: Systematic review and meta-analysis. Journal of global health. 2016;6(1):010401.

Lehnbom EC, Stewart MJ, Manias E, Westbrook JI. Impact of medication reconciliation and review on clinical outcomes. The Annals of pharmacotherapy. 2014;48(10):1298-312.

L'Engle KL, Mangone ER, Parcesepe AM, Agarwal S, Ippoliti NB. Mobile Phone Interventions for Adolescent Sexual and Reproductive Health: A Systematic Review. Pediatrics. 2016;138(3):1-16.

Lin Y, Yin S, Huang J, Du L. Impact of Pay for performance on Behavior of Primary Care Physicians and Patient Outcomes. Journal of evidence-based medicine. 2015;9(1):8-23.

Liu X, Dou L, Zhang H, Sun Y, Yuan B. Analysis of context factors in compulsory and incentive strategies for improving attraction and retention of health workers in rural and remote areas: a systematic review. Human resources for health. 2015;13:61.

Liu X, Hotchkiss DR, Bose S. The effectiveness of contracting-out primary health care services in developing countries: A review of the evidence. Health Policy and Planning. 2007; 23(1): 1-13.

Luangasanatip N, Hongsuwan M, Limmathurotsakul D, Lubell Y, Lee AS, Harbarth S, et al. Comparative efficacy of interventions to promote hand hygiene in hospital: systematic review and network meta-analysis. BMJ (Clinical research ed). 2015;351:h3728.

Mann BS, Barnieh L, Tang K, Campbell DJ, Clement F, Hemmelgarn B, et al. Association between drug insurance cost sharing strategies and outcomes in patients with chronic diseases: a systematic review. PloS one. 2014;9(3):e89168.

Martínez-González NA, Djalali S, Tandjung R, Huber-Geismann F, Markun S, Wensing M, et al. Substitution of physicians by nurses in primary care: a systematic review and meta-analysis. BMC health services research. 2014;14:214.

Martínez-González NA, Rosemann T, Tandjung R, Djalali S. The effect of physician-nurse substitution in primary care in chronic diseases: a systematic review. Swiss medical weekly. 2015;145(no pagination):w14031.

Martínez-González NA, Tandjung R, Djalali S, Rosemann T. The impact of physician-nurse task shifting in primary care on the course of disease: a systematic review. Human resources for health. 2015;13:55.

Mbuagbaw L, Sivaramalingam B, Navarro T, Hobson N, Keepanasseril A, Wilczynski NJ, et al. Interventions for Enhancing Adherence to Antiretroviral Therapy (ART): A Systematic Review of High Quality Studies. AIDS patient care and STDs. 2015;29(5):248-66.

McCollum R, Gomez W, Theobald S, Taegtmeyer M. How equitable are community health worker programmes and which programme features influence equity of community health worker services? A systematic review. BMC public health. 2016;16(1):419.

McCulloch P, Rathbone J, Catchpole K. Interventions to improve teamwork and communications among healthcare staff. The British journal of surgery. 2011;98(4):469-79.

McGrady ME, Ryan JL, Gutiérrez-Colina AM, Fredericks EM, Towner EK, Pai AL. The impact of effective paediatric adherence promotion interventions: systematic review and meta-analysis. Child: care, health and development. 2015;41(6):789-802.

McMillan SS, Kendall E, Sav A, King MA, Whitty JA, Kelly F, et al. Patient-centered approaches to health care: a systematic review of randomized controlled trials. Medical care research and review : MCRR. 2013;70(6):567-96. 
Mijovic H, McKnight J, English M. What does the literature tell us about health workers' experiences of task-shifting projects in sub-Saharan Africa? A systematic, qualitative review. Journal of clinical nursing. 2016;25(15-16):2083-100.

Montagu D, Goodman C, Berman P, Penn A, Visconti A. Recent trends in working with the private sector to improve basic healthcare: a review of evidence and interventions. Health policy and planning. 2016;31(8):1117-32.

Musa BM, Iliyasu Z, Yusuf SM, Uloko AE. Systematic review and metanalysis on community based interventions in tuberculosis care in developing countries. Nigerian journal of medicine: journal of the National Association of Resident Doctors of Nigeria. 2014;23(2):103-17.

Mwai GW, Mburu G, Torpey K, Frost P, Ford N, Seeley J. Role and outcomes of community health workers in HIV care in sub-Saharan Africa: a systematic review. Journal of the International AIDS Society. 2013;16(1):18586.

Nazar H, Nazar Z, Portlock J, Todd A, Slight SP. A systematic review of the role of community pharmacies in improving the transition from secondary to primary care. British journal of clinical pharmacology. 2015;80(5):936-48.

Nguyen DT, Leung KK, McIntyre L, Ghali WA, Sauve R. Does integrated management of childhood illness (IMCI) training improve the skills of health workers? A systematic review and meta-analysis. PloS one. 2013;8(6):e66030.

Nijmeijer KJ, Fabbricotti IN, Huijsman R. Is franchising in health care valuable? A systematic review. Health policy and planning. 2014;29(2):164-76.

Nilsson C, Lundgren I, Smith V, Vehvilainen-Julkunen K, Nicoletti J, Devane D, et al. Women-centred interventions to increase vaginal birth after caesarean section (VBAC): A systematic review. Midwifery. 2015;31(7):657-63.

Ofek Shlomai N, Rao S, Patole S. Efficacy of interventions to improve hand hygiene compliance in neonatal units: a systematic review and meta-analysis. European journal of clinical microbiology \& infectious diseases : official publication of the European Society of Clinical Microbiology. 2015;34:887-97.

Ogbechie OA, Hsu J. Systematic review of benefit designs with differential cost sharing for prescription drugs. The American journal of managed care. 2015;21(5):e338-48.

Olisemeke B, Chen YF, Hemming K, Girling A. The Effectiveness of Service Delivery Initiatives at Improving Patients' Waiting Times in Clinical Radiology Departments: A Systematic Review. Journal of digital imaging. 2014;27(6):751-78.

Owusu-Addo E, Cross R. The impact of conditional cash transfers on child health in low- and middle-income countries: a systematic review. International journal of public health. 2014;59(4):609-18.

Pallas SW, Minhas D, Pérez-Escamilla R, Taylor L, Curry L, Bradley EH. Community Health Workers in Low- and Middle-Income Countries: What Do We Know About Scaling Up and Sustainability? American journal of public health. 2013;103(7):e74-82.

Patel J, Ahmed K, Guru KA, Khan F, Marsh H, Shamim Khan M, et al. An overview of the use and implementation of checklists in surgical specialities - a systematic review. International journal of surgery (London, England). 2014;12(12):1317-23.

Rashidian A, Omidvari AH, Vali Y, Mortaz S, Yousefi-Nooraie R, Jafari M, et al. The effectiveness of regionalization of perinatal care services-a systematic review. Public health. 2014;128(10):872-85.

Robinson DJ. An integrative review: triage protocols and the effect on ED length of stay. Journal of emergency nursing: JEN : official publication of the Emergency Department Nurses Association. 2013;39(4):398-408.

Roque MD, Herdeiro MT, Soares SI, Teixeira Rodrigues A, Granadeiro LA, Gusman AF. Educational interventions to improve prescription and dispensing of antibiotics: a systematic review. BMC public health. 2014;14(1):1276.

Ruizendaal E, Dierickx S, Peeters Grietens K, Schallig HD, Pagnoni F, Mens PF. Success or failure of critical steps in community case management of malaria with rapid diagnostic tests: a systematic review. Malaria journal. 2014;13(1):229.

Russ S, Rout S, Sevdalis N, Moorthy K, Darzi A, Vincent C. Do safety checklists improve teamwork and communication in the operating room? A systematic review. Annals of surgery. 2013;258(6):856-71.

Ruth Lv, Francke AL, Mistiaen P. Effects of nurse prescribing of medication: a systematic review. The Internet Journal of Healthcare Administration. 2008;5(2).

Sacks GD, Shannon EM, Dawes AJ, Rollo JC, Nguyen DK, Russell MM, et al. Teamwork, communication and safety climate: a systematic review of interventions to improve surgical culture. BMJ quality \& safety. 2015;24(7):458-67.

Santschi V, Chiolero A, Colosimo AL, Platt RW, Taffé P, Burnier M, et al. Improving blood pressure control through pharmacist interventions: a meta-analysis of randomized controlled trials. Journal of the American Heart Association. 2014;3(2):e000718. 
Schepman S, Hansen J, de Putter ID, Batenburg RS, de Bakker DH. The common characteristics and outcomes of multidisciplinary collaboration in primary health care: a systematic literature review. International journal of integrated care. 2015;15:e027.

Schmutz J, Manser T. Do team processes really have an effect on clinical performance? A systematic literature review. British journal of anaesthesia. 2013;110(4):529-44.

Schweizer ML, Reisinger HS, Ohl M, Formanek MB, Blevins A, Ward MA, et al. Searching for an optimal hand hygiene bundle: a meta-analysis. Clinical infectious diseases : an official publication of the Infectious Diseases Society of America. 2014;58(2):248-59.

Suwannakeeree W, Picheansathian W. Strategies to Promote Adherence to Treatment by Pulmonary Tuberculosis Patients: A systematic review. JBI Database of Systematic Reviews and Implementation Reports. 2012;10(11):615.

Sweeney S, Obure CD, Maier CB, Greener R, Dehne K, Vassall A. Costs and efficiency of integrating HIV/AIDS services with other health services: a systematic review of evidence and experience. Sexually transmitted infections. 2012;88(2):85-99.

Thakkar J, Kurup R, Laba TL, Santo K, Thiagalingam A, Rodgers A, et al. Mobile Telephone Text Messaging for Medication Adherence in Chronic Disease: A Meta-analysis. JAMA internal medicine. 2016;176(3):340-9.

Trehan A, Maruthappu M, Barnett-Vanes A, Carty M, McCulloch P. Does feedback of surgical outcome data improve surgical performance? A systematic review. Journal of the American College of Surgeons. 2014;219(4):e148.

Tripathi A, Kabra SK, Sachdev HP, Lodha R. Home visits by community health workers to improve identification of serious illness and care seeking in newborns and young infants from low- and middle-income countries. Journal of perinatology : official journal of the California Perinatal Association. 2016;36 Suppl 1(S1):S74-82.

Tshiananga JK, Kocher S, Weber C, Erny-Albrecht K, Berndt K, Neeser K. The effect of nurse-led diabetes self-management education on glycosylated hemoglobin and cardiovascular risk factors: a meta-analysis. The Diabetes educator. 2011;38(1):108-23.

Tsiachristas A, Wallenburg I, Bond CM, Elliot RF, Busse R, van Exel J, et al. Costs and effects of new professional roles: Evidence from a literature review. Health policy (Amsterdam, Netherlands). 2015;119(9):1176-87.

Turcotte-Tremblay AM, Spagnolo J, De Allegri M, Ridde V. Does performance-based financing increase value for money in low- and middleincome countries? A systematic review. Health economics review. 2015;6(1):30.

Uyei J, Coetzee D, Macinko J, Guttmacher S. Integrated delivery of HIV and tuberculosis services in Sub-Saharan Africa: A systematic review. International Initiative for Impact Evaluation (3ie). 2011.

Van Camp YP, Van Rompaey B, Elseviers MM. Nurse-led interventions to enhance adherence to chronic medication: systematic review and meta-analysis of randomised controlled trials. European journal of clinical pharmacology. 2013;69(4):761-70.

van Velthoven MHMMT, Tudor Car L, Gentry S, Car J. Telephone delivered interventions for preventing HIV infection in HIV-negative persons. Cochrane Database of Systematic Reviews. 2013;5(5):CD009190.

Wagner B, Filice GA, Drekonja D, Greer N, MacDonald R, Rutks I, et al. Antimicrobial stewardship programs in inpatient hospital settings: a systematic review. Infection control and hospital epidemiology : the official journal of the Society of Hospital Epidemiologists of America. 2014;35(10):1209-28.

Wald DS, Butt S, Bestwick JP. One-way versus two-way text messaging on improving medication adherence: meta-analysis of randomized trials. The American journal of medicine. 2015;128(10):1139.e1-5.

Wallace AS, Ryman TK, Dietz V. Experiences integrating delivery of maternal and child health services with childhood immunization programs: systematic review update. The Journal of infectious diseases. 2012;205 Suppl 1:S6-19.

Wallace J, Byrne C, Clarke M. Improving the uptake of systematic reviews: a systematic review of intervention effectiveness and relevance. BMJ open. 2014;4(10):e005834.

Watson SJ, Aldus CF, Bond C, Bhattacharya D. Systematic review of the health and societal effects of medication organisation devices. BMC health services research. 2016;16(1):202.

Wilcher R, Hoke T, Adamchak SE, Cates W. Integration of family planning into HIV services: a synthesis of recent evidence. AIDS (London, England). 2013;27 Suppl 1:S65-75.

World Health Organization, University of California SF. Electronic reminders for promoting adherence to ART among people living with HIV. World Health Organization. 2013.

World Health Organziation, University of California SF. Integration of HIV and TB services. World Health Organization. 2013. 
Yamada J, Shorkey A, Barwick M, Widger K, Stevens BJ. The effectiveness of toolkits as knowledge translation strategies for integrating evidence into clinical care: a systematic review. BMJ open. 2015;5(4):e006808.

Zulu JM, Kinsman J, Michelo C, Hurtig AK. Integrating national community-based health worker programmes into health systems: a systematic review identifying lessons learned from low-and middle-income countries. BMC public health. 2014;14(1):987.

\section{CONTRIBUTIONS OF AUTHORS}

All of the authors contributed to drafting and revising the overview. All of the authors contributed important intellectual input to the overview.

\section{DECLARATIONS OF INTEREST}

Elizabeth Paulsen, Simon Lewin, Cristian A Herrera, Newton Opiyo, Tomas Pantoja, Gabriel Rada, and Andrew D Oxman are editors of the Cochrane Effective Practice and Organisation of Care (EPOC) Group. Charles S Wiysonge, Agustín Ciapponi, and Andrew D Oxman are authors of some of the included reviews.

\section{SOURCES OF SUPPORT}

\section{Internal sources}

- Department of Family Medicine, School of Medicine, Pontificia Universidad Católica de Chile, Santiago, Chile.

- Institute for Clinical Effectiveness and Health Policy, Buenos Aires, Argentina.

- South African Medical Research Council, Cape Town, South Africa.

- Norwegian Institute of Public Health, Oslo, Norway.

\section{External sources}

- National Research Foundation (CSW), South Africa.

- Norwegian Agency for Development Cooperation, Norway.

- The Effective Health Care Research Consortium which is funded by UK aid from the UK Government for the benefit of developing countries, UK.

\section{N DEX TERMS}

\section{Medical Subject Headings (MeSH)}

${ }^{\star}$ Review Literature as Topic; Developing Countries [ ${ }^{\star}$ economics]; Fees and Charges; Health Services Needs and Demand; Insurance, Health; National Health Programs [*economics] [standards]; Quality of Health Care [economics] [standards]

\section{MeSH check words}

Humans 